NBER WORKING PAPER SERIES

\title{
THE GREAT ESCAPE? A QUANTITATIVE EVALUATION OF THE FED’S LIQUIDITY FACILITIES
}

\author{
Marco Del Negro \\ Gauti Eggertsson \\ Andrea Ferrero \\ Nobuhiro Kiyotaki \\ Working Paper 22259 \\ http://www.nber.org/papers/w22259 \\ NATIONAL BUREAU OF ECONOMIC RESEARCH \\ 1050 Massachusetts Avenue \\ Cambridge, MA 02138 \\ May 2016
}

The views expressed in this paper are solely those of the authors and do not necessarily reflect those of the Federal Reserve Bank of New York, the Federal Reserve System, or the National Bureau of Economic Research. The first draft of this paper (2010) circulated with the title "The Great Escape?A Quantitative Evaluation of the Fed's Non-Standard Policies." We thank Sonia Gilbukh and Micah Smith for outstanding research assistance, and several colleagues at the FRBNY for help in obtaining and constructing financial data and for valuable suggestions (Nancy Duong, Michael Fleming, Domenico Giannone, Ernst Schaumburg, Or Shachar, Zachary Wojtowicz). We also thank for their helpful comments Pierpaolo Benigno, Luis Cespedes, Isabel Correia, Jesús Fernandez-Villaverde, James Hamilton, Thomas Laubach, Zheng Liu, John Moore, Diego Rodriguez, Cedric Tille, Oreste Tristani, Jaume Ventura, as well as participants in various seminars and conferences.

At least one co-author has disclosed a financial relationship of potential relevance for this research. Further information is available online at http://www.nber.org/papers/w22259.ack

NBER working papers are circulated for discussion and comment purposes. They have not been peer-reviewed or been subject to the review by the NBER Board of Directors that accompanies official NBER publications.

(C) 2016 by Marco Del Negro, Gauti Eggertsson, Andrea Ferrero, and Nobuhiro Kiyotaki. All rights reserved. Short sections of text, not to exceed two paragraphs, may be quoted without explicit permission provided that full credit, including $\odot$ notice, is given to the source. 
The Great Escape? A Quantitative Evaluation of the Fed's Liquidity Facilities Marco Del Negro, Gauti Eggertsson, Andrea Ferrero, and Nobuhiro Kiyotaki NBER Working Paper No. 22259

May 2016

JEL No. E44,E58

\section{$\underline{\text { ABSTRACT }}$}

We introduce liquidity frictions into an otherwise standard DSGE model with nominal and real rigidities and ask: Can a shock to the liquidity of private paper lead to a collapse in short-term nominal interest rates and a recession like the one associated with the 2008 U.S. financial crisis? Once the nominal interest rate reaches the zero bound, what are the effects of interventions in which the government provides liquidity in exchange for illiquid private paper? We find that the effects of the liquidity shock can be large, and show some numerical examples in which the liquidity facilities prevented a repeat of the Great Depression in 2008-2009.

Marco Del Negro

Federal Reserve Bank of New York

Macroeconomic \& Monetary Studies Function

Research and Statistics Group

33 Liberty Street

New York, NY 10045-0001

marco.delnegro@ny.frb.org

Gauti Eggertsson

Department of Economics

Brown University

64 Waterman Street

Providence, RI 02912

and NBER

gauti_eggertsson@brown.edu
Andrea Ferrero

Office 241

Manor Road Building

Manor Road

Oxford OX1 3UQ

United Kingdom

andrea.ferrero@economics.ox.ac.uk

Nobuhiro Kiyotaki

Department of Economics

Princeton University

Fisher Hall

Princeton, NJ 08544-1021

and NBER

kiyotaki@princeton.edu 


\section{Introduction}

In December 2008, the federal funds rate collapsed to zero. Standard monetary policy through interest rate cuts had reached its limit. Around the same time, the Federal Reserve started to expand its balance sheet. By January 2009, the overall size of the Fed's balance sheet exceeded $\$ 2$ trillion, an increase of more than $\$ 1$ trillion compared to a few months earlier (Figure 1). This expansion mostly involved the Federal Reserve exchanging government liquidity (money or government debt) for private financial assets through direct purchases or collateralized shortterm loans. These direct interventions in private credit markets were implemented via various facilities, such as the Term Auction Facility, the Primary Dealer Credit Facility, and the Term Securities Lending Facility. ${ }^{1}$ In broad terms, these facilities can be thought of as non-standard open market operations, whereby the government exchanges highly liquid government paper for less liquid private paper. Alternatively, one can think of them as non-standard discount window lending, which provides government liquidity using private assets as collateral. This paper studies the quantitative effects of these liquidity policies on macroeconomic and financial variables.

Ever since the irrelevance result of Wallace (1981), the benchmark for many macroeconomists is that non-standard open market operations in private assets are irrelevant. Eggertsson and Woodford (2003) show that this result extends to standard open market operations in models with nominal frictions and money in the utility function, provided that the nominal interest rate is zero. Once the nominal interest rate reaches its lower bound, liquidity has no further role in this class of models, or in most other standard models with various types of frictions, such as Rotemberg and Woodford (1997) or Christiano et al. (2005).

In this paper, we depart from such an irrelevance result by incorporating a particular form of credit frictions proposed by Kiyotaki and Moore (2012) (henceforth, KM). The KM credit frictions are of two distinct forms. First, a firm that faces an investment opportunity can borrow only up to a fraction of the value of its current investment. This friction is a relatively standard financing constraint. ${ }^{2}$ Second, a firm that faces an investment opportunity can sell

\footnotetext{
${ }^{1}$ See Armantier et al. (2008), Adrian et al. (2009), Fleming et al. (2009), Adrian et al. (2011), and Fleming and Klagge (2010) for details about the various facilities, and Madigan (2009) for a summary.

${ }^{2}$ This constraint is similar to the collateral requirement in Kiyotaki and Moore (1997). Kocherlakota (2000) and Cordoba and Ripoll (2004) argue that collateral constraints have a limited quantitative role in explaining macroeconomic fluctuations. This result is, however, conditional on the fundamental shocks that drive the
} 
Figure 1: Federal Reserve's Assets between July 2007 and July 2011.

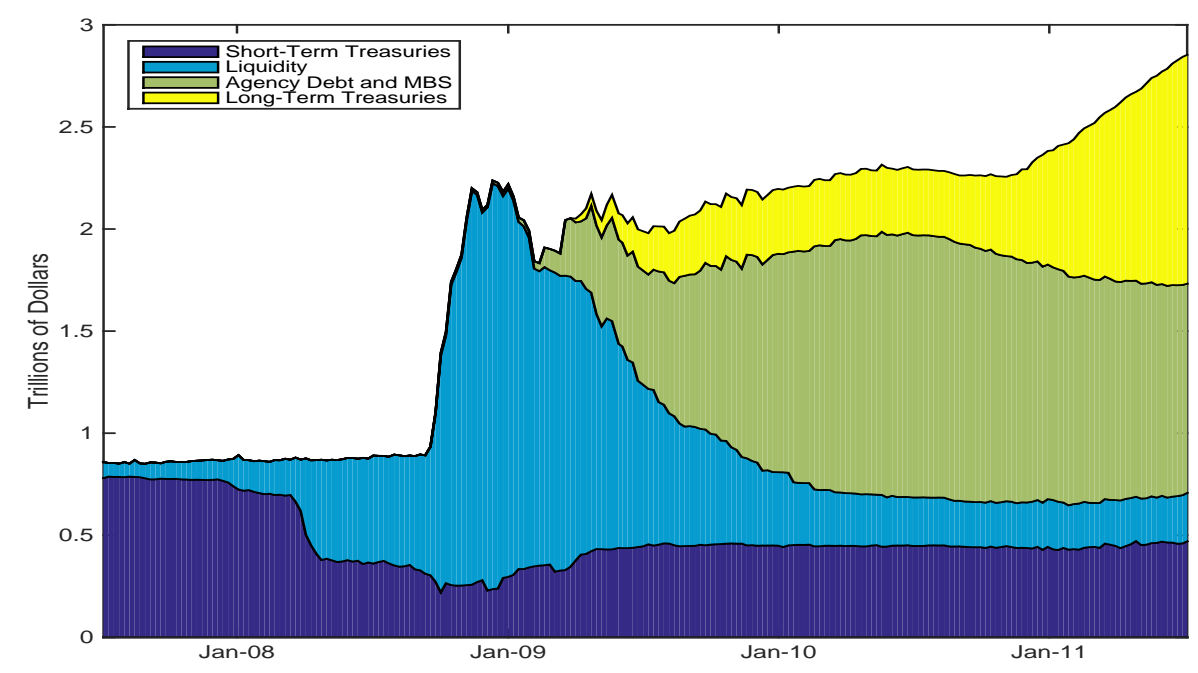

Note: The figure plots the evolution of the asset side of the Federal Reserve balance sheet between July 2007 and July 2011, decomposed in short-term Treasury securities (purple), lending to financial institutions and liquidity to key credit markets (cyan), Agency debt and MBS (green), and long-term Treasury securities (yellow). Source: Federal Reserve Bank of Cleveland.

only up to a certain fraction of the "illiquid" assets on its balance sheet in each period. In the model, these illiquid assets correspond to equity holdings of other firms. More generally, we interpret these illiquid assets as privately issued paper such as commercial paper, bank loans, mortgages, and so on. This friction is a less standard "resaleability" constraint.

In contrast to private assets, we follow KM and assume that government paper, i.e. money and bonds, is not subject to the resaleability constraint. This assumption gives government paper a primary role as liquidity. In this world, open market operations that change the composition of liquid and illiquid assets in the hands of the private sector affect the allocation of resources. The assumption of limited resaleability of private paper and the role of government paper as liquidity give a natural story for the crisis of 2008 and the ensuing Fed's response. In our study, the source of the crisis of 2008 is a shock to the resaleability of private paper. Suddenly, secondary markets for private papers (such as privately-issued mortgage-backed securities) froze. This shock led to a general decline of funding for investment and aggregate production through the interaction between the markets for assets, goods and labor. We think business cycle. Liu et al. (2013) and Nezafat and Slavik (2010) show that financial constraint do amplify the effects of shocks that shift the demand of collateral, capable of generating fluctuations of asset prices and aggregate production observed in data. 
of this propagation as capturing a central aspect of the crisis.

We embed the KM credit frictions in a relatively standard dynamic stochastic general equilibrium (DSGE) model along the lines of Christiano et al. (2005) and Smets and Wouters (2007). The model features nominal and real frictions, such as price and wage rigidities and aggregate capital adjustment costs. Conventional monetary policy is implemented via variations in the nominal interest rate according to a standard interest rate policy rule that is constrained by the zero bound. Non-conventional policy consists of open market operations in private assets that increase the overall level of liquidity in the economy. We use the expansion in the Fed's balance sheet after Lehman's bankruptcy to calibrate the non-standard policy reaction function of the government.

Our main result is that both the financial shock and the liquidity policy can have a quantitatively large effect. A shock to the resaleability constraint, calibrated to match the increase in the premium associated with very liquid assets during the crisis (what Krishnamurthy and Vissing-Jorgensen (2012) call the "convenience yield"), accounts for more than half of the drop in output observed in the data and all of the drop in inflation. As a response, the nominal interest in the model hits the zero lower bound. The impact of the policy intervention is substantial. In our baseline scenario, absent non-standard open market operations, output and inflation would have dropped by an additional $30 \%$ and $40 \%$ respectively. Our quantitative results depend crucially on the expected duration of the crisis. Had private agents expected a more persistent freeze in the private paper market, the economy may have suffered a second Great Depression in the absence of interventions. With intervention, in some of our numerical examples, the economy "escapes" from a repeat of the Great Depression (hence, the title of the paper). The reason is that liquidity policies can have especially large effects at zero interest rates - a result reminiscent of the case of the multiplier of government spending in Eggertsson (2011) and Christiano et al. (2011).

Nominal rigidities and the zero lower bound on nominal interest rates (henceforth, ZLB) play a crucial role in our analysis. Under flexible prices, the KM financial frictions can only account for a drop in investment. In this case, aggregate output is almost unchanged because consumption makes up for the fall in investment. The consumption boom requires the real interest rate to fall in order to induce people to spend more. Thus the real rate of interest on liquid paper absent nominal frictions - the so-called natural rate of interest - needs to fall 
substantially. Furthermore, the loss of liquidity of private paper drives up the premium people are willing to pay for holding liquid government paper. This additional channel leading to a decline in the natural rate of interest during financial stress is absent in standard DSGEs. ${ }^{3}$ But the real interest rate can hardly fall if the nominal interest rate cannot turn negative and prices are sluggish. As a consequence the freeze in the private paper market triggers a drop not only in investment, but also in consumption and aggregate output.

Unconventional policy can alleviate the crisis by targeting directly the source of the problem, which is the loss of liquidity of private paper. By swapping partially illiquid private paper for government liquidity, thus making the aggregate portfolio holdings of the private sector more liquid, the intervention lubricates financial markets, reducing the fall in investment and consumption. Importantly, we are not assuming that the policy intervention violates the private sector resaleability constraint. Instead, the intervention only increases the supply of government paper by purchasing private paper in the open market.

Our paper belongs to the strand of literature that studies the effect of financial disturbances in monetary DSGE models, such as Bernanke et al. (1999), Christiano et al. (2003), Christiano et al. (2010), Goodfriend and McCallum (2007), Curdia and Woodford (2015), Curdia and Woodford (2010), among many others, and is particularly close to the papers by Ajello (forthcoming), Gertler and Karadi (2011), and Gertler and Kiyotaki (2010). ${ }^{4}$ What distinguishes our paper from the rest of the literature is both the friction and the nature of the shock. Ajello constructs a model featuring resaleability constraints as in KM, estimated using standard U.S. macro time series and a measure of financial spreads. His main finding is that financial intermediation shocks are key drivers of business cycles and played a large role during the Great Recession. One important difference with our work is that the exoge-

\footnotetext{
${ }^{3}$ Fisher (2015) and Anzoategui et al. (2015) analyze the fall of the natural rate by assuming the that the household derives utility from holding Treasuries that shows up in the utility function, building on Krishnamurthy and Vissing-Jorgensen (2012).

${ }^{4}$ The work of Garleanu and Pedersen (2011) and Ashcraft et al. (2010) on the implications of margin requirements is also very related to ours. Margin requirements represent a constraint on the agents' ability to leverage when buying assets. An increase in the shadow value of the constraints, which captures a funding-liquidity crisis, is akin to a liquidity shock in our model, in that it causes a sharp drop in investment and an increase of the spread between high-margin ("illiquid") and low-margin ("liquid") assets. These authors also study the effect of the liquidity facilities. Both papers mainly focus on the asset pricing implications of margin constraints and liquidity crisis, and have limited quantitative implications for macroeconomic variables.
} 
nous financial shock in Ajello affects the intermediation technology as in Curdia and Woodford (2015). As such, this shock would have an effect on the economy even in absence of resaleability constraints, and hence bears more resemblance to the exogenous component of spreads in the model of Bernanke et al. (1999) than to the liquidity shock in KM. Furthermore, Ajello investigates neither the importance of the liquidity facilities nor the role of the ZLB, which are at the center of our analysis.

Gertler and Karadi (2011) and Gertler and Kiyotaki (2010) have also analyzed the role of non-conventional central bank policies during the Great Recession. The key difference with our paper is that in our model the source of the disturbance is financial, while in these other papers the recession is triggered by a real shock. Specifically, we characterize the crisis as a reduction in the resaleability of private paper - a drying-up of liquidity in the secondary markets for privately issued securities in the spirit of Gorton and Metrick (2010) and Gorton and Metrick (2012) - which in turn triggers the under-utilization of the factors of production. In contrast, in Gertler and Karadi (2011) and Gertler and Kiyotaki (2010), the shock that triggers a recession is an exogenous reduction in the quality of the capital stock. Our shock need not imply any reduction in output if the existing capital and labor were utilized at the same rate as pre-crisis. It is the interaction of the financial and nominal frictions, and the inability of the central bank to accommodate this shock due to the ZLB, that gives rise to our account of the crisis. Also, in these papers the intervention subsidizes financial intermediaries and improves their balance sheet by preventing asset prices from falling significantly. In our model the liquidity interventions are not a subsidy to financial intermediaries. In fact, the government "makes money" during the intervention, at least in expectations, as it did ex-post in the financial crisis.

Our main focus is on the Great Recession, which according to the National Bureau of Economic Research dates began in December 2007 and ended in June 2009, with the focal point being the default of Lehman Brothers in September 2008. Although the market for mortgage-backed securities stopped working well in August 2007, our paper concentrates on the events that followed the default of Lehman Brothers. The Fed facilities that we evaluate in this paper were started in December 2007 and were escalated with the collapse of Lehman in the fall of 2008 , when the fed funds rate ultimately reached zero. ${ }^{5}$

\footnotetext{
${ }^{5}$ Our analysis does not extend to the large-scale asset purchase program implemented during the fall of 2010 in response to the further weakening of economic activity, because this quantitative easing program (at least
} 
Before going further, we should emphasize a few important limitations of our analysis. The liquidity constraints proposed by KM are reduced form. Recently, Kurlat (2013) and Bigio (2015) explain these liquidity constraints as arising endogenously in a model in which entrepreneurs have asymmetric information about the quality of existing assets. ${ }^{6}$ An advantage of taking a reduced-form approach is that one does not have to take a stand on the specific mechanism behind the fall in liquidity in financial markets, whether due to asymmetric information or sunspots. ${ }^{7}$ The cost is that our model is silent on whether the Fed's interventions can affect the incentive structure of the private sector. This aspect is certainly important, as the private sector response may lead to an endogenous change in the liquidity constraints that we currently take as given. More generally, we abstract from the costs of intervening, which can take many different forms. Therefore, our paper has only positive, not normative, content: We show that liquidity interventions can be quantitatively important for macroeconomic stability in the short-run. Our findings suggest that understanding the consequences of these policies for the incentives of the private sector should be a high priority on the research agenda.

Sections 2 and 3 describe the model and its calibration. Section 4 discusses the results, and Section 5 concludes.

\section{The Model}

The model can be described as KM augmented with both nominal and real frictions. The economic actors in the model are households, whose members are entrepreneurs and workers, the government, intermediate and final goods firms, labor agencies, and capital producers.

when implemented via purchases of long term Treasuries) involves swapping one liquid asset for another type of liquid asset. The "preferred habitat" theory (studied in Vayanos and Vila (2009) and in Chen et al. (2012) in the context of an estimated DSGE model) can provide a rationale for this type of asset purchase program.

${ }^{6}$ In Kurlat (2013), for instance, markets for existing assets can shut down as a consequence of large enough investment-specific productivity shocks. More generally, the combination of shocks to fundamentals and adverse selection can induce large drops of price and trading volume in secondary markets. Cui and Radde (2014) construct a model in which private papers are traded subject to matching frictions in which shocks to the matching efficiency change the resaleability of private papers endogenously.

${ }^{7}$ One interpretation of our shock to the resaleability constraint is that the economy switches from a high resaleability to a low resaleability equilibrium due to "sunspots," i.e., without a change of the other fundamentals. 


\subsection{Households}

The economy is populated by a continuum of identical households of measure one. Each household consists of a continuum of members indexed by $j \in[0,1]$. In every period, household members receive an i.i.d. draw that determines whether they are entrepreneurs or workers. The probability of being an entrepreneur is $\varkappa$, which, by the law of large numbers, is also the fraction of entrepreneurs in the household. Each entrepreneur $j \in[0, \varkappa)$ has an opportunity to invest but does not work. Each worker member $j \in[\varkappa, 1]$ supplies differentiated labor of type $j$ but does not invest. ${ }^{8}$ The friction in our model described below affects the transfer of funds from those who do not have an investment opportunity (the workers) to those who do (the entrepreneurs).

Let $C_{t}(j)$ denote the amount of the consumption good each member of the household purchases in the market place in period $t$. An assumption of the representative household structure is that, at the end of the period, all members bring the consumption purchases back to the household, and these goods get distributed equally among all members. Utility thus depends upon the sum of all the consumption goods bought by the different household members

$$
C_{t} \equiv \int_{0}^{1} C_{t}(j) d j
$$

Let $H_{t}(j)$ be hours worked by worker member $j$. The household's objective is

$$
\mathbb{E}_{t} \sum_{s=t}^{\infty} \beta^{s-t}\left[\frac{C_{s}^{1-\sigma}}{1-\sigma}-\frac{\omega}{1+\nu} \int_{\varkappa}^{1} H_{s}(j)^{1+\nu} d j\right],
$$

where $\beta \in(0,1)$ is the subjective discount factor, $\sigma>0$ is the coefficient of relative risk aversion, $\nu>0$ is the inverse of Frisch elasticity of labor supply, and $\omega>0$ is a parameter that pins down the steady-state level of hours. This construction of the representative household permits us to study a situation in which people face idiosyncratic investment opportunities, while at the same time retaining the tractability of the representative household structure, thus abstracting from consumption heterogeneity across different types of agents.

\footnotetext{
${ }^{8}$ Although each member randomly becomes an entrepreneur or a worker, we re-number household members every period so that a member $j \in[0, \chi)$ is an entrepreneur and a member $j \in[\chi, 1]$ is a worker who supplies typej labor. The original KM model features heterogeneity. Each entrepreneur occasionally receives an opportunity to invest while workers never do. Aggregation is obtained by imposing a few additional assumptions. In this paper, we adopt a modified version of the KM model based on Shi (2015), which is more amenable to modifications, allowing us to perform a more extensive sensitivity analysis.
} 
At the end of each period, the household also shares all the assets accumulated during the period among members. Entering the next period, therefore, each member holds an equal share of the household's assets. An important assumption is that, after the idiosyncratic shock is realized and each member knows its type, the household cannot reshuffle the allocation of resources among its members. Instead, those household members who would like to obtain more funds need to seek the money from other sources. The assets available to household members are described in the table below, which summarizes the household's balance sheet at the beginning of period $t$ (before interest payments), expressed in terms of the consumption goods. Households own government-issued nominal bonds $B_{t}$, where $P_{t}$ is the price level, $K_{t}$ is physical capital, and $N_{t}^{O}$ represents claims on other households' capital. Households' liabilities consist of claims on own capital sold to other households $N_{t}^{I}$, and net equity $N_{t}$ is defined as

$$
N_{t}=N_{t}^{O}+K_{t}-N_{t}^{I}
$$

Capital is homogeneous, earns per-unit rental income $r_{t}^{k}$, and has a unit value $q_{t}$ in terms of consumption goods. A fraction $\delta$ of capital depreciates in each period. Bonds pay a gross nominal interest rate $R_{t}$. Note that all households liabilities - all claims to the assets of the private sector in the model - are in the form of equity.

\begin{tabular}{ll|cc}
\hline \hline \multicolumn{2}{c}{ Household's Balance Sheet (Tradable Assets) } \\
\hline \hline \multicolumn{2}{c}{ Assets } & \multicolumn{2}{c}{ Liabilities } \\
\hline nominal bonds & $B_{t} / P_{t}$ & equity issued & $q_{t} N_{t}^{I}$ \\
others' equity & $q_{t} N_{t}^{O}$ & & \\
capital stock & $q_{t} K_{t}$ & net worth & $q_{t} N_{t}+B_{t} / P_{t}$ \\
\hline
\end{tabular}

The owner of capital receives the rental income as well as profits of intermediate goods producers and capital goods producers as dividend in proportion of capital ownership. ${ }^{9}$ Define per-period real profits of all the intermediated goods producers and capital good producers as $D_{t}=\int_{0}^{1} D_{t}(i) d i$ and $D_{t}^{I}$ respectively. The dividend per unit of capital ownership is

$$
R_{t}^{k}=r_{t}^{k}+\frac{D_{t}+D_{t}^{I}}{K_{t}}
$$

\footnotetext{
${ }^{9}$ Here we consider an economy in which equity holders receive the returns from all the fixed factors of production, including physical capital, intangible capital (knowledge and patent to produce differentiated goods) and the fixed factor to limit investment goods production. Hall (2001) argues that intangible capital is essential for understanding stock market fluctuations.
} 
Finally, households pay lump-sum taxes $\tau_{t}$ to the government.

During the operation of the market, members decide how to allocate their resources between purchases of the non-storable consumption good, savings in the different assets, and, if entrepreneurs, investment in new capital. Those members who are workers also supply the hours demanded by firms at the wage contracted by the labor unions (as we shall see, workers have some monopolistic power and wages are sticky) and can therefore include their salaries among the available resources. Specifically, each household member's flow of funds is

$$
\begin{aligned}
C_{t}(j)+p_{t}^{I} I_{t}(j)+q_{t}\left[N_{t+1}(j)-I_{t}(j)\right]+\frac{B_{t+1}(j)}{P_{t}} & \\
= & {\left[R_{t}^{k}+(1-\delta) q_{t}\right] N_{t}+\frac{R_{t-1} B_{t}}{P_{t}}+\frac{W_{t}(j)}{P_{t}} H_{t}(j)-\tau_{t}, }
\end{aligned}
$$

where $H_{t}(j)=0$ for entrepreneurs $(j \in[0, \varkappa))$ and $I_{t}(j)=0$ for workers $(j \in[\varkappa, 1]), W_{t}(j)$ is the nominal wage for type- $j$ labor and $p_{t}^{I}$ is the price of new capital in terms of the consumption good, which differs from 1 due to capital adjustment costs.

Most of the action in the model is a consequence of the financial frictions, which translate into constraints on the financing of new investment projects by entrepreneurs and on the evolution of the balance sheet. ${ }^{10}$ The key frictions proposed by KM that we adopt here are of two forms. First, a borrowing constraint implies that any entrepreneur can only issue new equity up to a fraction $\theta$ of her investment. Second, a resaleability constraint implies that in any given period a household member can sell only a fraction $\phi_{t}$ of her existing equity holdings. An important simplification in $\mathrm{KM}$ is that the equity issued by the other households is a perfect substitute for the equity position in the household's own business (capital stock minus equity issued) and thus subject to exactly the same resaleability constraint. ${ }^{11}$ As a consequence, the borrowing constraint and the two resaleability constraints (on claims on capital of other

\footnotetext{
${ }^{10}$ These frictions are also front and center in the original KM formulation. We assume a slightly different asset market structure in which government-issued paper, rather than money (effectively a "bubble asset"), serves as the liquid asset and pays a nominal interest rate $R_{t}$. We make this assumption because we characterize conventional monetary policy in terms of nominal interest rate setting, as standard in the New Keynesian literature (e.g. Woodford, 2003) and we study issues related to the ZLB.

${ }^{11}$ Thus, in addition to selling a fraction $\phi_{t}$ of the equity holdings of the other households, each household can remortgage a fraction $\phi_{t}$ of capital stock that has not been borrowed against previously. This simplification is essential for aggregation in KM. While not indispensable in our model with a representative household, we continue to use this assumption in order to simplify the algebra.
} 
households and on claims on own capital) can be consolidated (see Appendix B.4 for the explicit derivation) and written in terms of net equity $N_{t}$ as

$$
N_{t+1}(j) \geq(1-\theta) I_{t}(j)+\left(1-\phi_{t}\right)(1-\delta) N_{t}
$$

The first part of the right-hand side of the inequality, $\left(1-\theta_{t}\right) I_{t}(j)$, represents a constraint on borrowing to finance new investment for those agents who have an investment opportunity. If $\theta$ were equal to 1 , the entrepreneur would be able to finance the entire investment by selling equity in financial markets. When $\theta<1$, the entrepreneur is forced to retain $1-\theta$ fraction of investment as own equity and use her own fund to partly finance the investment cost. The second part of the right-hand side, $\left(1-\phi_{t}\right)(1-\delta) N_{t}$, represents the resaleability constraint. In period $t$, household members can sell only a fraction $\phi_{t}$ of their existing equity.

While literally $\phi_{t}$ represents a restriction on transactions, we follow KM in interpreting changes in $\phi_{t}$ as "liquidity shocks." These shocks capture, in reduced form, changes in market liquidity. Alternatively, $\phi_{t}$ can also be thought of as one minus the haircut in the repo marketa measure of how much liquidity entrepreneurs can obtain for one dollar worth of collateral. Under this interpretation, shocks to $\phi_{t}$ would capture changes in funding conditions in the repo market. ${ }^{12}$ The purpose of this paper is to investigate whether this shock alone can be responsible for the bulk of the Great Recession, and the extent to which unconventional policy was successful in mitigating the impact of this shock.

Another significant feature of the model is that the asset $B_{t}$ is not subject to any resaleability constraint and is therefore "liquid." Obviously, household members for whom constraint (5) is binding would like to acquire resources from the market by issuing liquid assets. We rule out this possibility by assuming that only the government can issue the liquid asset while households can only take a long position in it:

$$
B_{t+1}(j) \geq 0
$$

Broadly speaking, we think of equity in the model as comprising all claims on private assets, which in reality take the form of equity or debt, while $B_{t}$ represents any form of government paper. We abstract from private banks as separate agents who supply liquid

\footnotetext{
${ }^{12}$ Gorton and Metrick (2012) argue that a run on the repo market is at the origin of the collapse of financial markets in the fall of 2008 .
} 
paper. Instead, all private assets are partially liquid in the same measure, and all private agents serve as financial intermediaries by simultaneously providing funds for others' capital investment and raising funds for their own investment. Indeed, even the investing entrepreneurs continue providing funds to the others due to the resaleability constraint. In an abstract way, the fall of the resaleability corresponds to the disruption of the financial system. ${ }^{13}$ The two constraints (5) and (6) are central to the analysis. The next section argues that, in equilibrium, both constraints are binding for entrepreneurs and studies the consequences for the household decision problem as a whole.

At the end of the period, household equity, bond holdings, and capital are given, respectively, by

$$
\begin{aligned}
N_{t+1} & =\int N_{t+1}(j) d j \\
B_{t+1} & =\int B_{t+1}(j) d j \\
K_{t+1} & =(1-\delta) K_{t}+\int I_{t}(j) d j .
\end{aligned}
$$

We now move to the actual decisions of each type of household member. An important assumption is that each member of the household acts in the interest of the whole family.

\subsubsection{Entrepreneurs}

The flow of funds for entrepreneur $j \in[0, \varkappa)$ is given by expression (4), with $H_{t}(j)=0$. That constraint clarifies that, as long as the market price of equity $q_{t}$ is greater than the price of newly produced capital $p_{t}^{I}$, entrepreneurs trying to maximize the household's utility will use all available resources to create new capital. In the rest of the paper, we focus on constrained equilibria in which the condition $q_{t}>p_{t}^{I}$ is satisfied. ${ }^{14}$ In these equilibria, entrepreneurs sell all holdings of government bonds because the expected return on new investment dominates the

\footnotetext{
${ }^{13}$ We assumed all the private paper is equity in our model. Even if some private papers were debt, because all members are identical ex-ante, each member's private net debt position would be zero at the beginning of the period. Thus, the equilibrium would not change unless we change the borrowing and resaleability constraints. This consideration is behind the idea of using of yield spreads between Treasury bonds and private bonds in zero net aggregate supply to calibrate the time series of liquidity in the next section.

${ }^{14}$ We first ensure that the condition $q_{t}>p_{t}^{I}$ holds at steady state, and then check that it is satisfied in our numerical experiments.
} 
return on the liquid asset. Furthermore, the entrepreneur also sells as much existing equity as possible and issues the maximum amount of new equity to take full advantage of the investment opportunity. As a consequence, the constraints arising from financial frictions (5) and (6) are both binding, and entrepreneurs spend no resources on consumption goods:

$$
\begin{aligned}
N_{t+1}(j) & =(1-\theta) I_{t}(j)+\left(1-\phi_{t}\right)(1-\delta) N_{t}(j) . \\
B_{t+1}(j) & =0 \\
C_{t}(j) & =0
\end{aligned}
$$

for $j \in[0, \varkappa)^{15}$

Substituting (10) through (12) into the flow of funds (4) and setting $H_{t}(j)=0$, we obtain the amount of investment by each entrepreneur:

$$
I_{t}(j)=\frac{\left[R_{t}^{k}+(1-\delta) q_{t} \phi_{t}\right] N_{t}+\frac{R_{t-1} B_{t}}{P_{t}}-\tau_{t}}{p_{t}^{I}-\theta q_{t}} .
$$

Therefore, aggregate investment in the economy equals

$$
I_{t}=\int_{0}^{\varkappa} I_{t}(j) d j=\varkappa \frac{\left[R_{t}^{k}+(1-\delta) q_{t} \phi_{t}\right] N_{t}+\frac{R_{t-1} B_{t}}{P_{t}}-\tau_{t}}{p_{t}^{I}-\theta q_{t}} .
$$

The denominator represents the liquidity needs for one unit of investment - the gap between the investment goods price and the amount the entrepreneur can finance by issuing equity $\left(\theta q_{t}\right)$. The numerator measures the amount of liquidity available to entrepreneurs. Clearly, a drop in $\phi_{t}$ reduces the amount of liquidity available to finance investment. ${ }^{16}$

\subsubsection{Workers}

The flow of funds for worker $j \in[\varkappa, 1]$ is given by expression (4), with $I_{t}(j)=0$. Workers do not choose hours directly. Rather, the union who represents each type of worker member sets

\footnotetext{
${ }^{15}$ Since entrepreneurs are constrained and the consumption good is jointly consumed at the end of the period, it is optimal for workers to buy all the consumption goods, directing all of the liquidity of entrepreneurs to investment.

${ }^{16}$ The entrepreneurs should not be thought of as the same characters populating the entrepreneurship literature in macroeconomics (see Quadrini (2009) for an extensive review). Instead, entrepreneurs here are best thought as capturing the broad functions of financial markets - funneling resources from savers to the production sector of the economy. The key friction in the model consists of an impediment to this "funneling", which intensifies in the event of a financial crisis.
} 
wages on a staggered basis. As a consequence, the household supplies labor as demanded by firms at the posted wages.

In order to find the workers' decisions in terms of asset and consumption choices, we derive the household's decisions for $N_{t+1}, B_{t+1}$, and $C_{t}$ as a whole, taking wages and hours as given. Since we know the solution for entrepreneurs from the last section (that is, $N_{t+1}(j), B_{t+1}(j)$ and $C_{t}(j)$ for $j \in[0, \varkappa)$ ), constraints (1), (7), and (8) determine $C_{t}(j), N_{t+1}(j)$, and $B_{t+1}(j)$ for workers. We then check that these choices satisfy the financing constraints (5) and (6) for workers.

The aggregation of workers' and entrepreneurs' budget constraints yields

$$
\begin{aligned}
C_{t}+p_{t}^{I} I_{t}+q_{t}\left(N_{t+1}-I_{t}\right)+ & \frac{B_{t+1}}{P_{t}} \\
& =\left[R_{t}^{k}+(1-\delta) q_{t}\right] N_{t}+\frac{R_{t-1} B_{t}}{P_{t}}+\int_{\varkappa}^{1} \frac{W_{t}(j) H_{t}(j)}{P_{t}} d j-\tau_{t} .
\end{aligned}
$$

Households choose $C_{t}, N_{t+1}$, and $B_{t+1}$ in order to maximize utility (2) subject to (14) and (15). As long as $q_{t}>p_{t}^{I}$, the first-order conditions for bonds and equity are, respectively,

$$
C_{t}^{-\sigma}=\beta \mathbb{E}_{t}\left\{C_{t+1}^{-\sigma} \frac{R_{t}}{\pi_{t+1}}\left[1+\frac{\varkappa\left(q_{t+1}-p_{t+1}^{I}\right)}{p_{t+1}^{I}-\theta q_{t+1}}\right]\right\},
$$

where $\pi_{t}$ is the gross inflation rate, and

$$
\begin{array}{ll}
C_{t}^{-\sigma}=\beta \mathbb{E}_{t}\left\{C _ { t + 1 } ^ { - \sigma } \left[\frac{R_{t+1}^{k}+(1-\delta) q_{t+1}}{q_{t}}+\frac{\varkappa\left(q_{t+1}-p_{t+1}^{I}\right)}{p_{t+1}^{I}-\theta q_{t+1}}\right.\right. & \\
\left.\left.\frac{R_{t+1}^{k}+(1-\delta) \phi_{t+1} q_{t+1}}{q_{t}}\right]\right\} .
\end{array}
$$

Equations (14), (16), and (17) describe the household's choice of investment, consumption and portfolio for a given price process.

The payoff from holding paper, either bonds or equity, consists of two parts. The first is the standard return: $\frac{R_{t}}{\pi_{t+1}}$ for bonds and $\frac{R_{t+1}^{k}+(1-\delta) q_{t+1}}{q_{t}}$ for equity. The second is the premium associated with the fact that this paper, when in the hand of entrepreneurs, relaxes their investment constraint. The value of this premium is $\frac{\varkappa\left(q_{t}-p_{t}^{I}\right)}{p_{t}^{I}-\theta q_{t}}$. The quantity $\frac{\varkappa}{p_{t}^{I}-\theta q_{t}}$ measures the increase in investment afforded by an extra dollar of liquidity, where $\varkappa$ and $\frac{1}{p_{t}^{I}-\theta q_{t}}$ capture the fraction of liquidity going to entrepreneurs and the extent to which the investment increases by an extra unit of liquidity, respectively. The magnitude $q_{t}-p_{t}^{I}$ measures the marginal value 
to the household of relaxing the constraint. The larger the difference between $q_{t}$ and $p_{t}^{I}$, the more valuable for the household to acquire capital by investing and pay $p_{t}^{I}$ per unit, rather than pay $q_{t}$ on the market. This premium for liquidity applies to the entirety of bond returns, but only to the liquid part of the equity return $\frac{R_{t+1}^{k}+(1-\delta) \phi_{t+1} q_{t+1}}{q_{t}}$, if $\phi_{t+1}$ is less than 1 . Hence, equity pays a premium in the expected rate of return relative to bonds because of its lower liquidity.

\subsection{The Convenience Yield}

At the heart of our model is the idea that government paper is more liquid than privately issued papers: agents are willing to pay a premium for holding Treasuries - what Krishnamurthy and Vissing-Jorgensen (2012) (henceforth KVJ) call the convenience yield. In our model the convenience yield arises because liquid assets relax the financing constraint in the next period. It is then natural to define it as

$$
C Y_{t} \equiv \mathbb{E}_{t}\left[\frac{\varkappa\left(q_{t+1}-p_{t+1}^{I}\right)}{p_{t+1}^{I}-\theta q_{t+1}}\right],
$$

where $\frac{\varkappa\left(q_{t+1}-p_{t+1}^{I}\right)}{p_{t+1}^{I}-\theta q_{t+1}}$ is the premium due to the relaxation of the investment constraint.

Because what we observe in financial markets are spreads, we find it convenient in terms of our calibration described below to express $C Y_{t}$ as a spread. As shown above, the gross nominal interest rate $R_{t}$ on a perfectly liquid one-period Treasury security satisfies Euler equation (16). The Euler equation for an otherwise identical security offering no convenience services is ${ }^{17}$

$$
C_{t}^{-\sigma}=\beta \mathbb{E}_{t}\left\{C_{t+1}^{-\sigma} \frac{R_{t}^{0}}{\pi_{t+1}}\right\}
$$

where $R_{t}^{0}$ is its gross nominal interest rate. The spread between these two securities is given by

$$
\overline{C Y}_{t}=\left[R_{t}^{0}-R_{t}\right] \mathbb{E}_{t}\left(\frac{1}{\pi_{t+1}}\right)
$$

We show in Appendix B.7 that $\overline{C Y}_{t}$ is approximately equal to $C Y_{t}{ }^{18}$

\footnotetext{
${ }^{17}$ Imagine this illiquid bond repays to the holder at the end of the next period. It is too late for the bond holder to finance investment even though it is not late for consumption. In our model we assume that these securities are small enough supply that they can be ignored. Nonetheless we can price them.

${ }^{18}$ Appendix B.7 shows how the convenience yield is related to the yield spread between a pair of longer maturity zero-coupon bonds, one perfectly liquid and the other perfectly illiquid.
} 


\subsection{Final and Intermediate Good Firms, Capital Producers, and Labor Markets}

The remainder of the production side is standard along the lines of Christiano et al. (2005) and Smets and Wouters (2007). We refer the details to Appendix B.1 through B.3, and sketch the framework below. Perfectly competitive final good producers combine intermediate goods, $Y_{i t}$, to sell a homogeneous final good $Y_{t}$ to households and capital producers. Each intermediate good producer pays a fixed cost, and hires capital and a composite labor to produce output. Facing a downward sloping demand curve with monopoly power parameter $\lambda_{p}$ for its product, each producer sets its price on a staggered basis, where $1-\xi_{p}$ is the probability of resetting the price in each period. As in Erceg et al. (2000), we introduce wage rigidities assuming labor unions represent each type of imperfectly substitutable labor inputs $H_{t}(j)$, which are combined into a homogeneous composite sold to the intermediate firms. Facing a downward sloping demand curve with monopoly power $\lambda_{w}$, each union sets the wage of each type of labor on a staggered basis so that in each period a new wage is set for a particular type of labor with probability $1-\xi_{w}$. Finally, perfectly competitive capital producers produce investment goods, sold to the entrepreneurs at price $p_{t}^{I}$, under decreasing returns to scale technology. The total cost of producing $I_{t}$ investment goods equals $I_{t}\left[1+S\left(I_{t} / I\right)\right]$, where $I$ is investment in steady state. We assume $S(1)=S^{\prime}(1)=0$ and $S^{\prime \prime}\left(I_{t} / I\right)>0$ so that the price of investment goods differs from the price of consumption goods in the short run.

\subsection{The Government}

The government conducts conventional monetary policy, unconventional credit policy, and fiscal policy. Conventional monetary policy consists of the central bank setting the nominal interest rate following a standard feedback rule subject to the ZLB

$$
R_{t}=\max \left\{R \pi_{t}^{\psi_{\pi}}\left(\frac{Y_{t}}{Y}\right)^{\psi_{y}}, 1\right\}
$$

where $\psi_{\pi}>1$ and $\psi_{y}>0$. Unconventional credit policy corresponds to government purchases of private paper (denoted by $N_{t+1}^{g}$ ) as a function of its liquidity

$$
N_{t+1}^{g}=\psi_{k}\left(\phi_{t}-\phi\right)
$$


where $\psi_{k}<0$. Rule (21) captures the behavior of the Federal Reserve in terms of the liquidity facilities, as shown in Figure 1. According to this rule, the government intervenes when the liquidity of private paper is abnormally low. When the liquidity returns to normal, the facilities are discontinued. Since we consider a crisis state as low resaleability $\phi_{t}$ state, we believe that this description of the intervention captures the behavior of the Fed during the financial crisis of 2008. We calibrate the parameter $\psi_{k}$ to deliver a balance-sheet increase in line with the data.

We stress that the government intervenes in the open market. Therefore, the intervention does not directly relax any agents' resaleability constraint (5). ${ }^{19}$ The intervention affects macroeconomic outcomes by changing the aggregate portfolio composition of the private sector, skewing it toward liquid assets. Therefore, even if the economy is subject to a liquidity shock, entrepreneurs can muster resources to finance investments (see expression 14). In the first period, the portfolio composition of the private sector is predetermined, however. Hence, on impact, the intervention is effective only via its impact on expectations and prices.

The government budget constraint is

$$
q_{t} N_{t+1}^{g}+\frac{R_{t-1} B_{t}}{P_{t}}=\tau_{t}+\left[R_{t}^{k}+(1-\delta) q_{t}\right] N_{t}^{g}+\frac{B_{t+1}}{P_{t}}
$$

The government purchase of equity and debt repayment is financed by a net tax (primary surplus), returns on equity holdings, and the new debt issuances. We assume that the government ensures intertemporal solvency by following a fiscal rule, written in deviations from steady state, according to which net taxes are proportional to the beginning-of-period government net debt position

$$
\tau_{t}-\tau=\psi_{\tau}\left[\left(\frac{R_{t-1} B_{t}}{P_{t}}-\frac{R B}{P}\right)-q_{t} N_{t}^{g}\right],
$$

where $\psi_{\tau}>0$, and where $\tau$ and $\frac{R B}{P}$ are steady-state taxes and beginning-of-period government debt, respectively (the steady-state value of $N_{t}^{g}$ is zero by assumption). Because the adjustment of taxes to debt is gradual (to the extent that $\psi_{\tau}$ is small), the government has to finance emergency private paper purchases almost entirely by issuing debt.

\footnotetext{
${ }^{19}$ Hence our policy intervention is somewhat different from that in Ashcraft et al. (2010), where the government directly relaxes the margin requirements.
} 


\subsection{Equilibrium and Solution Strategy}

In equilibrium, households and firms maximize their objectives subject to their constraints. Aggregate capital evolves according to

$$
K_{t+1}=(1-\delta) K_{t}+I_{t}
$$

where the capital stock is owned by either households or government according to

$$
K_{t+1}=N_{t+1}+N_{t+1}^{g}
$$

Finally, the aggregate resource constraint requires that

$$
Y_{t}=C_{t}+\left[1+S\left(\frac{I_{t}}{I}\right)\right] I_{t}
$$

We consider an economy in which the liquidity constraints are always binding. A formal definition of the equilibrium, with a detailed list of the set of equations, is relegated to the appendix. We assume $\phi_{t}$ follows a stationary $A R(1)$ process, and consider a crisis as a large negative shock to $\phi_{t}$. Specifically, we assume that a large negative shock to $\phi_{t}$ unexpectedly hits the economy at time $t$, starting from a steady state in period $t-1$, and that no more shocks occur afterwards. We use a Newton-Raphson algorithm to examine the non-linear perfect foresight path, taking into account that the nominal interest rate may be constrained endogenously by the zero bound in the early stage. ${ }^{20}$

\section{Calibration}

We calibrate the model at quarterly frequency and use a post-war/pre-Great Recession sample (1953Q1-2008Q3) in the United States to compute our targets. Table 1 shows the calibrated values of the parameters.

\footnotetext{
${ }^{20}$ We implement the solution by using Dynare. We have also experimented with several other solution methods, such as the two-state stochastic Markov process approach in Eggertsson (2008), which uses perturbation methods, in earlier variations of the paper, finding similar results. The current approach has the advantage of capturing the full non-linear dynamics of the model, although at the expense of abstracting from uncertainty.
} 
Table 1: Parameters

\begin{tabular}{|c|c|c|c|c|c|c|}
\hline$\phi$ & $\theta$ & $\begin{array}{l}\text { Steady } \\
\beta\end{array}$ & State Param & ers & $\gamma$ & $\frac{B / P}{A Y}$ \\
\hline $\begin{array}{l}\text { Resaleability } \\
\text { constraint }\end{array}$ & $\begin{array}{l}\text { Borrowing } \\
\text { constraint }\end{array}$ & $\begin{array}{l}\text { Discount } \\
\text { factor }\end{array}$ & $\begin{array}{l}\text { Probability } \\
\text { of investmment } \\
\text { opportunity }\end{array}$ & $\begin{array}{l}\text { Depreciation } \\
\text { rate }\end{array}$ & $\begin{array}{l}\text { Capital } \\
\text { share }\end{array}$ & $\begin{array}{l}4 Y \\
\text { Annualized } \\
\text { s.s. liquidity }\end{array}$ \\
\hline 0.309 & 0.792 & 0.993 & 0.009 & 0.024 & 0.340 & 0.400 \\
\hline \multicolumn{7}{|c|}{ Parameters Characterizing the Dynamics } \\
\hline$\sigma$ & $\nu$ & $S^{\prime \prime}(1)$ & $\zeta_{p}$ & $\zeta_{w}$ & $\lambda_{p}$ & $\lambda_{w}$ \\
\hline $\begin{array}{l}\text { Relative } \\
\text { risk aversion }\end{array}$ & $\begin{array}{l}\text { Inverse Frisch } \\
\text { elasticity }\end{array}$ & $\begin{array}{l}\text { Investment } \\
\text { adjustment cost }\end{array}$ & $\begin{array}{l}\text { Price Calvo } \\
\text { probability }\end{array}$ & $\begin{array}{l}\text { Wage Calvo } \\
\text { probability }\end{array}$ & $\begin{array}{l}\text { Price s.s. } \\
\text { markup }\end{array}$ & $\begin{array}{l}\text { Wage s.s. } \\
\text { markup }\end{array}$ \\
\hline 1.000 & 1.000 & 0.750 & 0.750 & 0.750 & 0.100 & 0.100 \\
\hline & $\psi_{y}$ & $\psi_{\tau}$ & & & & \\
\hline $\begin{array}{l}\text { Taylor rule } \\
\text { inflation } \\
\text { response }\end{array}$ & $\begin{array}{l}\text { Taylor rule } \\
\text { output } \\
\text { response }\end{array}$ & $\begin{array}{l}\text { Tax rule } \\
\text { response }\end{array}$ & & & & \\
\hline 1.500 & 0.125 & 0.100 & & & & \\
\hline \multicolumn{7}{|c|}{ Liquidity Shock and Policy Response } \\
\hline$\Delta \phi$ & $\begin{array}{c}\text { Baseline } \\
\rho_{\phi}\end{array}$ & $\psi_{k}$ & & $\Delta \phi$ & $\begin{array}{l}\text { reat Escape } \\
\rho_{\phi}\end{array}$ & $\psi_{k}$ \\
\hline $\begin{array}{c}\text { Size of } \\
\text { liquidity shock }\end{array}$ & $\begin{array}{c}\text { Shock } \\
\text { persistence }\end{array}$ & $\begin{array}{l}\text { Policy } \\
\text { intervention }\end{array}$ & & $\begin{array}{c}\text { Size of } \\
\text { liquidity shock }\end{array}$ & $\begin{array}{l}\text { Shock } \\
\text { persistence }\end{array}$ & $\begin{array}{l}\text { Policy } \\
\text { intervention }\end{array}$ \\
\hline-0.218 & 0.953 & -4.801 & & same & 0.984 & same \\
\hline
\end{tabular}

Notes: The table shows the parameter values of the model for the baseline calibration. The last three rows also report the size and the persistence of the shock, and the coefficient in the government rule for purchases of private assets in the Great Escape calibration.

\subsection{Steady State Parameters}

The centerpiece of our calibration strategy for the parameters characterizing the degree of steady state financial frictions is based on the work of KVJ, who provide us with an empirical estimate of the convenience yield. Specifically, KVJ model the convenience yield as a piecewise linear function $b_{1} \max \left\{b_{2}-\frac{B}{P Y}, 0\right\}$, and estimate $b_{1}$ and $b_{2}$ (in their regression $\frac{B}{P Y}$ is measured by the ratio of Treasuries over GDP). Also in our model $C Y_{t}$ depends on the supply of liquid assets. In fact, KVJ's functional form is consistent with our framework: As the amount of liquidity in the economy increases, the liquidity premium drops because the entrepreneurs' constraint become less binding. After some threshold $\frac{\bar{B}}{P Y}$, the constraint is no longer binding, $q$ drops to 1 (the steady state value of $p^{I}$ ), $K$ approaches the efficient level, and the convenience yield becomes zero.

Figure 2 shows that the model can replicate the results of the KVJ's regressions shown in 
the first two columns of Table 3 of their paper and reproduced by the dashed lines. ${ }^{21}$ The solid line plots the convenience yield in the model as a function of $\frac{B}{P Y} \cdot{ }^{22}$ The average value of $\frac{B}{P Y}$ in our sample, which is $40 \%$ and is indicated by the vertical line in Figure 2, implies a steady state convenience yield of $0.455 \% .^{23}$

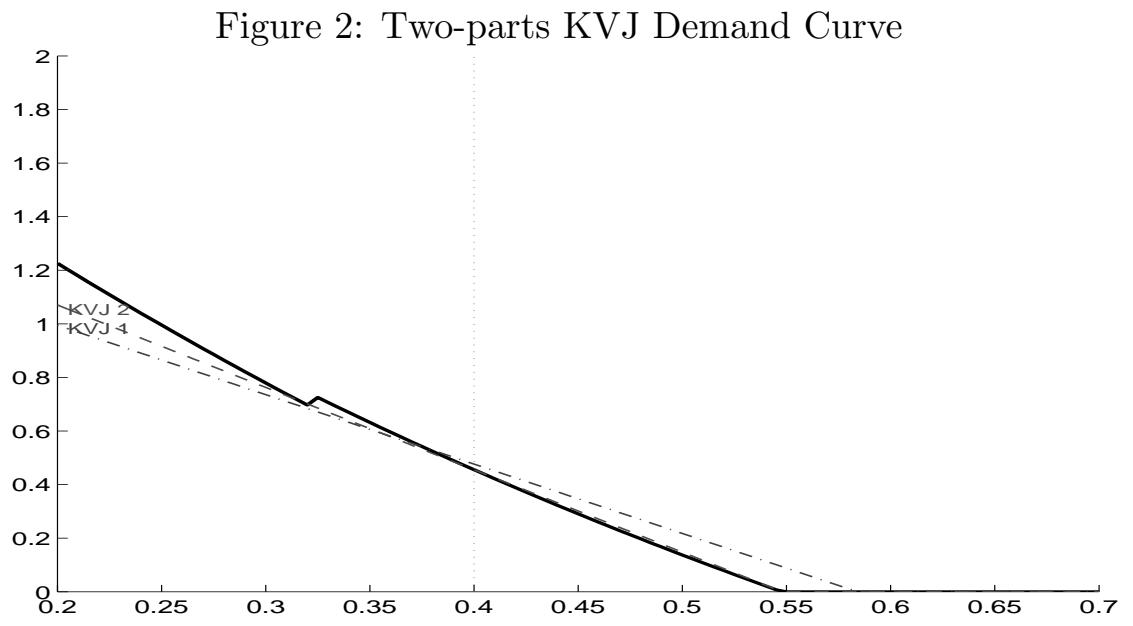

Notes: The figure plots the regressions line $C Y=b_{1} \max \left\{b_{2}-\frac{B}{P Y}, 0\right\}$ where the estimates of $b_{1}$ and $b_{2}$ come from the first two columns of Table 3 of Krishnamurthy and Vissing-Jorgensen (2012) (dashed lines). The average value of $\frac{B}{P Y}$ in our sample $(40 \%)$ is indicated by the vertical line.

The three parameters that characterize the degree of financial frictions in the model are $\theta$ (the borrowing constraint), $\phi$ (the resaleability constraint), and $\chi$ (the fraction of entrepreneurs). These parameters directly affect the tightness of the financing constraint in the steady state. Replicating the two-piece linear KVJ regression provides two targets for the calibration - the steady state convenience yield and the threshold $\overline{\frac{B}{P Y}}$. An additional target is

\footnotetext{
${ }^{21}$ The two regressions are from slightly different samples. We chose to replicate the results in column (2) (the sample closest to ours) but the two sets of coefficients are very close.

${ }^{22}$ Two comments are in order. First, since KVJ's regressions are obtained using annual data and capture secular movements in the liquidity premium, we compute the mapping between liquidity $\frac{B}{P Y}$ and the convenience yield the steady state relationships. Second, because KVJ use spreads to measure the convenience yield, we use $\overline{C Y}$ as opposed to $C Y$ (see Section 2.2) in computing this mapping. Appendix B.7 shows that at steady state $\overline{C Y}$ and $C Y$ are the same regardless of the maturity of the security.

${ }^{23}$ In order to be consistent with KVJ, we measure $\frac{B}{P Y}$ as the amount of Treasury securities relative to GDP. If we adopt the notion of liquid assets in the hands of the public used in the construction of the liquidity share (essentially subtracting assets in the balance sheet of the central bank, and adding its liabilities) we obtain a very similar number, namely $38.1 \%$.
} 
provided by the average "liquidity share" in our sample, defined as

$$
L S_{t}=\frac{B_{t+1}}{B_{t+1}+P_{t} q_{t} K_{t+1}} .
$$

The liquidity share provides indirect evidence on the value of capital $q$, and hence on the stringency of financial constrains. As the financing constraint gets tighter with smaller $\theta, \phi$, and $\chi$, the gap between $q$ and one (the steady state value of $p^{I}$ ) expands for a given supply of government liquid asset $B / P Y$, and the liquidity share drops (see Figure A-5 in the online appendix). We construct the empirical counterpart of this variable using U.S. Flow of Funds data, and obtain an average of $12.55 \%$ in our sample. ${ }^{24}$

Table 2: Targets and Model-Implied Values in Loss Function-Based Calibration of Steady State Parameters

\begin{tabular}{lcccccc} 
Targets & CY & $\frac{\bar{B}}{P Y}$ & Real rate & $\begin{array}{c}\text { Liquidity } \\
\text { Share }\end{array}$ & $\begin{array}{c}\text { Labor } \\
\text { Share }\end{array}$ & $\begin{array}{c}\text { Investment/GDP } \\
\text { Ratio }\end{array}$ \\
\hline Data & 0.455 & 0.548 & 2.200 & 12.55 & 0.65 & 0.260 \\
Model & 0.455 & 0.548 & 2.200 & 12.55 & 0.66 & 0.264
\end{tabular}

Notes: The table shows the empirical targets and the model-implied values in the loss function-based calibration of the six steady state parameters. The first two targets are obtained from the regressions in the second column of Table 3 of Krishnamurthy and Vissing-Jorgensen (2012). We set $C Y=b_{1} \max \left\{b_{2}-\frac{B}{P Y}, 0\right\}$, where $\frac{B}{P Y}$ is the average value of government debt in our sample, and $\overline{\frac{B}{P Y}}=b_{2}$. The construction of the liquidity share is described in section A.1 of the appendix, and the construction of the remaining three data counterparts - which is standard - is described in footnote 25 of section 3.1. The sample used to compute the data counterparts of the targets is 1953Q1-2008Q3.

The remaining targets are chosen to pin down the other steady state parameters. Loosely speaking, the average real rate of return in the economy (for given convenience yield), the labor share, and the investment to output ratio pin down the discount rate $\beta$, the capital share in the production function $\gamma$, and the depreciation rate $\delta .{ }^{25}$ Of course, all steady state parameters affect all targets, so we choose them as to minimize the squared deviations of model implied values from the data-both of which are shown in Table 2. Our calibration

\footnotetext{
${ }^{24}$ Section A.1 in the Appendix describes the details, and Figure A-4 shows the data over our sample.

${ }^{25}$ We target a real interest rate of $2.2 \%$, which is in between the average ex-post real returns (nominal yield minus realized CPI inflation rate) over the period 1953Q1-2008Q3 on one-year Treasury bills (1.72\%) and ten-year Treasuries (2.57\%). The source for the labor share is the Federal Reserve Bank of St. Louis FRED database, while the investment to output ratio is measured from NIPA data, and our notion of investment includes both NIPA investment and durable consumption, consistently with most of the RBC/DSGE literature (e.g., Justiniano et al., 2010) and the empirical counterparts in the reminder of the paper.
} 
yields values of $0.31,0.79$ and $0.9 \%$ for $\phi, \theta$, and $\chi$, respectively. Our calibrated value for $\theta$ is in line with that assumed by many papers using borrowing constraints á la Kiyotaki and Moore (1997). The value for $\chi$ is smaller than the existing literature on lumpy investment (e.g. Doms and Dunne, 1998; Gourio and Kashyap, 2007). However, we should stress that we choose to calibrate $\chi$ using financial data, rather than technological data on lumpy investment, as we broadly consider entrepreneurs as those who are involved in funneling resources from saving to investing agents and face the financing constraint. ${ }^{26}$

As a sanity check on our assumed steady state value for the convenience yield - and the associated value for $\phi$ - the left panel of Table A-2 of the Appendix computes the implied value of the liquidity parameter for a cross-section of spreads between pairs of bonds which have almost identical payout and different liquidity. These are the same spreads that we will use in Section 3.3 to extract a time series of the convenience yield and measure its increase during the crisis (we describe these spreads below in footnote 30 and more in detail in Appendix A.2). For each security $j$, we measure its average spread for the pre-crisis period using daily data from 2004/07/21 to 2007/06/29 - the common pre-crisis sample for which we have data for almost all of these securities - and compute its associated degree of liquidity $\phi^{j}$ using the steady state formula derived in Appendix B.7

$$
1-\phi^{j}=\frac{1+C Y}{C Y} \frac{\left(\operatorname{ytm}^{(T, j)}-\mathrm{ytm}^{(T, l)}\right) \beta(1+C Y)}{1+\left(\operatorname{ytm}^{(T, j)}-\operatorname{ytm}^{(T, l)}\right) \beta(1+C Y)},
$$

where $\mathrm{ytm}^{(T, j)}$ and $\mathrm{ytm}^{(T, l)}$ are the steady state real yields to maturity for zero coupon bond $j$ with maturity $T$ and the liquid security of the same maturity. ${ }^{27}$ The left panel of Table A-2 shows that for most of these securities, which are relatively liquid, the associated $\phi^{j}$ is not far from one. This is what we would expect for instance for short-dated Refcorp bonds, offthe-run Treasury bonds, and high-grade CDS-covered corporate bonds. Longer-dated Refcorp

\footnotetext{
${ }^{26}$ Because our entrepreneurs perform both capital and financial investment, it may not be unrealistic that entrepreneurs may not have much time to liquidate private paper before loosing the investment opportunity, and that the fraction of critical entrepreneurs who are financially constrained is small at each point in time. Of course, in a richer setup with technological and financial investment opportunities, an investment function like (14) may be too simplistic. Using a higher value of $\chi$, consistent with the literature on lumpy investment, we could still match the KVJ value of the convenience yield as well as the average liquidity share, but we would not longer be able to match the value of the threshold $\overline{\frac{B}{P Y}}$.

${ }^{27}$ While our model accommodates only one representative illiquid security, we can price any illiquid security $j$ whose associated liquidity is $\phi^{j}$ as long as its net aggregate supply is small enough that it does not affect the aggregate equilibrium conditions. See footnote 13.
} 
bonds, and especially inflation-swapped TIPS, and non-covered Aaa corporate tend to have substantially lower values of $\phi^{j} .^{28}$

\subsection{Parameters Characterizing the Dynamics}

The parameters characterizing the dynamics of the model correspond to standard values in the business cycle literature. We set the CRRA parameter $\sigma$ to 1 , the inverse Frisch elasticity of labor supply $\nu$ to 1 , and $S^{\prime \prime}(1)=0.75$ so that the price elasticity of investment is consistent with instrumental variable estimates in Eberly (1997). The average duration of price and wage contracts is 4 quarters $\left(\zeta_{p}=\zeta_{w}=0.75\right)$, in line with the recent estimates in Nakamura and Steinsson (2008). ${ }^{29}$ We calibrate symmetrically the degree of monopolistic competition in labor and product markets, assuming a steady-state markup of 10\% ( $\left.\lambda_{p}=\lambda_{w}=0.1\right)$, which are commonly assumed values in the literature. Finally, we set the feedback coefficient on inflation $\left(\psi_{\pi}\right)$ and the output gap $\left(\psi_{y}\right)$ in the interest rate rule $(20)$ to 1.5 and 0.125 , respectivelythe values in line of literature which follows Taylor (1993). Transfers slowly adjust to the government net wealth position after intervention $\left(\psi_{\tau}=0.1\right)$ so that government debt finances most of the intervention in the short run and transfers follow a smooth path.

In Appendix D we study the robustness of our results to alternative values for some of the parameters. As a further check on the reasonableness of our benchmark calibration (and the model), we also consider in Appendix $\mathrm{C}$ the impulse response function of the variables of the model to other shocks often studied in the literature, such as technology, government spending, and conventional monetary policy shocks. Broadly speaking, the effect of these shocks is similar in our model with what has been observed elsewhere in the literature.

\footnotetext{
${ }^{28}$ The reader should bear in mind that there may be measurement issues for any specific security, as well as micro-structure factors other than liquidity affecting the average spread, so one should not take the $\phi^{j}$ 's shown in Table A-2 at face value. Note that when constructing the time series of the convenience yield in Section 3.3 we address these measurement issues (and other factors, assuming they are security-specific) by taking the principal component. For Aaa corporate bond (without CDS cover), the spread may have some residual credit risk. When KVJ regress the Aaa corporate-Treasury spread on the ratio of treasury supply to GDP, they obtain a significant positive intercept (equal to $0.347 \%$ ), which they considered as the non-liquidity component of the Aaa spread.

${ }^{29} \mathrm{~A}$ lower degree of price rigidities (more in line with the evidence in Bils and Klenow, 2004) would deliver the same value for the reduced-form slope of the Phillips curve if we were to incorporate real rigidities in the model.
} 


\subsection{Liquidity Shock and Policy Response}

We calibrate the size of the post-Lehman crisis liquidity shock from financial data. Because we do not know if any traded security corresponds to our representative illiquid asset, we adopt a strategy that mirrors the one we undertook in the calibration of the steady state parameters: instead of trying to match a specific spread, we target the change in the convenience yield. Unlike in the case of the steady state value of $C Y$, we cannot rely on existing work to obtain a time series of the convenience yield. The remainder of this section describes how we do so. The bottom line is that an arguably conservative estimate of the post-Lehman increase in the convenience yield is 180 basis points. We use this measure to calibrate the size of the liquidity shock.

We take a panel of 18 different financial markets spreads, which differ by assets type and/or maturity, and which the literature argues are mostly — if not solely — driven by liquidity. ${ }^{30} \mathrm{We}$ measure the extent of their co-movement over time, that is, we extract the common factor, using a sample of almost ten years of daily data (from July 212004 to December 31 2014). We use this sample because it includes data for most of our series, and address the fact that we do

${ }^{30}$ The set of spreads includes: 1) The Refcorp/Treasury yield spreads at various maturities (6 months, 1, 2, 3, $4,5,7,10$, and 20 year). Longstaff (2004) suggests that the Refcorp/Treasury spread is mostly due to liquidity as Refcorp bonds are effectively guaranteed by the U.S. government, and are subject to the same taxation. 2) The TIPS-Treasury spreads, which we measure by taking the differences between the constant maturity yield curves for TIPS and Treasury zero-coupon bonds at various maturities (5, 7, 10, and 20 year), adjusting the former using the inflation swap spreads for the same maturities. Fleckenstein et al. (2014) provide evidence of a "TIPSTreasury bond puzzle," that is, of differences in prices between Treasury bonds and inflation-swapped TIPS exactly replicating the cash flows of the Treasury bond, and argue that this difference is orders of magnitude larger than the transaction costs of executing the arbitrage strategy. 3) The CDS-Bond basis spread, constructed as the difference between the yield on corporate bonds whose credit risk is hedged using a credit default swap (CDS) and a Treasury security of equivalent maturity. Bai and Collin-Dufresne (2013) find that measures of funding liquidity are the main drivers of the CDS-Bond basis. Similarly, Longstaff et al. (2005) find that the non-default component of corporate spreads (essentially, the CDS-Bond basis) is strongly related to measures of bond-specific illiquidity as well as to macroeconomic measures of bond market liquidity. We do not know the exact maturity of the underlying contracts in each index, but we suspect it is approximately five-year (Choi and Shachar, 2013). 4) The spread between the most recently issued and older 10-year Treasury bonds of the same maturity, called the on-the-run/off-the-run or the bond/old-bond spread, which is a commonly used measure of market liquidity (Krishnamurthy, 2002). 5) The Aaa-Treasury spread, which Krishnamurthy and VissingJorgensen (2012) argue is primarily driven by liquidity given the low default rate on Aaa bonds. Section A.2 of the online appendix provides a detailed description of the data. 
not have a fully balanced panel by using a principal component approach that allows for missing observations (Stock and Watson, 2002). Figures A-6 and A-7 in the online appendix show time series of the individual spreads as well as their the projection on the common factor for each spread, and document that for the vast majority of the spreads the common factor captures the bulk of fluctuations following the Lehman episode, except for some shorter-maturity TIPSTreasury spreads.

The gist of our strategy for measuring the change in the convenience yield rests on the assumption that this common component is proportional to the convenience yield, that is, that $C Y_{t}=a+b f_{t}$, where $f_{t}$ is the common factor. This is approximately true in our model, and is a reasonable assumption in the data as well, as long as the spreads we use mostly capture liquidity. ${ }^{31}$ Even with the factor at hand, in order to obtain a time series for $C Y_{t}$ we need to know the parameters $a$ and $b$. We do so by making two assumptions. The first is that the average convenience yield from the beginning of the sample $(2004 / 07 / 21)$ to the very beginning of the financial crisis $(2007 / 06 / 29)$ equals the steady state value assumed in Section 3.1, namely $0.46 \%$. The second is that the asset with the highest spread in 2008Q4 (this is the BBB CDS-Bond basis) is essentially illiquid at the height of the financial crisis. Since the convenience yield is the yield spread between a completely illiquid and fully liquid security, under this assumption the average of $C Y_{t}$ in 2008Q4 approximately coincides with this spread, and equals $3.42 \%$ annualized (see Appendix B.7 for a more formal discussion).

There are two reasons why this value can be viewed as a conservative estimate of $C Y_{t}$ in 2008Q4. First, even at the height of the crisis the BBB CDS-Bond basis may still have

\footnotetext{
${ }^{31}$ In our model, the endogenous variables including the convenience yield is a function of the state variables $K_{t}, N_{t}^{g}, R_{t-1} L_{t}, w_{t-1}, \Delta_{t-1}, A_{t}, \phi_{t}$ (where $L_{t}=B_{t-1} / P_{t-1}, w_{t}=W_{t} / P_{t}$ and $\Delta_{t}$ is a distortion measure due to price dispersion - see the Appendix for details). Because these state variables are either approximately linear function of $\phi_{t}$ (such as $N_{t}^{g}$ and $\left.R_{t-1} L_{t}\right)$, or slow moving $\left(K_{t}, w_{t-1}, \Delta_{t-1}\right)$ with constant TFP shock as in our main calibration, the convenience yield is approximately a linear function of $\phi_{t}$ and a common factor $f_{t}$ proportional to $\phi_{t}$. Empirically though it is an open question whether $C Y_{t}$ and $\phi_{t}$ are perfectly correlated-that is, whether spreads follow a one factor model or a multi-factor model, where the other factors capture drivers of the convenience yield that are not related to $\phi_{t}$. In order to address this issue, we estimated a two factor model. Figures A-8 and A-9 in the online appendix show that the projections of spreads on the two factors are very similar to those from the one factor model, suggesting that at least in the sample under consideration using one factor only is reasonable. Finally, the spreads under consideration are associated with different maturities. Appendix B.7 shows that under some assumptions the spreads still follow a one factor model, where the loading on the factor-for given $\phi^{j}$ - depends on the maturity of the asset.
} 
retained some liquidity premium, implying that the convenience yield is higher than its spread. Second, the securities underlying this spread are long-term (their maturity is approximately five years), so the spread in 2008Q4 should reflect the average expected $C Y_{t}$ over the duration of the contract, as opposed to the value in that period. To the extent that $C Y_{t}$ was expected to decline in the following quarters, the value of $3.42 \%$ is a lower bound.

These two assumptions allow us to translate the common factor into a daily time series of the convenience yield $C Y_{t}$, which we plot in Figure 3. Once we have this time series, we can compute the average convenience yield for the pre-Lehman period (that is, the average for 2008/Q2-Q3 excluding the month of September), which is 1.33\%. This value suggests that the change in $C Y_{t}$ due to the Lehman shock was roughly 210 basis points. However, in the weeks preceding the Lehman crisis, the convenience yield had already begun to rise, reaching for instance $1.56 \%$ on September 1st. Therefore, in order to be conservative, we calibrate the size of the shock to achieve an increase of 180 basis point in the convenience yield. ${ }^{32}$

Figure 3: A Time-Series for the Convenience Yield

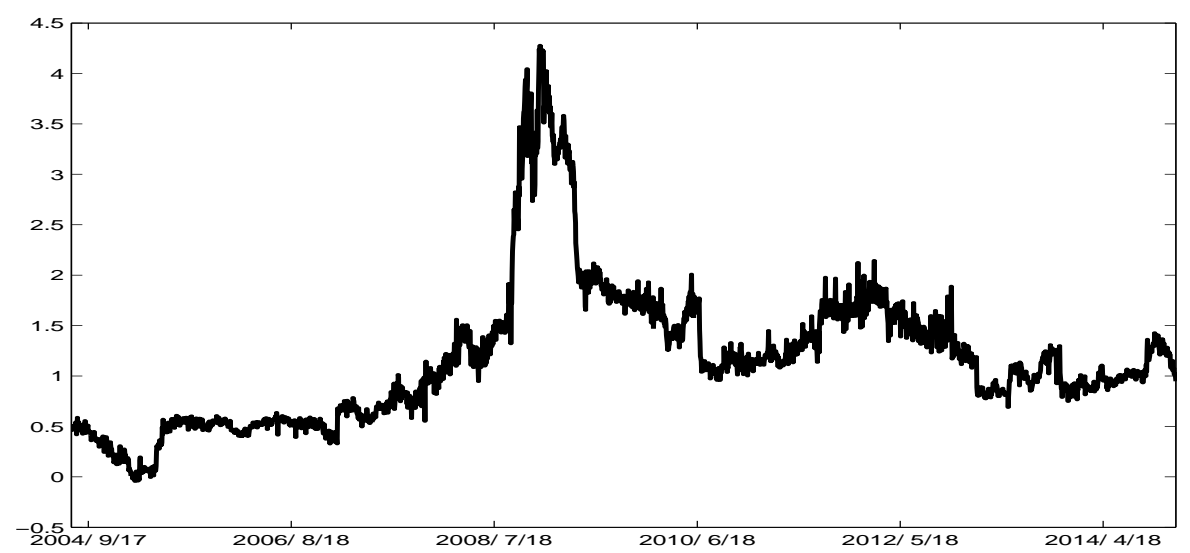

Notes: The figure plots a daily time series of the convenience yield from July 212004 to December 312014 , constructed using a panel of 18 liquidity-related spreads as described in 3.3.

We choose the persistence of the shock $\rho_{\phi}=0.953$ so that the implied expected duration of the ZLB episode is six quarters. This value falls close to the midpoint between survey evidence of market participants (Moore, 2008) and the predictions of an estimated interest rate rule (Rudebusch, 2009). Later, we present results based on expectations of more severe financial disruption.

\footnotetext{
${ }^{32}$ The fall in the resaleability constraint that we obtain - about $70 \%$ - is broadly consistent with the increase in haircuts after Lehman's failure documented by Gorton and Metrick (2012).
} 
Finally, the parameter $\psi_{k}$ is calibrated to generate a government intervention of about $\$ 1.4$ trillion (10\% of GDP), consistent with the increase in the asset side of the Fed's balance sheet after the collapse of Lehman Brothers, as displayed in Figure 1. ${ }^{33}$

\section{Results}

\subsection{Simulating the Financial Crisis: The Impact on Macroeconomic and Financial Variables}

Figure 4 shows the response of output, inflation, and the nominal interest rate to the calibrated liquidity shock $\phi_{t}$ in the model, and compares it to the dynamics in the data during the Great Recession. Specifically, the right-hand column plots the predicted path of variables for sixteen quarters, conditional on the shock hitting at the beginning of the first period under perfect foresight. The left-hand column shows the changes in the data also for sixteen quarters (i.e., until 2012Q3) relative to 2008Q3, when the Lehman bankruptcy occurred. We measure output as the log of the sum of consumption and investment from the NIPA tables. We report the percentage deviation from a linear trend estimated from 2000Q1 to 2012Q3, normalized to zero in 2008Q3. For inflation, we use the annualized percentage change in the GDP deflator, and express it in deviation from the two percent inflation long run objective of the Fed. The nominal interest rate is the effective federal funds rate.

\footnotetext{
${ }^{33}$ We include currency swaps with foreign central banks in computing the size of the intervention. The rational for this choice lies in the fact that a key purpose of the currency swaps was to provide dollar liquidity to foreign banks that needed funding for dollar-denominated assets, as discussed in Fleming and Klagge (2010). While it is hard to know for sure what these dollar denominated assets represented, arguably they were mostly claims originated in the U.S., such as mortgage-backed securities. We exclude however many other important policy during this period, such as expansion of FDIC insurance, Temporary Liquidity Guarantee Program and Federal Home Loan Bank System Loan Facilities. We do so to stay on the conservative side in our counterfactual experiment. Because we calibrate the size of liquidity shock to the increase in convenience yield observed in the data, the difference between intervention and no intervention would be larger with a larger size of the intervention. The second reason for not incorporating these policies into our analysis is that they are harder to quantify as they largely consist in providing insurance rather than the actual liquidity injections done by the central bank, which we can measure in the data. Moreover, our framework is best suited to analyze the effects of policy which directly changes the compositions of private holdings of assets of different liquidity. Concerning policies which may indirectly improve the working of private financial intermediaries, our framework has less to say.
} 
Figure 4: Response of Output, Inflation, and the Nominal Interest Rate to the Liquidity Shock
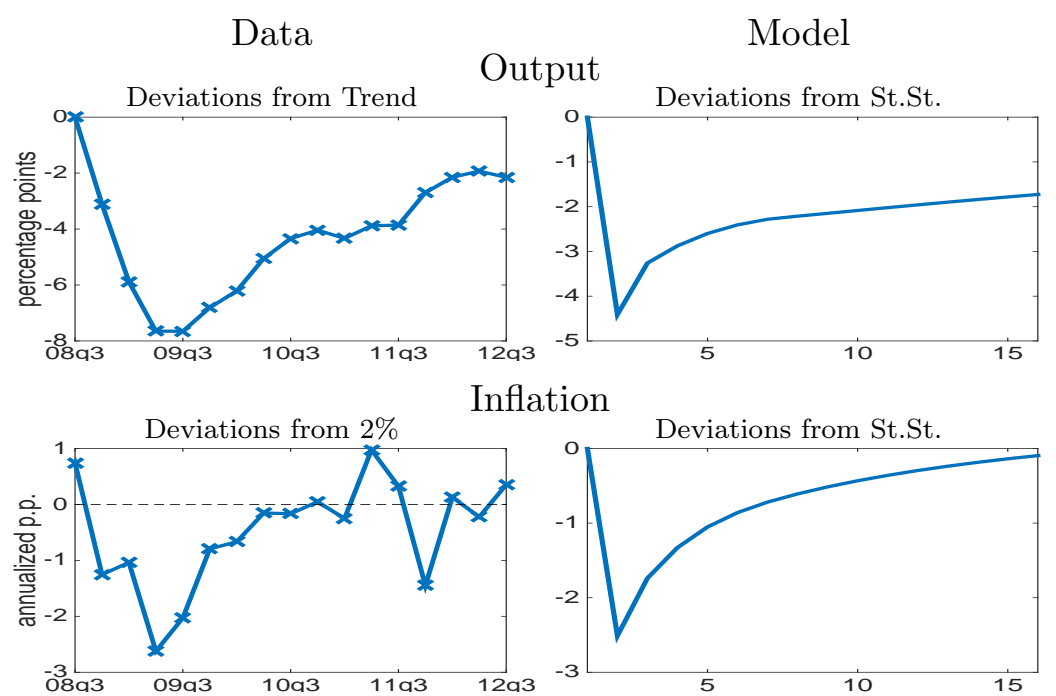

Federal Funds Rate
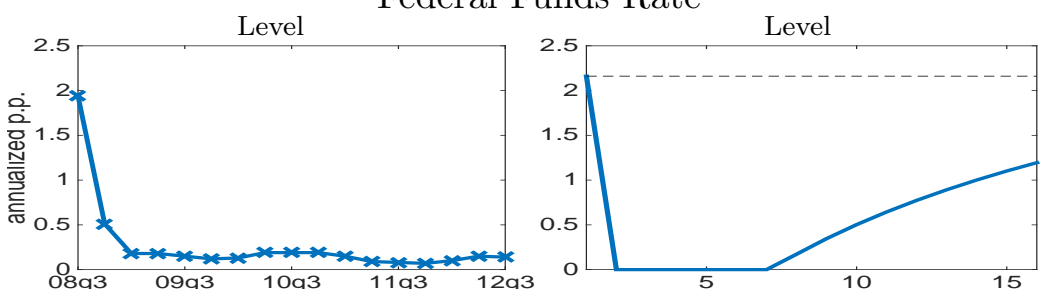

Notes: The figure compares the evolution of output, inflation, and the nominal interest rate in the data (left column) and in the model in response to the calibrated liquidity shock (right column). The data start in 2008Q3. Both data and model are plotted for 16 quarters. Output in the data (top-left) is the sum of consumption and investment, in percentage log-deviations from a linear trend estimated from 2000Q1 to 2012Q3, and is normalized to zero in 2008Q3. Inflation in the data (middle-left) is the annualized quarterly inflation rate of the GDP deflator. The interest rate in the data (bottom-left) is the annualized effective Federal Funds Rate. Output in the model (top-right) is the log-deviation from steady state in percentage points. Inflation in the model (middle-right) is expressed in annualized percentage points. The interest rate in the model (bottom-right) is the annualized level of the nominal interest rate in percentage points (the horizontal line is its steady state value).

The liquidity shock explains a large component of the response of the macroeconomy to the Lehman episode. The model explains more than fifty percent of the output reduction ( $-4.4 \%$ in the model versus $-7.8 \%$ in the data); it also accounts for a two and a half percent drop in the inflation rate, which corresponds to the entire fall of inflation relative to target in the data, and to three quarters of the change from its value in $2008 \mathrm{Q} 3$; finally, it shows the nominal interest rate hitting the zero lower bound following the crisis and remaining there for a considerable period. Note that the model expects the recovery of real activity after the shock to be sluggish, which was indeed the case in the data.

The first row of Figure 5 shows the decomposition of the output drop in the relative 
Figure 5: Response of Consumption, Investment, the Nominal Value of Capital, and Convenience Yield to the Liquidity Shock

\section{Data}

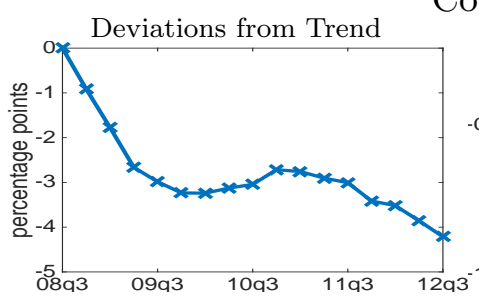

Consumption

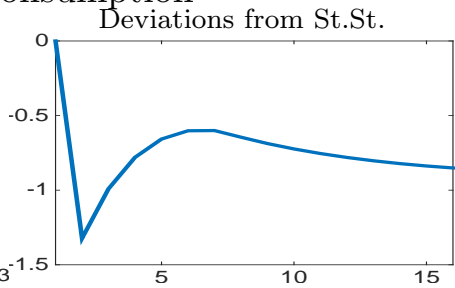

Convenience Yield
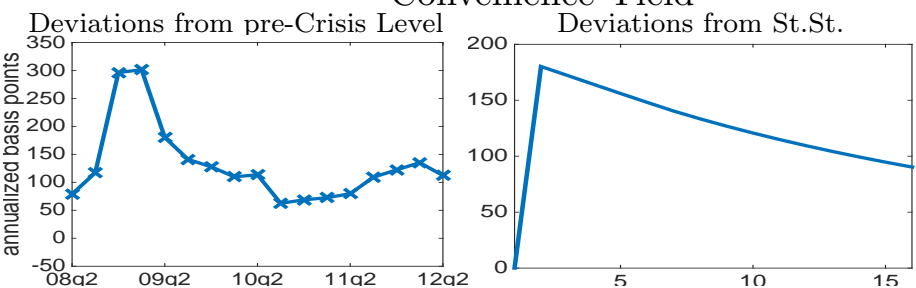

Data

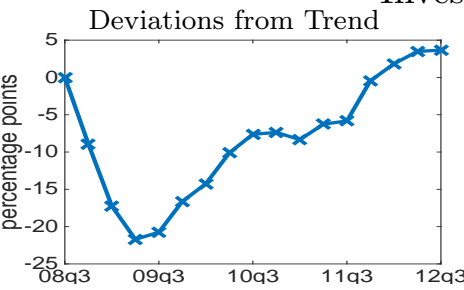

Investment

Model

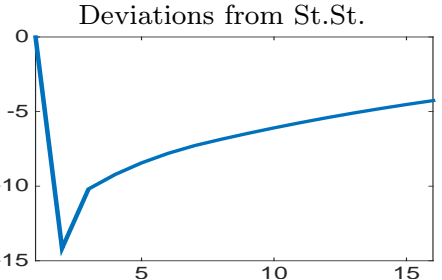

Value of Capital
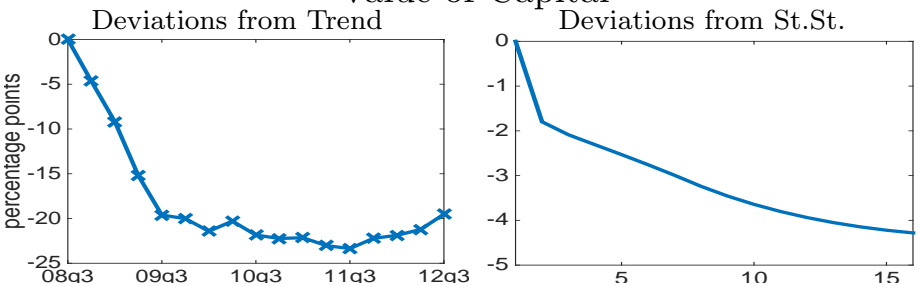

Note: The figure compares the evolution of consumption, investment, nominal value of capital, and convenience yield in the data (left column) and in the model in response to the calibrated liquidity shock (right column). The data start in 2008Q3. Both data and model are plotted for 16 quarters. Consumption in the data (top-left) is total consumption minus durable consumption. Investment in the data (top-middle-left) is investment plus durable consumption. The nominal value of capital in the data (bottom-middle-left) is the value of illiquid assets from the flow of funds as defined in the text. These three variables are expressed in percentage log-deviations from a linear trend estimated from 2000Q1 to 2012Q3, and are normalized to zero in 2008Q3. The convenience yield in the data (bottom-left) is in annualized basis points (its computation is described in section 3.2). Consumption (top-right), investment (top-middle-right), and the nominal value of capital (bottom-middle-right) in the model are log-deviations from steady state in percentage points. The convenience yield in the model (bottom-right) is the annualized absolute deviation from steady state expressed in basis points.

contribution of consumption (left panels) and investment (right panels) in the model and in the data. ${ }^{34}$ The model explains about two-thirds of the actual fall in investment $(-14.2 \%$ versus $-22.3 \%)$, and almost one half of the fall in consumption (-1.3\% versus $-3.0 \%)$. The model underpredicts the fall investment, possibly because of the absence of an explicit residential sector. Nevertheless, the broad empirical patterns are correct, in that investment drops substantially more than consumption in percentage terms both in the model and the data.

The bottom row of Figure 5 shows the behavior of the convenience yield $C Y_{t}$ (left panels), which is the quarterly average of the time series shown in Figure 3 and is expressed in deviations from the KVJ steady state value of $0.46 \%$, and the total nominal value of capital, measured

\footnotetext{
${ }^{34}$ Our empirical counterpart of consumption excludes durable goods, which instead we treat as part of investment, consistently with much of the literature (Justiniano et al., 2010). As for output, both the variables are measured in logs, and are shown in percentage deviation from a linear trend estimated from 2000Q1 to 2012Q3 (separately estimated for each variable), and are normalized to zero in 2008Q3.
} 
in the data using the Flow of Funds (see Appendix A.1) and in the model as $P_{t} q_{t} K_{t} \cdot{ }^{35}$ By construction, the rise in $C Y_{t}$ in the model matches the change in the convenience yield between the pre-Lehman period and the 2008Q4 average. In the data $C Y_{t}$ rises again between 2008Q4 and 2009Q1, and then falls faster than the model would have predicted in the second half of 2009, possibly because of a number of other factors and policy interventions (e.g., the stress test and the first round of large-scale asset purchases) that are not incorporated in the model. Bear in mind that the model impulse responses capture ex-ante expectations as on 2008Q4, while the data measure ex-post outcomes. We should also recognize that our deterministic simulations are set to match the modal expectations of the duration of the ZLB as of 2008Q4 (six quarters), but do not capture the uncertainty concerning the expected duration of the crisis, which was pervasive.

The model can only account for about one fifth of the observed decline in the value of capital. $^{36}$ Shi (2015) discusses the reason why, in the absence of other frictions, a liquidity shock in the KM model generally leads to a rise in the real value of equity. As the resaleability constraint tightens, the demand for assets increases relative to the supply (including the equity with limited resaleability), which tends to push up equity prices ceteris paribus. Our results indicate that incorporating nominal frictions and the ZLB does generate a fall in the value of equity, even though such a fall is smaller than observed in the data. One way in which this limitation could be addressed is to explain the liquidity shock endogenously. Cui and Radde (2014) embed a search-and-matching framework into the KM model and argue that this approach addresses Shi's critique. ${ }^{37}$

In short, our simulated crisis generates movements in macroeconomic variables following a liquidity shock that are not far from their empirical counterparts following Lehman's bankruptcy. Apart from the insufficient drop of equity prices, the model does not fully account for two aspects of the data, which we believe are related. The first is that the model

\footnotetext{
${ }^{35}$ The convenience yield is computed as the spread $\overline{C Y}_{t}$ (the spread between a perfectly illiquid and a perfectly liquid bond, see the discussion in section 2.2), and is expressed in annualized basis points. The value of capital is measured in logs, and like the other variables is shown in percentage deviation from a linear trend estimated from 2000Q1 to 2012Q3, normalized to zero in 2008Q3.

${ }^{36}$ The model predicts the real value of capital $q_{t}$ to fall, as shown in Figure A-10 in the Appendix. The Figure shows that nominal rigidities and the ZLB are essential for this result.

${ }^{37}$ Other natural candidates include mechanisms that relate the fall in resaleability to a concurrent drop in current or expected future total factor productivity. See Guerron-Quintana and Jinnai (2015).
} 
only explains a little bit more than half of the observed fall in output. The second is that in the model, the nominal interest rate starts increasing 6 quarters after the onset of the shock, while in the data the duration of the ZLB was much longer.

Obviously, several other shocks played an important role in the crisis in addition to the negative shock to the liquidity of private paper, such as the debt-deleveraging process at the household level, studied theoretically in Eggertsson and Krugman (2012) and documented empirically in Mian and Sufi (2014), or slow-moving secular factors (e.g. Eggertsson and Mehrotra, 2014)). These additional forces can account for both the drop in output our model does not explain, as well as the delay in the interest rate liftoff in the data relative to our model's forecast, which is only conditioned on the shock to the liquidity of private paper. Our paper only focuses on the macroeconomic consequences of the disruption in the financial system following Lehman's bankruptcy, and on the effect of the Federal Reserve's policies to mitigate such a disruption.

\subsection{The Great Escape? What Would Have Happened in the Absence of the Liquidity Facilities?}

What would have happened after the liquidity shock in the absence of unconventional policy? This is the central question of the paper, which we can address using our model with liquidity constraints. The left panel of Figure 6 shows the gain in output and inflation in the baseline scenario due to the intervention. The model suggests that, without the facilities, the drop in output would have been significantly larger, $-5.8 \%$ instead of $-4.4 \%$, that is, the output contraction would have been $30 \%$ more severe in the absence of the intervention. In addition, inflation would have declined by almost three and half percentage points, compared to two and a half with intervention. Figure 6 also makes the point that looking at the first period understates the importance of unconventional policy. Given our assumption that, on impact, the facilities do not relax the entrepreneurs' resaleability constraint, entrepreneurial investment cannot avoid the direct hit due to the fall in resaleability. The policy effect in the first period

is still significant because it affects asset prices and consumption through expectations. From the second period onward, the effect is larger, as the policy changes the aggregate amount of liquidity in the economy by changing the household portfolio towards the liquid asset. 
Figure 6: The Effect of the Liquidity Facilities on Output and Inflation in the Baseline and in the Great Escape Experiment

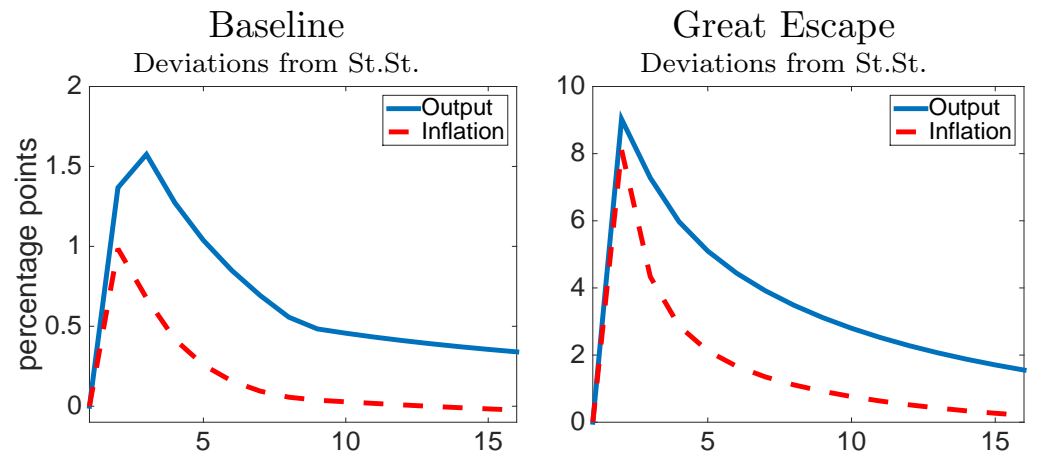

Notes: The figure shows the difference between counterfactual and actual response of output (solid blue) and inflation (dashed red) in the model in response to the calibrated liquidity shock under the baseline persistence (left panel), and with increased persistence such that the zero lower bound binds for twenty quarters (right panel).

The effect of the liquidity facilities on the convenience yield is not negligible ( 45 basis points annualized - see Figure A-12 in the Appendix), but smaller as a fraction of the initial response than in the case of the macro variables. Much of the early literature on the effect of the facilities focused on the reduction in spreads as the main metric to interpret their success (McAndrews et al., 2008; Taylor and Williams, 2009). Our model suggests that this metric may not be entirely appropriate. Even if the reduction in spreads is limited, the macroeconomic impact is substantial. In the model, not only is the private sector better off because of the liquidity injection, but the government actually ends up making money off the transaction $— \$ 27$ billion in the first year in our baseline calibration. ${ }^{38}$

In the baseline scenario, we calibrate the persistence of the shock assuming that the private sector expected the ZLB to bind for six quarters right after Lehman's bankruptcy. Yet, given the intensity of the crisis, and the degree of disruption in financial markets, the Great Recession has often been compared to previous financial crises, such as the Great Depression and Japan's "Lost Decades." These episodes, also characterized by downward pressure on prices and zero nominal interest rates, lasted much longer than six quarters.

To capture the possibility that the public had expected a Depression-like crisis, we consider the same shock but increase its persistence, so that the ZLB binds for twenty quarters (five years). The right panel of Figure 6 shows the gain in output (solid) and inflation (dashed) due

\footnotetext{
${ }^{38}$ Federal Reserve transfers to the U.S. Treasury (profits minus operating expenses) reached two consecutive records in 2009 ( $\$ 47.4$ billion) and 2010 (\$78.4 billion), largely as a result of the increased interest income on security holdings.
} 
to the intervention in this alternative scenario, calibrating the size of the intervention as before at $\$ 1.4$ trillion. Without the intervention, the drop in output (almost twenty percent) and inflation (about fifteen percent) is of an order of magnitude not seen in the US since the Great Depression. In this case, thus, unconventional credit policy becomes much more effective. The policy response cuts the losses in output and inflation by roughly a half-generating a recession of similar order as seen in the data.

This "divine coincidence" (Christiano et al., 2011), according to which the policy intervention becomes more effective as the economy approaches the "disaster area", represents an element of commonality with the literature on the multiplier of government spending in a liquidity trap (see also Eggertsson, 2011). A key reason for the effectiveness of the policy intervention is the assumption of price rigidities and the presence of the ZLB. In the absence of these two frictions, the intervention would have substantially less effect, as shown in Figure A14 in the Appendix, which shows the increase in output as a result of the policy under different assumptions. With flexible prices, the intervention is almost irrelevant while in the absence of the ZLB, traditional monetary policy (via interest cuts) largely substitutes unconventional policy, hence making it much less necessary. We clarify the logic for these results in the next two sections.

Finally, in Appendix D we consider several perturbation of the baseline parameters to explore the sensitivity of the results. The overall tenor of the results remain unchanged: the liquidity shock generates a recession, and the liquidity facilities are effective in mitigating the consequences of the shock.

\subsection{The Role of Nominal Frictions}

The previous two sections showed that the KM liquidity shocks can rationalize the behavior of macroeconomic and financial variables during the Great Recession, and that unconventional credit policy might have prevented an even larger downturn. The next two sections shed some light on the ingredients behind our main results. We start from the role of nominal rigidities. Absent this friction, liquidity shocks would only affect the composition of output, decreasing investment and increasing consumption, but would have had very little effect on aggregate activity. 
Figure 7: The Role of Nominal Rigidities

Output Investment

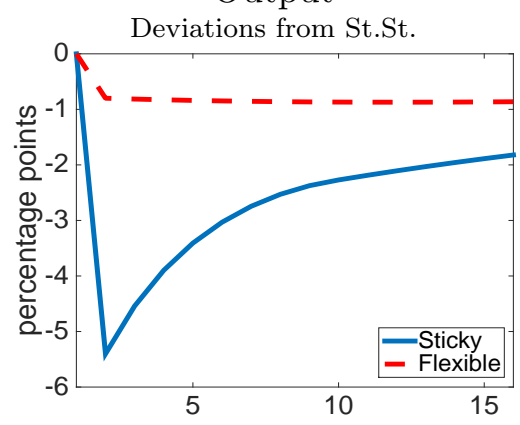

Deviations from St.St.

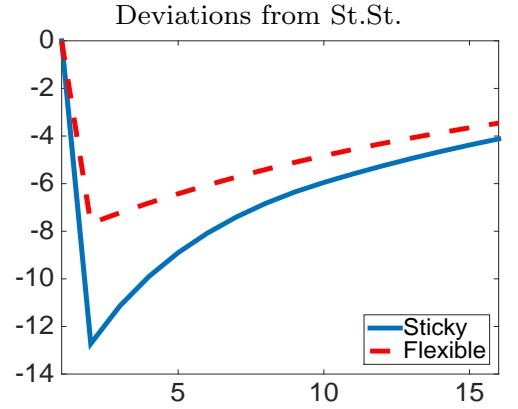

Consumption

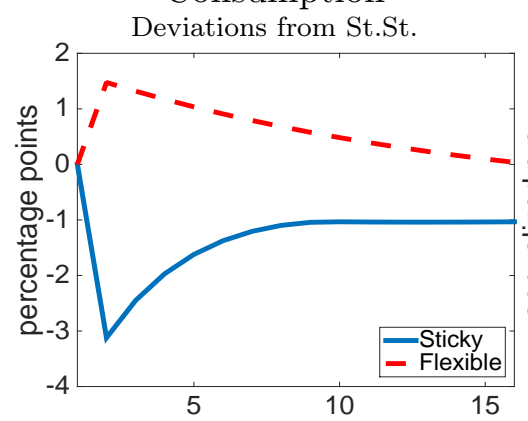

Real Interest Rate

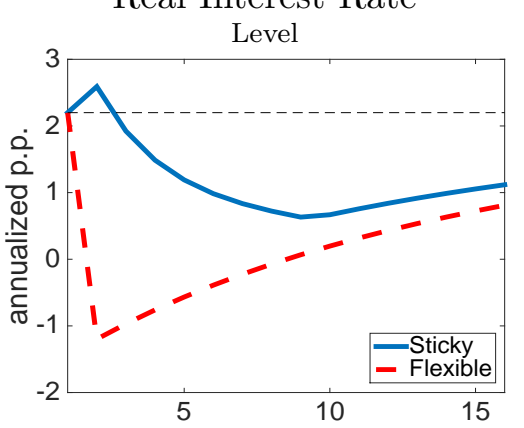

Notes: The figure compares the response of output (top-left), investment (top-right), consumption (bottom-left), and the real interest rate (bottom-right) to the liquidity shock under the baseline calibration in the absence of intervention with (solid blue) and without (dashed red) nominal price and wage rigidities.

The four panels of Figure 7 show the response of output, investment, consumption, and the real interest rates with (solid) and without (dashed) nominal rigidities under the baseline calibration. For simplicity, but also to magnify the differences, we show the responses without policy intervention. The top-left panel of Figure 7 shows that, with flexible prices and wages, the response of output is indeed very small, even though the liquidity shock has still a large impact on investment (top-right panel). The equilibrium condition for investment (14) shows that when $\phi_{t}$ falls the amount of resources available to entrepreneurs for investment drops, regardless of nominal rigidities. Clearly, the financial frictions are driving the fall in investment. Nominal frictions exacerbate the effect of the shock by depressing current and future economic activity and therefore equity prices. This channel explains why quantitatively the response of investment is larger with nominal rigidities, but qualitatively the two impulse responses are similar.

Conversely, consumption moves in opposite directions depending on whether prices and wages are flexible or not (bottom-left panel). Consumption rises under flexible prices and 
wages, instead of falling as in our simulation with nominal rigidities. Intuitively, consumption needs to make up for the drop in investment since, in that case, output does not drop as much without nominal frictions. The reason for small response of output absent nominal rigidities is that the liquidity shock only affects the accumulation of the capital to be used for production in the future, but has no effect on either productivity or the existing capital stock. Output would drop substantially only if, for some reason, labor were to be used much less intensively for production. If prices are flexible and the elasticity of labor supply is not too extreme, however, the effect on hours is not very pronounced. Hence, aggregate output remains more or less unchanged.

The mechanism of adjustment hinges upon the behavior of the real interest rate. To get households to spend more, the real interest rate needs to decline. The bottom-right panel of Figure 7 shows that the real interest rate absent nominal frictions (the so-called natural rate of interest) becomes negative in response to the liquidity shock, so that consumption rises. ${ }^{39}$ This fall in the real interest rate is hard to achieve, however, when prices are rigid. With some (but not full) price flexibility, the private sector starts expecting some deflation in future periods when the shock is still perturbing the economy, while the Taylor rule implies zero inflation as soon as the shock is over. The interaction of the ZLB and price frictions leads to higher real interest rates owing to expected deflation, which causes consumption to fall with investment. The longer the private sector expects the shock to last, the stronger deflation is, and hence the rise in real rates. The fact that the liquidity shock cannot generate much effect if all prices are flexible is an important quantitative findings of this paper.

\subsection{The Zero Lower Bound}

Given the relevance of nominal rigidities stressed in the previous section, not surprisingly conventional monetary policy also plays an important role in our results. But the presence of the ZLB impairs full monetary policy stabilization.

Figure 8 shows the response of output, the nominal interest rate, and the real interest rate ignoring the ZLB constraint, with (solid) and without (dashed) the liquidity facilities. In order

\footnotetext{
${ }^{39}$ We note in passing that in our framework financial frictions have a direct effect on the natural rate of interest via the convenience yield, as equation (16) highlights. The relationship between liquidity and the natural rate of interest is a potentially important one for monetary policy. We leave its analysis for future research.
} 
Figure 8: The Role of the Zero Lower Bound
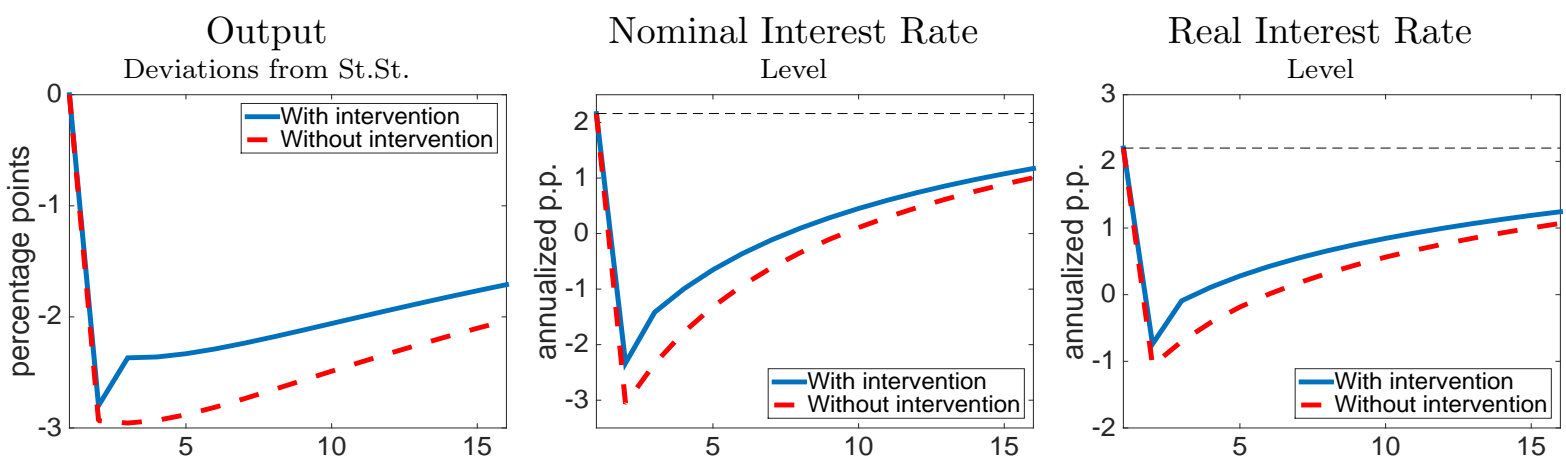

Notes: The figure compares the response of output (left), nominal interest rate (middle), and real interest rate (right) to the liquidity shock under the baseline calibration when the zero lower bound on the nominal interest rate is ignored with (solid blue) and without (dashed line) intervention.

to show that the ZLB works as an amplification mechanism for the liquidity shock, let us first focus on the case without intervention - that is, the dashed lines. As we have seen in Figure 6 , output drops by almost six percent without intervention when the ZLB is binding. In the absence of the ZLB, even without intervention, output would have fallen only by half that amount. The reason is that, in this case, a monetary authority following the Taylor rule (20) would have lowered the nominal interest rates below zero, thereby inducing a fall in the real interest rate from $2.2 \%$ percent (the steady state) into negative territory.

In contrast, under the ZLB the nominal interest rate is stuck at zero. The zero bound amplifies the effect of the liquidity shock not only because the constraint is binding in a given period, but especially because agents expect it to be binding in the future. This belief lowers expected future income and generates deflationary expectations. Such expectations lead to a rise in real rates (shown in Figure 7) and a decline in demand. In this situation, unconventional policy stimulates demand by changing the portfolio composition of the private sector, thereby enabling entrepreneurs to pursue more investment opportunities. The impact of the policy on investment supports demand in all periods when the economy is in a crisis, indirectly boosting consumption via its effect on inflation expectations, and hence lowering the real rate. In this sense, unconventional policy can substitute for interest rate policy when the latter is hindered by the ZLB. ${ }^{40}$ Yet, the actual liquidity facilities (as per our calibration) are less than a perfect

\footnotetext{
${ }^{40}$ The "Great Escape" calibration forcefully illustrates the role of expectations in determining the effectiveness of unconventional policy, as it shows that unconventional policy becomes very effective when ZLB is expected to be binding for a long time.
} 
substitute. At the ZLB, the size of the liquidity intervention necessary to achieve the same output response to the crisis as when the nominal interest rate can go negative is almost $30 \%$ of GDP - three times more than the baseline liquidity injection (see Appendix Figure A-13).

If the ZLB is not binding, unconventional policy is much less needed, simply because conventional policy can do its job in boosting demand. Indeed, Figure 8 shows that the paths of output with and without unconventional policy are not very different when the ZLB is not binding.

\section{Conclusions}

In this paper, we have proposed an analysis of the economic and financial crisis of 2008 based on shocks to the liquidity of private paper. We have incorporated a set of financial frictions into a standard DSGE model to show that the Federal Reserve's liquidity facilities made a material difference in preventing the recession from becoming deeper, substituting for the conventional interest rate policy that was constrained by the zero lower bound. Had market participants in 2008 expected the zero lower bound to last for as long as it did, the Fed may have prevented the Great Recession from becoming a second Great Depression, although this hypothesis is admittedly extreme. Our analysis does not deny the importance of other shocks in explaining the crisis nor the importance of other policy intervention, such as fiscal policy.

Our results rely on the crucial distinction that the government can issue perfectly liquid papers while the private sector cannot. The ability of governments to issue fiat currency and raise taxes provides a rationale for this assumption. If government bonds become subject to default risk and sensitive to information on a possible default, also their liquidity would become much less than perfect, as in the recent cases of Greece, Portugal, and Ireland. In this case, the government has only limited ability to conduct unconventional credit policy and the expectations about future fiscal policy would affect both the valuation and the liquidity of government bonds. We leave this topic for future research. ${ }^{41}$

\footnotetext{
${ }^{41}$ We have also abstracted from the wealth distribution across heterogeneous agents by assuming complete sharing of consumption and assets among family members at the end of every period. Absent this pooling of resources, the distribution of net worth across heterogeneous producers and consumers affects aggregate production and asset prices as in Bernanke and Gertler (1989) and Kiyotaki and Moore (1997). Because the balance sheet takes time to adjust, the recovery of aggregate production may be slow after a large financial
} 


\section{References}

Adrian, Tobias, Christopher Burke, and James McAndrews, "The Federal Reserve's Primary Dealer Credit Facility," Current Issues in Economics and Finance, 2009, 15 (4).

_ , Karin Kimbrough, and Dina Marchioni, "The Federal Reserve's Commercial Paper Funding Facility," Economic Policy Review, 2011, 17 (1), 25-39.

Ajello, Andrea, "Financial Intermediation, Investment Dynamics and Business Cycle Fluctuations," American Economic Review, forthcoming.

Anzoategui, Diego, Diego Comin, Mark Gertler, and Joseba Martinez, "Endogenous Technology Adoption and R\&D as Sources of Business Cycle Persistence," 2015. New York University working paper.

Armantier, Olivier, Sandra Krieger, and James McAndrews, "The Federal Reserve's Term Auction Facility," Current Issues in Economics and Finance, 2008, 14 (5).

Ashcraft, Adam, Nicolae Garleanu, and Lasse Heje Pedersen, "Two Monetary Tools: Interest Rates and Haircuts," NBER Macroeconomics Annual, 2010, pp. 143-180.

Bai, Jennie and Pierre Collin-Dufresne, "The CDS-Bond Basis," in "AFA 2013 San Diego Meetings Paper" 2013.

Bernanke, Ben and Mark Gertler, "Agency Costs, Net Worth, and Business Fluctuations," American Economic Review, 1989, 79 (1), 14-31.

_ , _ , and Simon Gilchrist, "The Financial Accelerator in a Quantitative Business Cycle Framework," in John Taylor and Michael Woodford, eds., Handbook of Macroeconomics, Vol. 1, Amsterdam: North Holland, 1999, chapter 21, pp. 1341-1393.

Bigio, Saki, "Endogenous Liquidity and the Business Cycle," American Economic Review, 2015, 105 (6), 1883-1927.

Bils, Mark and Peter Klenow, "Some Evidence on the Importance of Sticky Prices," Journal of Political Economy, 2004, 112 (5), 947-985.

Calvo, Guillermo, "Staggered Prices in a Utility-Maximizing Framework," Journal of Monetary Economics, 1983, 12 (3), 383-398.

Chen, Han, Vasco Curdia, and Andrea Ferrero, "The Macroeconomic Effects of LargeScale Assets Purchase Programs," Economic Journal, 2012, 122 (564), F289-F315.

Choi, Jaewon and Or Shachar, "Did Liquidity Providers Become Liquidity Seekers?," FRBNY Staff Report No. 650, 2013.

Christiano, Lawrence, Martin Eichenbaum, and Charles Evans, "Nominal Rigidities and the Dynamic Effects of a Shock to Monetary Policy," Journal of Political Economy, 2005, 113 (1), 1-45.

_ , _ , and Sergio Rebelo, "When Is the Government Spending Multiplier Large?," Journal of Political Economy, 2011, 119 (1), 78-121.

_ , Roberto Motto, and Massimo Rostagno, "The Great Depression and the FriedmanSchwartz Hypothesis," Journal of Money, Credit, and Banking, 2003, 35 (6, Part 2), 11191197.

crisis. In such an economy, the government purchase of illiquid private paper with government paper may not be enough to avoid a deep and prolonged recession. 
${ }_{-},{ }_{-}$, and _ , "Financial Factors in Business Cycles," ECB Working Paper Series No. 1192, 2010.

Cordoba, Juan Carlos and Maria Ripoll, "Credit Cycles Redux," International Economic Review, 2004, 45 (5), 1011-1046.

Cui, Wei and Soren Radde, "Search-Based Endogenous Illiquidity and the Macroeconomy," Available at SSRN 2432935, 2014.

Curdia, Vasco and Michael Woodford, "Conventional and Unconventional Monetary Policy," Federal Reserve Bank of St. Louis Review, 2010, 92 (4), 229-264.

_ and _ , "Credit Frictions and Optimal Monetary Policy," NBER Working Paper No. 21820, 2015 .

Doms, Mark and Timothy Dunne, "Capital Adjustment Patterns in Manufacturing Plants," Review of Economic Dynamics, 1998, 1 (2), 409-429.

Eberly, Janice, "International Evidence on Investment and Fundamentals," European Economic Review, 1997, 41 (6), 1055-1078.

Eggertsson, Gauti, "Great Expectations and the End of the Depression," American Economic Review, 2008, 98 (4), 1476-1516.

_ , "What Fiscal Policy Is Effective at Zero Interest Rates?," in Daron Acemoglu and Michael Woodford, eds., NBER Macroeconomics Annual 2010, Vol. 25, University of Chicago Press, 2011, pp. 59-112.

- and Michael Woodford, "The Zero Bound on Interest Rates and Optimal Monetary Policy," Brookings Papers on Economic Activity, 2003, 34 (1), 139-235.

- and Neil Mehrotra, "A Model of Secular Stagnation," NBER Working Paper No. 20574, 2014.

- and Paul Krugman, "Debt, Deleveraging, and the Liquidity Trap: A Fisher-Minsky-Koo Approach," Quarterly Journal of Economics, 2012, 127 (3), 1469-1513.

Erceg, Christopher, Dale Henderson, and Andrew Levin, "Optimal Monetary Policy with Staggered Wage and Price Contracts," Journal of Monetary Economics, 2000, 46 (2), $281-313$.

Fisher, Jonas, "On the Structural Interpretation of the Smets-Wouters Risk Premium Shock," Journal of Money, Credit and Banking, 2015, 47 (2-3), 511-516.

Fleckenstein, Matthias, Francis Longstaff, and Hanno Lustig, "The TIPS-Treasury Bond Puzzle," The Journal of Finance, 2014, 69 (4), 2151-2197.

Fleming, Michael and Nicholas Klagge, "The Federal Reserves Foreign Exchange Swap Lines," Current Issues in Economics and Finance, 2010, 16 (4).

_, Warren Hrung, and Frank Keane, "The Term Securities Lending Facility: Origin, Design, and Effects," Current Issues in Economics and Finance, 2009, 15 (2).

Garleanu, Nicolae and Lasse Heje Pedersen, "Margin-Based Asset Pricing and Deviations from the Law of One Price," Review of Financial Studies, 2011, 24 (6), 1980-2022.

Gertler, Mark and Nobuhiro Kiyotaki, "Financial Intermediation and Credit Policy in Business Cycle Analysis," in Benjamin M. Friedman and Michael Woodford, eds., Handbook of Monetary Economics, Vol. 3, Elsevier, 2010, chapter 11, pp. 547-599. 
- and Peter Karadi, "A Model of Unconventional Monetary Policy," Journal of Monetary Economics, 2011, 58 (1), 17-34.

Goodfriend, Marvin and Bennett McCallum, "Banking and Interest Rates in Monetary Policy Analysis: A Quantitative Exploration," Journal of Monetary Economics, 2007, 54 (5), 1480-1507.

Gorton, Gary and Andrew Metrick, "Haircuts," Federal Reserve Bank of St. Louis Review, 2010, 92 (6), 507-519.

_ and _ , "Securitized Banking and the Run on Repo," Journal of Financial Economics, $2012,104(3), 425451$.

Gourio, Francois and Anil Kashyap, "Investment Spikes: New Facts and a General Equilibrium Exploration," Journal of Monetary Economics, 2007, 54 (Supplement 1), 1-22.

Guerron-Quintana, Pablo and Ryo Jinnai, "Liquidity Shocks and Asset Prices," 2015. Working Paper, Federal Reserve Bank of Philadelphia.

Hall, Robert, "Struggling to Understand the Stock Market," American Economic Review, 2001, 91 (2), 1-11.

Justiniano, Alejandro, Giogrio Primiceri, and Andrea Tambalotti, "Investment Shocks and Business Sycles," Journal of Monetary Economics, 2010, 57 (2), 132-145.

Kara, Engin and Jasmin Sin, "The Fiscal Multiplier in a Credit-Constrained New Keynesian Economy," Scandinavian Journal of Economics, Forthcoming.

Kiyotaki, Nobuhiro and John Moore, "Credit Cycles," Journal of Political Economy, 1997, 105 (2), 211-248.

_ and _., "Liquidity, Business Cycles, and Monetary Policy," NBER Working Paper No. 17934, 2012.

Kocherlakota, Narayana, "Creating Business Cycles Through Credit Constraints," Federal Reserve Bank of Minneapolis Quarterly Review, 2000, 24 (3), 2-10.

Krishnamurthy, Arvind, "The Bond/Old-Bond Spread," Journal of Financial Economics, 2002, 66 (2), 463-506.

- and Annette Vissing-Jorgensen, "The Aggregate Demand for Treasury Debt," Journal of Political Economy, 2012, 120 (2), 233-267.

Kurlat, Pablo, "Lemons Markets and the Transmission of Aggregate Shocks," American Economic Review, 2013, 103 (4), 1463-1489.

Liu, Zheng, Pengfei Wang, and Tao Zha, "Land-Price Dynamics and Macroeconomic Fluc," Econometrica, 2013, 81 (3), 1147-1184.

Longstaff, Francis, "The Flight-to-Liquidity Premium in US Treasury Bond Prices," The Journal of Business, 2004, 77 (3), 511-526.

_ , Sanjay Mithal, and Eric Neis, "Corporate Yield Spreads: Default Risk or Liquidity? New Evidence from the Credit Default Swap Market," Journal of Finance, 2005, 60 (5), $2213-2253$.

Madigan, Brian, "Bagehot's Dictum in Practice: Formulating and Implementing Policies to Combat the Financial Crisis," Federal Reserve Bank of Kansas City's Annual Economic Symposium, Jackson Hole, Wyoming, 2009, pp. 169-189. 
McAndrews, James, Asani Sarkar, and Zhenyu Wang, "The Effect of the Term Auction Facility on the London Inter-Bank Offered Rate," FRBNY Staff Report No. 335, 2008.

Mian, Atif and Amir Sufi, "What Explains the 2007-2009 Drop in Employment?," Econometrica, 2014, 82 (6), 2197-2223.

Moore, Randall, Blue Chip Economic Indicators, Aspen Publishers, 2008.

Nakamura, Emi and Jon Steinsson, "Five Facts About Prices: A Reevaluation of Menu Cost Models," Quarterly Journal of Economics, 2008, 123 (4), 1415-1464.

Nezafat, Pedram and Ctirad Slavik, "Asset Prices and Business Cycles with Financial Shocks," 2010. Working Paper, Goethe University Frankfurt.

Quadrini, Vincenzo, "Entrepreneurship in Macroeconomics," Annals of Finance, 2009, 5 (3), 295-311.

Rotemberg, Julio and Michael Woodford, "An Optimization-Based Econometric Framework for the Evaluation of Monetary Policy," in Ben Bernanke and Julio Rotemberg, eds., NBER Macroeconomics Annual 1997, Vol. 12, MIT Press, 1997, pp. 297-361.

Rudebusch, Glenn D., "The Fed's Monetary Policy Response to the Current Crisis," Federal Reserve Bank of San Francisco Economic Letter, 2009, 17.

Shi, Shouyong, "Liquidity, Assets, and Business Cycles," Journal of Monetary Economics, 2015, 70, 116-132.

Smets, Frank and Rafael Wouters, "Shocks and Frictions in US Business Cycles: A Bayesian DSGE Approach," American Economic Review, 2007, 97 (3), 586-606.

Stock, James $\mathbf{H}$ and Mark W Watson, "Macroeconomic Forecasting using Diffusion Indexes," Journal of Business \& Economic Statistics, 2002, 20 (2), 147-162.

Study Group-Committee on the Global Financial System, "Market-Making and Proprietary Trading: Industry Trends, Drivers and Policy Implications," CGFS Papers 52, BIS 2014.

Taylor, John, "Discretion versus Policy Rules in Practice," Carnegie-Rochester Conference Series on Public Policy, 1993, 39, 195-214.

- and John Williams, "A Black Swan in the Money Market," American Economic Journal: Macroeconomics, 2009, 1 (1), 58-83.

Vayanos, Dimitri and Jean-Luc Vila, "A Preferred-Habitat Model of the Term Structure of Interest Rates," NBER Working Paper No. 15487, 2009.

Wallace, Neil, "A Modigliani-Miller Theorem for Open-Market Operations," American Economic Review, 1981, 71 (3), 267-274.

Woodford, Michael, Interest and Prices: Foundations of a Theory of Monetary Policy, Princeton University Press, 2003. 


\title{
Online Appendix for The Great Escape? A Quantitative Evaluation of the Fed's Liquidity Facilities
}

\author{
Marco Del Negro, Gauti Eggertsson, Andrea Ferrero, Nobuhiro Kiyotaki
}

\section{A Data Appendix}

\section{A.1 Construction of the Liquidity Share}

The liquidity share in the model is defined as $L S_{t}=\frac{B_{t+1}}{B_{t+1}+P_{t} q_{t} K_{t+1}}$ (equation (24)). The two quantities in the definition of the liquidity share are the dollar value of the amount of U.S. government liabilities $B_{t+1}$ (by assumption, the empirical counterpart of the liquid assets in the model) and of net claims on private assets (capital) $P_{t} q_{t} K_{t+1}$, respectively.

Recall that in the model, as in the actual economy, households hold claims on the capital held by other households (the $N_{t+1}^{O}$ and $N_{t+1}^{I}$ terms mentioned in the discussion of the household's balance sheet). The term $P_{t} q_{t} K_{t+1}$, however, measures the net amount of these claims - that is, the value of capital in the economy. We therefore consolidate the balance sheet of households, the non-corporate and the corporate sectors to obtain the market value of aggregate capital. For households, we sum real estate (B.100 line 3), equipment and software of non-profit organizations (B.100 line 6), and consumer durables (B.100 line 7). For the non-corporate sector, we sum real estate (B.103 line 3), equipment and software (B.103 line 6) and inventories (B.103 line 9). For the corporate sector, we obtain the market value of the capital stock by summing the market value of equity (B.102 line 35) and liabilities (B.102 line 21) net of financial assets (B.102 line 6). We then subtract from the market value of capital for the private sector the government credit market instruments (B.106 line 5), TARP (B.106 line 10), and trade receivables (B.106 line 11).

Our measure of liquid assets $B_{t+1}$ consists of all liabilities of the federal government - that is, Treasury securities (L.106 line 17) net of holdings by the monetary authority (L.106 line 12) and the budget agency (L.209 line 20) plus reserves (L.108 line 26), vault cash (L.108 line 27) and currency (L.108 line 28) net of remittances to the federal government (L.108 line 29).

Three qualifications are in order. First, no data are available for the physical capital stock of the financial sector. Second, not all of the assets in the flow of funds are evaluated at 
market value. Specifically, the capital stock of households (consumer durable goods) and noncorporate firms (equipment and software owned by non-profit organizations) are measured at replacement cost. Last, in our calculations we do not net out liquid and illiquid assets held by the rest of the world. Even if we do, however, the numbers are not very different, since the rest of the world, on net, holds both liquid (government liabilities) and illiquid (private sector liabilities) assets in roughly the same proportion. The liquidity share calculated excluding the foreign sector averages $10.56 \%$, as opposed to $12.64 \%$, over the sample period and exhibits very similar dynamics.

\section{A.2 Liquidity Spreads}

We collect daily data on a number of spreads that the literature has identified as having to do mostly with liquidity, broadly defined:

- The Refcorp/Treasury spread for various maturities, which Longstaff (2004) suggests is mostly (if not entirely) due to liquidity as Refcorp bonds are effectively guaranteed by the U.S. government, and are subject to the same taxation. ${ }^{42}$ As in Longstaff (2004), we measure the spread by taking the differences between the constant maturity .50, 1-, 2-, 3-, 4-, 5-, 7-, 10-, and 20-year points on the Bloomberg fair value curves for Refcorp and Treasury zero-coupon bonds. ${ }^{43}$ The Bloomberg mnemonics are 'C091[X]Y Index' and 'C079[X]Y Index', respectively, where $[\mathrm{X}]$ represents the maturity. We collect daily data from $4 / 16 / 1991$ to $9 / 06 / 2014 .^{44}$

- Fleckenstein et al. (2014) provide ample evidence of what they call the "TIPS-Treasury bond puzzle," that is, of differences in prices between Treasury bonds of various maturities and inflation-swapped Treasury Inflation-Protected Securities (TIPS) issues exactly replicating the cash flows of the Treasury bond of the same maturities. Specifically,

\footnotetext{
${ }^{42}$ Refcorp bonds differ from most other agency bonds in that their principal is fully collateralized by Treasury bonds and full payment of coupons is guaranteed by the Treasury under the provisions of the Financial Institutions Reform, Recovery, and Enforcement Act of 1989.

${ }^{43}$ We do not use the yield on the 30-year bond as it has a limited sample, and on the 3-month bill as our model is quarterly.

${ }^{44}$ Specifically, the Bloomberg description states: C091[X]Y Index (BFV USD US REFCO Strips Yield $[\mathrm{X}]$ ). C079[X]Y Index (BFV USD US Treasury Strips). The indices are composite yields derived from BVAL -priced bonds. Quote type: yield /mid. The index ... are the zero coupon yields derived by stripping the par coupon curve. We use the Bloomberg default setting (PX LAST), indicating that the underlying security prices correspond to the mid point between the bid and ask values for the last transaction in each day.
} 
they find that the price of a Treasury bond and an inflation-swapped TIPS issue exactly replicating the cash flows of the Treasury bond can differ by more than $\$ 20$ per $\$ 100$ notional - a difference that, they argue, is orders of magnitude larger than the transaction costs of executing the arbitrage strategy. We therefore collect TIPS-Treasury spreads, which we measure by taking the differences between the constant maturity 5-, 7-, 10-, 20-, and 30-year points on the Bloomberg fair value curves for TIPS and Treasury zerocoupon bonds, and adjusting the former using the inflation swap spreads for the same maturities. The Bloomberg mnemonics are 'H15X[X]YR Index', 'H15T[X]Y Index', and 'USSWIT $[\mathrm{X}]$ Curncy' respectively for TIPS, nominal Treasuries, and inflation swaps, where X represents the maturity. We collect daily data from $7 / 21 / 2004$ to $12 / 31 / 2014{ }^{45}$

- The CDS-Bond basis spread is the difference between the yield on corporate bonds whose credit risk is hedged using a credit default swap (CDS) and a Treasury security of equivalent maturity. Bai and Collin-Dufresne (2013) find that measures of funding liquidity (i.e., the Libor-OIS, and the repo-Tbill spreads; see Garleanu and Pedersen (2011)) are the main drivers of the CDS-Bond basis. Similarly, Longstaff et al. (2005) find that the non-default component of corporate spreads (essentially, the CDS-Bond basis) is strongly related to measures of bond-specific illiquidity as well as to macroeconomic measures of bond market liquidity. We obtain indices of "Par Equivalent" CDS-Bond basis spreads from the JP Morgan database for portfolios of corporate bonds of rating AA, A, and BBB (the mnemonics are 'High Grade AA CDS-Bond Basis', 'High Grade A CDS-Bond Basis', and 'High Grade BBB CDS-Bond Basis'). We do not know the exact maturity of the underlying contracts in each index, however five-year maturity CDS contracts are the most prevalent (Choi and Shachar (2013)). We collect daily data from 9/5/2006 to $9 / 8 / 2014$.

- A commonly used measure of market liquidity is the spread between the most recently

\footnotetext{
${ }^{45}$ Specifically, the Bloomberg description states: H15X[X]YR Index (Federal Reserve US H.15 TII Constant Maturity $[\mathrm{X}]$ ). Yields on Treasury inflation protected securities (TIPS) adjusted to constant maturities. Index ... are the par return on the zero coupon yields. H15T[X]Y Index (US Treasury Yield Curve Rate $\mathrm{T}$ Note Constant Maturity [X]). Yields on actively traded non-inflation -indexed issues adjusted to constant maturities. The index ... are the zero coupon yields derived by stripping the par coupon curve. USSWIT[X] Curncy (USD Infl Zero Coupon [X]) Inflation swap quoted as the zero coupon fixed rate leg necessary to build a par swap against a leg on zero coupon CPI appreciation on CPURNSA Index [CPI-U NSA]. Quoted from various contributors with standard defaults of LAG (3 months) and interpolation. We use the Bloomberg default setting (PX LAST), indicating that the underlying security prices correspond to the mid point between the bid and ask values for the last transaction in each day.
} 
issued and older Treasury bonds of the same maturity, called the on-the-run/off-therun or the bond/old-bond spread. Krishnamurthy (2002) finds that the bond/old-bond spread is highly correlated with the three-month commercial paper (CP) Treasury Bills spread. We use a measure of the 10-year on-the-run/off-the-run spread constructed by the FRBNY Research department for a recent BIS report (Study Group-Committee on the Global Financial System (2014)), which is based on the difference between yields of the 10-year on-the-run Treasury and a synthetic counterpart. The FRBNY data are available from $11 / 4 / 2005$ to $2 / 12 / 2014$.

- Krishnamurthy and Vissing-Jorgensen (2012) argue that the Aaa-Treasury spread is primarily driven by liquidity given the low default rate on Aaa bonds. We collect daily data from FRED, the same sources of Krishnamurthy and Vissing-Jorgensen (2012), from $10 / 01 / 1993$ to $12 / 31 / 2014$ (the mnemonics are 'DAAA' and 'DGS20' for the and the 20-year Treasury, respectively).

Given that our model is quarterly we chose not to include very short term products (3-months) to our cross-section of spreads. In robustness analysis (not shown) we added the 3-month Refcorp spread and the spread between the 3-month safe CP and Treasury-Bill used in Krishnamurthy and Vissing-Jorgensen (2012) and found the time series of $C Y_{t}$ to be virtually the same as that shown in Figure $3 .^{46}$

\footnotetext{
${ }^{46}$ We collect daily data from FRED from 01/02/1997 to 12/31/2014. The mnemonics are 'DCPN3M' and 'DTB3' for the safe Commercial Paper and the 3-month Treasury bill, respectively.
} 


\section{B Additional Model Details and Derivations}

\section{B.1 Final and Intermediate Goods Producers}

Competitive final-goods producers combine intermediate goods $Y_{i t}$, where $i \in[0,1]$ indexes intermediate-goods-producing firms, to sell a homogeneous final good $Y_{t}$ according to the technology

$$
Y_{t}=\left[\int_{0}^{1} Y_{i t}^{\frac{1}{1+\lambda_{p}}} d i\right]^{1+\lambda_{p}},
$$

where $\lambda_{p}>0$. Their demand for the generic $i^{\text {th }}$ intermediate good is

$$
Y_{i t}=\left[\frac{P_{i t}}{P_{t}}\right]^{-\frac{1+\lambda_{p}}{\lambda_{p}}} Y_{t},
$$

where $P_{i t}$ is the nominal price of good $i$. The zero profit condition for competitive final goods producers implies that the aggregate price level is

$$
P_{t}=\left[\int_{0}^{1} P_{i t}^{-\frac{1}{\lambda_{p}}} d i\right]^{-\lambda_{p}}
$$

The intermediate goods firm $i$ uses $K_{i t}$ units of capital and $H_{i t}$ units of composite labor to produce output $Y_{i t}$ according to the production technology

$$
Y_{i t}=A_{t} K_{i t}^{\gamma} H_{i t}^{1-\gamma}-\Gamma
$$

where $\gamma \in(0,1)$ is share of capital, $\Gamma>0$ is fixed cost of production, and $A_{t}$ is an aggregate productivity shock. Intermediate-goods firms operate in monopolistic competition and set prices on a staggered basis (Calvo (1983)) taking the real wage $\frac{W_{t}}{P_{t}}$ and the rental rate of capital $r_{t}^{k}$ as given. With probability $1-\zeta_{p}$, the firm resets its price, while with the complementary probability the price remains fixed. In the event of a price change at time $t$, the firm chooses the price $\tilde{P}_{i t}$ to maximize the present discounted value of profits $\left(D_{i s}=P_{i s} Y_{i s}-w_{s} H_{i s}-r_{s}^{K} K_{i s}-\Gamma\right.$, $s \geq t$ ) conditional on not changing prices in the future subject to the demand for its own good (A-2). We assume that the profit is zero in the deterministic steady state. ${ }^{47}$

\footnotetext{
${ }^{47}$ We choose the fixed cost of production so that the free entry in the long-run leads to a steady state in which exactly a unit mass of intermediate goods producer continues production. In the short-run, there is no entry nor exit so that the profit can be positive or negative.
} 


\section{B.2 Labor Agencies and Wage Setting}

Competitive labor agencies combine $j$-specific labor inputs into a homogeneous composite $H_{t}$ according to

$$
H_{t}=\left[\left(\frac{1}{1-\varkappa}\right)^{\frac{\lambda w}{1+\lambda_{w}}} \int_{\varkappa}^{1} H_{t}(j)^{\frac{1}{1+\lambda_{w}}} d j\right]^{1+\lambda_{w}},
$$

where $\lambda_{w}>0 .{ }^{48}$ Firms hire the labor input from the labor agencies at the wage $W_{t}$, which in turn remunerate the household for the labor actually provided. The zero profit condition for labor agencies implies that

$$
W_{t} H_{t}=\int_{\varkappa}^{1} W_{t}(j) H_{t}(j) d j
$$

The demand for the $j^{\text {th }}$ labor input is

$$
H_{t}(j)=\frac{1}{1-\varkappa}\left[\frac{W_{t}(j)}{W_{t}}\right]^{-\frac{1+\lambda_{w}}{\lambda_{w}}} H_{t},
$$

where $W_{t}(j)$ is the wage specific to type $j$ and $W_{t}$ is the aggregate wage index that comes out of the zero profit condition for labor agencies

$$
W_{t}=\left[\frac{1}{1-\varkappa} \int_{\varkappa}^{1} W_{t}(j)^{-\frac{1}{\lambda_{w}}} d j\right]^{-\lambda_{w}} .
$$

Labor unions representing workers of type $j$ set wages on a staggered basis, taking as given the demand for their specific labor input (Erceg et al. (2000)). In each period, with probability $1-\zeta_{w}$, a union is able to reset the wage $W_{t}(j)$, while with the complementary probability the wage remains fixed. Workers are committed to supply whatever amount of labor is demanded at that wage. In the event of a wage change at time $t$, unions choose the wage $\tilde{W}_{t}(j)$ to minimize the present discounted value of the disutility from work conditional on not changing the wage in the future subject to $(\mathrm{A}-7) .{ }^{49}$

\section{B.3 Capital-Goods Producers}

Capital-goods producers are perfectly competitive. These firms transform consumption goods into investment goods. Their problem consists of choosing the amount of investment goods

\footnotetext{
${ }^{48}$ We add constant $(1-\varkappa)^{-1}$ to the labor composite $(A-5)$ so that it is equal to the average labor used under symmetry. Because there is no entry of new types of labor, it only simplifies the notation without changing the substance.

${ }^{49}$ Although each household supplies many types of labor, it is difficult for unions (which represent many households) to cooperate. Thus, each union is monopolistically competitive, taking the wages of the other unions as given.
} 
produced $I_{t}$ to maximize the profits

$$
D_{t}^{I}=\left\{p_{t}^{I}-\left[1+S\left(\frac{I_{t}}{I}\right)\right]\right\} I_{t}
$$

taking the price of investment goods $p_{t}^{I}$ as given. The price of investment goods differs from the price of consumption goods because of the adjustment cost function, which depends on the deviations of actual investment from its steady-state value $I$. We assume that, when evaluated in steady state, the adjustment cost function and its first derivative are zero $\left(S(1)=S^{\prime}(1)=0\right)$, while its second derivative is positive $\left(S^{\prime \prime}\left(I_{t} / I\right)>0\right)$ globally.

\section{B.4 Derivation of Liquidity Constraint}

The household's balance sheet (excluding human capital) is given in Table in Section 2.1 in the text. The existence of two financial frictions constrains the evolution of both equity issued and others' equity. The entrepreneur cannot issue new equity more than a fraction $\theta$ of the investment undertaken in the current period plus a fraction $\phi_{t}^{I} \in(0,1)$ of the undepreciated capital stock previously not mortgaged $\left(K_{t}-N_{t}^{I}\right)$. Therefore, equity issued evolves according to

$$
N_{t+1}^{I}(j) \leq(1-\delta) N_{t}^{I}+\theta I_{t}(j)+(1-\delta) \phi_{t}^{I}\left(K_{t}-N_{t}^{I}\right)
$$

Similarly, the entrepreneur cannot sell more than a fraction $\phi_{t}^{O}$ of holdings of the others' equity remained. Therefore, others' equity evolves according to

$$
N_{t+1}^{O}(j) \geq(1-\delta) N_{t}^{O}-(1-\delta) \phi_{t}^{O} N_{t}^{O}
$$

The key assumption that allows us to derive a single constraint on the evolution of net equity $\left(N_{t} \equiv N_{t}^{O}+K_{t}-N_{t}^{I}\right)$ is that the "resaleability" parameters are the same, that is $\phi_{t}^{I}=\phi_{t}^{O}=\phi_{t}$. Then two constraints ( A-10) and (A-11) yield (5) in the text.

\section{B.5 Optimality conditions}

\section{B.5.1 Household's Optimality Conditions}

Because each entrepreneur must satisfy the financing constraints on equity holdings (5), bond holdings (6) and non-negativity constraint of consumption, the aggregate investment of the representative household must satisfy:

$$
I_{t} \equiv \int_{0}^{\chi} I_{t}(j) d j \leq \varkappa \frac{\left[R_{t}^{k}+(1-\delta) q_{t} \phi_{t}\right] N_{t}+\frac{R_{t-1} B_{t}}{P_{t}}-\tau_{t}}{p_{t}^{I}-\theta q_{t}} .
$$


As explained in the text, we separate the wage setting from the consumption, investment and portfolio decision. The household chooses $C_{t}, I_{t}, N_{t+1}$ and $B_{t+1}$ to maximize the utility (2) subject to the budget constraint (15) and the financing constraint of investment (A-12). Let $\xi_{t}$ and $\eta_{t}$ be the Lagrange multipliers attached to (15) and (A-12). The first order conditions for consumption, investment, equity and government bond are respectively

$$
\begin{aligned}
C_{t}^{-\sigma} & =\xi_{t} \\
\xi_{t}\left(q_{t}-p_{t}^{I}\right) & =\eta_{t} \\
q_{t} \xi_{t} & =\beta \mathbb{E}_{t}\left\{\xi_{t+1}\left[R_{t+1}^{k}+(1-\delta) q_{t+1}\right]+\eta_{t+1} \frac{\varkappa\left[R_{t+1}^{k}+(1-\delta) \phi_{t+1} q_{t+1}\right]}{p_{t+1}^{I}-\theta q_{t+1}}\right\} \\
\xi_{t} & =\beta \mathbb{E}_{t}\left[\frac{R_{t}}{\pi_{t+1}}\left(\xi_{t+1}+\eta_{t+1} \frac{\varkappa}{p_{t+1}^{I}-\theta_{t+1} q_{t+1}}\right)\right]
\end{aligned}
$$

We focus on equilibria in which financing constraint on investment is sufficiently tight so that the equity price is bigger than its installation cost, i.e. $q_{t}>p_{t}^{I}$ in the neighborhood of the steady state equilibrium. This condition is also always satisfied in our simulations outside the steady state. Therefore, the Lagrange multiplier $\eta_{t}$ on the financing constraint on investment equation (A-12) is always positive. This implies that each entrepreneur satisfy the financing constraints on equity holdings (5) bond holdings (6) with equality and his/her consumption is zero $C_{t}(j)=0$ for $j \in[0, \chi)$. Also (A-12) holds with equality, or we have (14) in the text. Substituting the Lagrange multipliers from (A-13) and (A-14) into (A-15) and (A-16) gives the Euler equations for bond and equity that characterize the household portfolio decisions (16) and (17). We first define the premium of liquidity from relaxing the investment constraint as

$$
\Lambda_{t}=\varkappa \frac{q_{t}-p_{t}^{I}}{p_{t}^{I}-\theta q_{t}}
$$

The convenience yield in our model is defined as the expected value of the premium of liquidity of the next period as

$$
C Y_{t}=\mathbb{E}_{t}\left(\Lambda_{t+1}\right)
$$

The Euler equations $(16,17)$ become

$$
\begin{gathered}
C_{t}^{-\sigma}=\beta \mathbb{E}_{t}\left[C_{t+1}-\sigma \frac{R_{t}}{\pi_{t+1}}\left(1+\Lambda_{t+1}\right)\right] \\
C_{t}^{-\sigma}=\beta \mathbb{E}_{t}\left\{C_{t+1}-\sigma \frac{R_{t+1}^{k}+(1-\delta) q_{t+1}}{q_{t}}\left[1+\Lambda_{t+1} \frac{R_{t+1}^{k}+\phi_{t+1}(1-\delta) q_{t+1}}{R_{t+1}^{k}+(1-\delta) q_{t+1}}\right]\right\} .
\end{gathered}
$$

Let us $L_{t+1}$ be the real value of liquid assets at the end of period

$$
L_{t+1} \equiv \frac{B_{t+1}}{P_{t}} .
$$


Together with the expression for dividends, aggregate investment (14) can be rewritten as

$$
I_{t}=\varkappa \frac{\left[R_{t}^{k}+(1-\delta) q_{t} \phi_{t}\right] N_{t}+\frac{R_{t-1} L_{t}}{\pi_{t}}-\tau_{t}}{p_{t}^{I}-\theta q_{t}}
$$

\section{B.5.2 Wage Setting Decision}

Competitive labor agencies chooses $H_{t}(j)$ to maximize their profits

$$
W_{t} H_{t}-\int_{\chi}^{1} W_{t}(j) H_{t}(j) d j
$$

subject to (A-5), taking wages $W_{t}(j)$ as given. The first order condition determines the demand for the $j^{\text {th }}$ labor input (A-7), where $W_{t}(j)$ is the wage specific to type $j$ and $W_{t}$ is the aggregate wage index that comes out of the zero profit condition for labor agencies (A-8).

Labor unions representing suppliers of type- $j$ labor set wages on a staggered basis, taking as given the demand for their specific labor input. In each period, with probability $1-\zeta_{w}$, a union is able to reset the wage $W_{t}(j)$, while with the complementary probability the wage remains fixed. Household are committed to supply whatever labor is demanded at that wage. In the event of a wage change at time $t$, unions choose the wage $\tilde{W}_{t}(j)$ to maximize

$$
\mathbb{E}_{t} \sum_{s=t}^{\infty}\left(\beta \zeta_{w}\right)^{s-t}\left[\frac{C_{s}^{1-\sigma}}{1-\sigma}-\frac{\omega}{1+\nu} \int_{\chi}^{1} H_{s}(j)^{1+\nu} d j\right]
$$

subject to (15) and (A-7) with $W_{t+s}(j)=\tilde{W}_{t}(j), \forall s \geq 0$.

The first order condition for this problem is

$$
\mathbb{E}_{t} \sum_{s=t}^{\infty}\left(\beta \zeta_{w}\right)^{s-t} C_{s}^{-\sigma}\left[\frac{\tilde{W}_{t}(j)}{P_{s}}-\left(1+\lambda_{w}\right) \frac{\omega H_{s}(j)^{\nu}}{C_{s}^{-\sigma}}\right] H_{s}(j)=0 .
$$

All unions face an identical problem. We focus on a symmetric equilibrium in which all unions choose the same wage $\tilde{W}_{t}(j)=\tilde{W}_{t}$. Let $w_{t} \equiv W_{t} / P_{t}$ denote the real wage. The first order condition for optimal wage setting becomes

$$
\mathbb{E}_{t} \sum_{s=t}^{\infty}\left(\beta \zeta_{w}\right)^{s-t} C_{s}^{-\sigma}\left\{\frac{\tilde{w}_{t}}{\pi_{t, s}}-\left(1+\lambda_{w}\right) \frac{\omega\left[\left(\frac{\tilde{w}_{t}}{\pi_{t, s} w_{s}}\right)^{-\frac{1+\lambda w}{\lambda_{w}}} H_{s}\right]^{\nu}}{C_{s}^{-\sigma}}\right\}\left(\frac{\tilde{w}_{t}}{\pi_{t, s} w_{s}}\right)^{-\frac{1+\lambda_{w}}{\lambda_{w}}} H_{s}=0
$$

where $\pi_{t, s}=P_{s} / P_{t}$. 
By the law of large numbers, the probability of changing the wage corresponds to the fraction of types who actually do change their wage. Consequently, from expression (A-8), the real wage evolves according to

$$
w_{t}^{-\frac{1}{\lambda_{w}}}=\left(1-\zeta_{w}\right) \tilde{w}_{t}^{-\frac{1}{\lambda_{w}}}+\zeta_{w}\left(\frac{w_{t-1}}{\pi_{t}}\right)^{-\frac{1}{\lambda_{w}}} .
$$

Defining the wage inflation as $\pi_{t}^{w}=W_{t} / W_{t-1}$ and using (A-24), (A-23) becomes

$$
\left(\frac{1-\zeta_{w} \pi_{t}^{w \frac{1}{\lambda_{f}}}}{1-\zeta_{w}}\right)^{-\lambda_{w}+\left(1+\lambda_{w}\right) \nu}=\frac{X_{1 t}^{w}}{X_{2 t}^{w}}
$$

where $X_{1 t}^{w}$ and $X_{2 t}^{w}$ are the expected present value of marginal disutility of work and real marginal wage revenue as

$$
\begin{aligned}
X_{1 t}^{w} & =\frac{\omega}{(1-\varkappa)^{\nu}} H_{t}^{1+\nu}+\beta \zeta_{w} \mathbb{E}_{t}\left(\pi_{t+1}^{w} \frac{(1+\lambda w)(1+\nu)}{\lambda w} X_{1 t+1}^{w}\right) \\
X_{2 t}^{w} & =\frac{1}{1+\lambda_{w}} C_{t}^{-\sigma} w_{t} H_{t}+\beta \zeta_{w} \mathbb{E}_{t}\left(\pi_{t+1}^{w} \frac{1}{\lambda w} X_{2 t+1}^{w}\right)
\end{aligned}
$$

\section{B.5.3 Final and Intermediate Goods Producers}

Competitive final goods producers choose $Y_{t}(i)$ to maximize profits

$$
P_{t} Y_{t}-\int_{0}^{1} P_{t}(i) Y_{t}(i) d i
$$

where $P_{t}(i)$ is the price of the $i^{t h}$ variety, subject to (A-1). The solution to the profit maximization problem yields the demand for the generic $i^{\text {th }}$ intermediate good (A-2). The zero profit condition for competitive final goods producers implies that the aggregate price level is $(\mathrm{A}-3)$.

Monopolistically competitive intermediate goods producers hire labor from households and rent capital from entrepreneurs to produce intermediate goods according to the production technology (A-4) and subject to the demand condition (A-2). We solve the problem for intermediate goods producers in two steps. First, we solve for the optimal amount of inputs (capital and labor) demanded. For this purpose, intermediate goods producers minimize costs

$$
r_{t}^{k} K_{i t}+w_{t} H_{i t}
$$

subject to (A-4). Let $m c_{i t}$ be the Lagrange multiplier on the constraint, the real marginal cost. The first order condition implies that the capital-labor ratio at the firm level is independent of firm-specific variables as

$$
\frac{K_{i t}}{H_{i t}}=\frac{K_{t}}{H_{t}}=\frac{\gamma}{1-\gamma} \frac{w_{t}}{r_{t}^{k}}
$$


Then the marginal cost is independent of firm-specific variables as

$$
m c_{i t}=m c_{t}=\frac{1}{A_{t}}\left(\frac{r_{t}^{k}}{\gamma}\right)^{\gamma}\left(\frac{w_{t}}{1-\gamma}\right)^{1-\gamma} .
$$

The second step consists of characterizing the optimal price setting decision in the event that firm $i$ can adjust its price. Recall that this adjustment occurs in each period with probability $1-\zeta_{p}$, independent of previous history. If a firm can reset its price, it chooses $\tilde{P}_{t}(i)$ to maximize

$$
\mathbb{E}_{t} \sum_{s=t}^{\infty}\left(\beta \zeta_{p}\right)^{s-t} C_{s}^{-\sigma}\left[\frac{\tilde{P}_{t}(i)}{P_{s}}-m c_{s}\right] Y_{s}(i)
$$

subject to (A-2). The first order condition for this problem is

$$
\mathbb{E}_{t} \sum_{s=t}^{\infty}\left(\beta \zeta_{p}\right)^{s-t} C_{s}^{-\sigma}\left[\frac{\tilde{P}_{t}(i)}{P_{s}}-\left(1+\lambda_{f}\right) m c_{s}\right] Y_{s}(i)=0 .
$$

All intermediate goods producers face an identical problems. As for the wage setting decision, we focus on a symmetric equilibrium in which all firms choose the same price $\tilde{P}_{t}(i)=\tilde{P}_{t}$. Let $\tilde{p}_{t} \equiv \tilde{P}_{t} / P_{t}$ denote the optimal relative price. The first order condition for optimal price setting becomes

$$
\mathbb{E}_{t} \sum_{s=t}^{\infty}\left(\beta \zeta_{p}\right)^{s-t} C_{s}^{-\sigma}\left[\frac{\tilde{p}_{t}}{\pi_{t, s}}-\left(1+\lambda_{f}\right) m c_{s}\right]\left(\frac{\tilde{p}_{t}}{\pi_{t, s}}\right)^{-\frac{1+\lambda_{f}}{\lambda_{f}}} Y_{s}=0 .
$$

By the law of large numbers, the probability of changing the price coincides with the fraction of firms who actually do change the price in equilibrium. Therefore, from expression (A-3), inflation depends on the optimal reset price according to

$$
1=\left(1-\zeta_{p}\right) \tilde{p}_{t}^{-\frac{1}{\lambda_{f}}}+\zeta_{p}\left(\frac{1}{\pi_{t}}\right)^{-\frac{1}{\lambda_{f}}}
$$

Using (A-31), the price setting rule (A-30) becomes

$$
\left(\frac{1-\zeta_{p} \pi_{t}^{\frac{1}{\lambda_{f}}}}{1-\zeta_{p}}\right)^{-\lambda_{f}}=\frac{X_{1 t}^{p}}{X_{2 t}^{p}}
$$

where $X_{1 t}^{p}$ and $X_{2 t}^{p}$ are expected present value of real marginal cost and real marginal revenue as

$$
\begin{aligned}
& X_{1 t}^{p}=C_{t}^{-\sigma} Y_{t} m c_{t}+\beta \zeta_{p} \mathbb{E}_{t}\left(\pi_{t+1}{ }^{\frac{1+\lambda_{f}}{\lambda_{f}}} X_{1 t+1}^{p}\right) \\
& X_{2 t}^{p}=\frac{1}{1+\lambda_{f}} C_{t}^{-\sigma} Y_{t}+\beta \zeta_{p} \mathbb{E}_{t}\left(\pi_{t+1}^{\frac{1}{\lambda_{f}}} X_{2 t+1}^{p}\right)
\end{aligned}
$$


The evolution of real wage is given by

$$
\frac{w_{t}}{w_{t-1}}=\frac{\pi_{t}^{w}}{\pi_{t}}
$$

The fact that the capital-output ratio is independent of firm-specific factors implies that we can obtain an aggregate production function

$$
A_{t} K_{t}^{\gamma} H_{t}^{1-\gamma}-\Gamma=\int_{0}^{1} Y_{t}(i) d i=\sum_{s=0}^{\infty} \zeta_{p}\left(1-\zeta_{p}\right)^{t-s}\left(\frac{\tilde{p}_{t-s}}{\pi_{t-s, t}}\right)^{-\frac{1+\lambda_{f}}{\lambda_{f}}} Y_{t}
$$

where $K_{t} \equiv \int_{0}^{1} K_{i t} d i$ and $H_{t} \equiv \int_{0}^{1} H_{i t} d i$. Defining the effect of price dispersion as

$$
\Delta_{t}=\sum_{s=0}^{\infty} \zeta_{p}\left(1-\zeta_{p}\right)^{t-s}\left(\frac{\widetilde{p}_{t-s}}{\pi_{t-s, t}}\right)^{-\frac{1+\lambda_{f}}{\lambda_{f}}}
$$

the aggregate production function becomes

$$
A_{t} K_{t}^{\gamma} H_{t}^{1-\gamma}-\Gamma=\Delta_{t} Y_{t}
$$

Using (A-31), we can define $\Delta_{t}$ recursively as

$$
\Delta_{t}=\zeta_{p} \Delta_{t-1} \pi_{t}^{\frac{1+\lambda_{f}}{\lambda_{f}}}+\left(1-\zeta_{p}\right)\left(\frac{1-\zeta_{p} \pi_{t}^{\frac{1}{\lambda_{f}}}}{1-\zeta_{p}}\right)^{1+\lambda_{f}}
$$

\section{B.5.4 Capital Producers}

Capital producers transform consumption into investment goods and operate in a competitive national market. Their problem consists of choosing the amount of investment goods produced $I_{t}$ to maximize (A-9) taking the price of investment goods $p_{t}^{I}$ as given. The first order condition for this problem is

$$
p_{t}^{I}=1+S\left(\frac{I_{t}}{I}\right)+S^{\prime}\left(\frac{I_{t}}{I}\right) \frac{I_{t}}{I}
$$

\section{B.5.5 Dividend of Equity}

The dividend per unit of equity is the sum of rental rate of capital and the profits of intermediate goods producers and capital goods producers per unit of capital as

$$
R_{t}^{k}=r_{t}^{k}+\frac{Y_{t}-w_{t} H_{t}-r_{t}^{k} K_{t}+p_{t}^{I} I_{t}-I_{t}\left[1+S\left(\frac{I_{t}}{I}\right)\right]}{K_{t}}
$$




\section{B.5.6 Government budget}

Using the expression of real value of liquidity, government budget constraint and tax rule $(22,23)$ can be written as

$$
\begin{gathered}
q_{t} N_{t+1}^{g}+\frac{R_{t-1} L_{t}}{\pi_{t}}=\tau_{t}+\left[R_{t}^{k}+(1-\delta) q_{t}\right] N_{t}^{g}+L_{t+1} . \\
\tau_{t}-\tau=\psi_{\tau}\left(\frac{R_{t-1} L_{t}}{\pi_{t}}-\frac{R L}{\pi}-q_{t} N_{t}^{g}\right)
\end{gathered}
$$

\section{B.6 Market-Clearing and Equilibrium}

The market-clearing conditions for composite labor and capital use are

$$
H_{t}=\int_{0}^{1} H_{i t} d i
$$

and

$$
K_{t}=\int_{0}^{1} K_{i t} d i .
$$

The aggregate capital stock evolves according to

$$
K_{t+1}=(1-\delta) K_{t}+I_{t}
$$

and capital stock is owned by either households or government as

$$
K_{t+1}=N_{t+1}+N_{t+1}^{g}
$$

Finally, the aggregate resource constraint requires that

$$
Y_{t}=C_{t}+\left[1+S\left(\frac{I_{t}}{I}\right)\right] I_{t}
$$

The total factor productivity and resaleability $\left(A_{t}, \phi_{t}\right)$ follow an exogenous Markov process. In addition to these, we have five endogenous state variables of $\left(K_{t}, N_{t}^{g}, R_{t-1} L_{t}, w_{t-1}, \Delta_{t-1}\right)$ - aggregate capital stock, government ownership of capital, a real liquidity measure, the real wage rate and the effect of price dispersion from the previous period. The recursive competitive equilibrium is given by nine quantities $\left(C_{t}, I_{t}, H_{t}, Y_{t}, \tau_{t}, K_{t+1}, N_{t+1}, N_{t+1}^{g}, L_{t+1}\right)$, and fifteen prices $\left(R_{t}, q_{t}, p_{t}^{I}, w_{t}, r_{t}^{k}, R_{t}^{k}, m c_{t}, \Lambda_{t}, \pi_{t}, \pi_{t}^{w}, X_{1 t}^{p}, X_{2 t}^{p}, X_{1 t}^{w}, X_{2 t}^{w}, \Delta_{t}\right)$ as a function of the state variables $\left(K_{t}, N_{t}^{g}, R_{t-1} L_{t}, w_{t-1}, \Delta_{t-1}, A_{t}, \phi_{t}\right)$ which satisfies the twenty four equilibrium conditions (20, 21, A-42, A-43, A-44, A-17, A-19, A-20, A-22) (A-25 - A-29), (A-32 - A-41). Once all the market clearing condition and the government budget constraints are satisfied, the household budget constraint (15) is satisfied by Walras' Law. 
Additionally, we define:

$$
R_{t}^{q}=\mathbb{E}_{t}\left[\frac{R_{t+1}^{k}+(1-\delta) q_{t+1}}{q_{t}}\right]: \text { Expected rete of return on equity. }
$$

\section{B.6.1 Steady state}

We consider a steady state economy in which there is no change in the total factor productivity, resaleability, the nominal price level, and the endogenous quantities and prices. Condition (A28) at steady state implies

$$
\frac{K}{H}=\frac{\gamma}{1-\gamma} \frac{w}{r^{k}}
$$

In steady state all firms charge the same price, hence $\tilde{p}=1$ and the real marginal cost is equal to the inverse of the markup

$$
m c=\frac{1}{A}\left(\frac{r^{k}}{\gamma}\right)^{\gamma}\left(\frac{w}{1-\gamma}\right)^{1-\gamma}=\frac{1}{1+\lambda_{p}}
$$

We also choose the fixed cost of production so that the profit equals zero in the steady state as

$$
Y=m c \cdot(Y+\Gamma)
$$

Incorporating these three equations into the steady state version of the production function (A-36) yields a relation between the capital-output ratio and the rental rate of capital

$$
\frac{Y}{K}=\frac{r^{k}}{\gamma}
$$

Because the ratio between capital and hours is a function of the capital-output ratio (from the production function), equation (A-47) also yields an expression for the real wage as a function of the rental rate

$$
w=(1-\gamma)\left(\frac{A}{1+\lambda_{f}}\right)^{\frac{1}{1-\gamma}}\left(\frac{\gamma}{r^{k}}\right)^{\frac{\gamma}{1-\gamma}}
$$

In steady state, the real wage is equal to a markup over the marginal rate of substitution between labor and consumption

$$
w=\left(1+\lambda_{w}\right) \frac{\omega H^{\nu}}{C^{-\sigma}} .
$$

From the steady state version of (16), we can solve for the steady state real interest rate $(r \equiv R / \pi=R)$ as a function of $q$

$$
\beta^{-1}=r\left(1+\varkappa \frac{q-1}{1-\theta q}\right)
$$


where we used the fact that in steady state $p^{I}=1$ because $\left(S(1)=S^{\prime}(1)=0\right.$ (from A-38). This condition implies that the liquid asset has a return that is less that $\beta^{-1}$ as long as $1<q<1 / \theta$.

Steady state tax obtain from (A-40)

$$
\tau=(r-1) L
$$

In steady state, zero profit condition implies

$$
R^{k}=r^{k}
$$

Then condition (A-22) implies

$$
I=\varkappa \frac{\left[R^{k}+(1-\delta) \phi q\right] K+r L-\tau}{1-\theta q}=\varkappa \frac{\left[r^{k}+(1-\delta) \phi q\right] K+L}{1-\theta q},
$$

where we used (A-53) to eliminate transfers and the fact that in steady state $K=N$ since by assumption $N^{g}=0$. Steady state investment is simply equal to depreciated steady state capital

$$
\frac{I}{K}=\delta
$$

Combining (A-54) with (A-55), we obtain

$$
\delta(1-\theta q)=\varkappa\left[r^{k}+(1-\delta) \phi q+\frac{L}{K}\right] .
$$

Using the steady state capital output ratio (A-49), we obtain a relationship between $r^{k}$ and $q$

$$
\delta-[\delta \theta+\varkappa(1-\delta) \phi] q=\varkappa\left(1+\frac{1}{\gamma} \frac{L}{Y}\right) r^{k},
$$

where $L / Y$ is ratio of liquid assets to GDP that we take as exogenous in our calibration.

Another relationship between $r^{k}$ and $q$ obtains from the steady state version of (17)

$$
\beta^{-1}=\frac{r^{k}+(1-\delta) q}{q}\left(1+\varkappa \frac{q-1}{1-\theta q}\right)-\frac{\varkappa(1-\delta)(1-\phi)(q-1)}{1-\theta q}
$$

where $\left(r^{k}+\lambda q\right) / q$ is the steady state return on equity. As long as $\phi<1$, the return on equity is larger than the steady state return on the liquid assets by

$$
\frac{\varkappa(1-\delta)(1-\phi)(q-1)}{(1-\theta q)\left(1+\varkappa \frac{q-1}{1-\theta q}\right)}
$$

We can insert the solution for $r^{k}$ from (A-57) into (A-58) and solve for $q$. Once we have $q$ and $r^{k}, r$ can be obtained from (A-52), $w$ from (A-50), $K / Y$ from (A-49), $K / H$ from (A-46), $I / K$ from (A-55) and $C / Y$ from the resource constraint. Finally economy size $Y$ is determined to satisfy (A-51). The size of fixed cost $\Gamma$ is chosen so that zero profit condition is satisfied with exactly the unit mass of intermediate goods producers in (A-48). 


\section{B.7 Zero-Coupon Bonds Returns}

While the paper only considers one-period perfectly liquid securities and illiquid stocks, our empirical analysis in Section 3.2 describing the calibration of the liquidity shock considers the spread between illiquid and liquid long term securities, most of which are zero-coupon bonds. Therefore in this section we derive the spreads for zero-coupon bonds with varying degree of liquidity $\phi^{j}$. As mentioned in the paper, we assume that the net supply of these bonds is zero so that the equilibrium condition does not change from our model.

We will show that, for short term bonds the convenience yield in our model $C Y_{t}$ approximately equals the spread between perfectly illiquid and perfectly liquid assets $\overline{C Y}_{t}$. For long term bonds this is not the case: intuitively, the spread in this case is proportional to the average of expected future convenience yields, as shown in expression (A-70) below. The last part of the section also shows that under the assumption that the $\phi_{t}^{j}$ have a common and an idiosyncratic component, the yield spreads have a factor structure where the common factor is proportional to the convenience yield.

Let $P_{t}^{(T, j)}$ be the price of a long-term zero coupon bond $j$ with maturity $T$ which pays $\$ 1$ at date $\mathrm{t}+\mathrm{T}$ for sure. Euler equation is given by

$$
P_{t}^{(T, j)}=\mathbb{E}_{t}\left[\frac{m_{t+1}}{\pi_{t+1}}\left(1+\phi_{t+1}^{j} \Lambda_{t+1}\right) P_{t+1}^{(T-1, j)}\right],
$$

where $P_{t+1}^{(T-1, j)}$ is the price of this bond at $\mathrm{t}+1$ (as it becomes bond with maturity $\mathrm{T}-1$ ), and $m_{t+1}=\beta\left(c_{t+1} / c_{t}\right)^{-\sigma}$ is marginal rate of substitution.

Iterating this equation forward we obtain:

$$
P_{t}^{(T, j)}=\mathbb{E}_{t}\left[\prod_{s=1}^{T} \frac{m_{t+s}}{\pi_{t+s}}\left(1+\phi_{t+s}^{j} \Lambda_{t+s}\right)\right] .
$$

The nominal gross yield to maturity $\operatorname{nytm}_{t}^{(T, j)}$ and the price are related as $\left(\operatorname{nytm}_{t}^{(T, j)}\right)^{T}=$ $1 / P_{t}^{(T, j)}$. We can then rewrite the Euler condition for the long term bonds as

$$
1=\operatorname{nytm}_{t}^{(T, j)}\left(\mathbb{E}_{t}\left[\prod_{s=1}^{T} \frac{m_{t+s}}{\pi_{t+s}}\left(1+\phi_{t+s}^{j} \Lambda_{t+s}\right)\right]\right)^{1 / T}
$$

Let $j=l$ denote the bond that is always perfectly liquid, i.e., $\phi_{t}^{l}=1$ for all $\mathrm{t}$, and let $j=0$ denote the bond that is always totally illiquid, i.e., $\phi_{t}^{0}=0$ for all $t$. Then we have

$$
1=\operatorname{nytm}_{t}^{(T, l)}\left(\mathbb{E}_{t}\left[\prod_{s=1}^{T} \frac{m_{t+s}}{\pi_{t+s}}\left(1+\Lambda_{t+s}\right)\right]\right)^{1 / T} \text { and }
$$




$$
1=\operatorname{nytm}_{t}^{(T, 0)}\left(\mathbb{E}_{t}\left[\prod_{s=1}^{T} \frac{m_{t+s}}{\pi_{t+s}}\right]\right)^{1 / T} .
$$

Here we assume entrepreneurs cannot use the return on the totally illiquid bond for funding investment even at the maturity date.

At steady state these conditions imply:

$$
1=\operatorname{nytm}^{(T, j)} \frac{\beta}{\pi}\left(1+\phi^{j} C Y\right)=\operatorname{nytm}^{(T, l)} \frac{\beta}{\pi}(1+C Y)
$$

or

$$
\mathrm{ytm}^{(T, j)}-\mathrm{ytm}^{(T, l)}=\frac{\operatorname{nytm}^{(T, j)}}{\pi}-\frac{\operatorname{nytm}^{(T, j)}}{\pi}=\beta^{-1} \frac{C Y}{1+C Y} \frac{1-\phi^{j}}{1+\phi^{j} C Y},
$$

where $\phi^{j}$ is liquidity of the private bonds in the steady state. From the spread before the crisis (which we consider the deterministic steady state), we can estimate $\phi^{j}$ as

$$
1-\phi^{j}=\frac{1+C Y}{C Y} \frac{\beta\left(\mathrm{ytm}^{(T, j)}-\mathrm{ytm}^{(T, l)}\right)(1+C Y)}{1+\beta\left(\mathrm{ytm}^{(T, j)}-\mathrm{ytm}^{(T, l)}\right)(1+C Y)} .
$$

This is the equation (25) in the text. We also use (A-62, A-63) to get

$$
\overline{C Y} \equiv \operatorname{ytm}^{(T, 0)}-\mathrm{ytm}^{(T, l)}=\beta^{-1} \frac{C Y}{1+C Y} \simeq C Y .
$$

In the steady state, the convenience yield approximately equals the yield spread between totally illiquid and perfectly liquid bonds.

In practice our data on yields are percent annualized net nominal returns $Y T M^{(T, j)}$ and $Y T M^{(T, l)}$. We compute the spread in real terms $\left(y t m^{(T, j)}-y t m^{(T, l)}\right)$ as $\exp \left\{\left(Y T M^{(T, j)}-\right.\right.$ $\bar{\pi}) / 400\}-\exp \left\{\left(Y T M^{(T, l)}-\bar{\pi}\right) / 400\right\}$ where $\bar{\pi}$ is net inflation, percent annualized. We compute the steady state convenience yield as the difference between annualized gross returns of perfectly illiquid and perfectly liquid bonds, in percent. Of course $C Y$ and $\overline{C Y}$ are not the same, but in practice they are very close. When computing $\phi^{j}$ in Table A-2 we use expression (A-65).

Outside the steady state, for discount bond of one-period maturity, we can use (A-62, A-63) to obtain by ignoring the covariance terms as

$$
\begin{gathered}
1=\operatorname{nytm}_{t}^{(1,0)} \mathbb{E}_{t}\left(\frac{m_{t+1}}{\pi_{t+1}}\right) \\
\simeq \operatorname{nytm}_{t}^{(1,0)} \mathbb{E}_{t}\left(m_{t+1}\right) \mathbb{E}_{t}\left(\frac{1}{\pi_{t+1}}\right) \\
1=\operatorname{nytm}_{t}^{(1, l)} \mathbb{E}_{t}\left[\frac{m_{t+1}}{\pi_{t+1}}\left(1+\Lambda_{t+1}\right)\right] \\
\simeq \operatorname{nytm}_{t}^{(1, l)} \mathbb{E}_{t}\left(m_{t+1}\right) \mathbb{E}_{t}\left(\frac{1}{\pi_{t+1}}\right)\left(1+C Y_{t}\right)
\end{gathered}
$$


Thus we learn

$$
\overline{C Y}_{t}=\left[\operatorname{nytm}_{t}^{(1,0)}-\operatorname{nytm}^{(1, l)}\right] \mathbb{E}_{t}\left(\frac{1}{\pi_{t+1}}\right) \simeq \frac{1}{\mathbb{E}_{t}\left(m_{t+1}\right)} \frac{C Y_{t}}{1+C Y_{t}} \simeq C Y_{t}
$$

Thus, even outside the steady state, the convenience yield of our model $C Y_{t}$ defined in (A-18) approximately equals the yield spread between perfectly illiquid and perfectly liquid one-period bonds, both of which do not have default risk.

When we use the zero coupon bond with longer maturity, such simple relationship no longer holds. Applying the log-linearization of approximation to (A-61) and (A-62) by denoting $\widehat{x}_{t} \equiv \ln x_{t}-\ln x \simeq\left(x_{t}-x\right) / x$ as approximately proportional deviation of $x_{t}$ from the steady state, we get:

$$
\begin{aligned}
0= & \widehat{\operatorname{nytm}}_{t}^{(T, j)}+\mathbb{E}_{t}\left[\frac{1}{T} \sum_{s=1}^{T} \hat{m}_{t+s}\right]-\mathbb{E}_{t}\left[\frac{1}{T} \sum_{s=1}^{T} \hat{\pi}_{t+s}\right] \\
& +\frac{\phi^{j} C Y}{1+\phi^{j} C Y}\left\{\mathbb{E}_{t}\left[\frac{1}{T} \sum_{s=1}^{T} \hat{\phi}_{t+s}^{j}\right]+\mathbb{E}_{t}\left[\frac{1}{T} \sum_{s=1}^{T} \widehat{\Lambda}_{t+s}\right]\right\} \\
= & \widehat{\operatorname{nytm}}_{t}^{(T, j)}+\mathbb{E}_{t}\left[\frac{1}{T} \sum_{s=1}^{T} \hat{m}_{t+s}\right]-\mathbb{E}_{t}\left[\frac{1}{T} \sum_{s=1}^{T} \hat{\pi}_{t+s}\right] \\
& +\left[1-\beta \operatorname{ytm}^{(T, j)}\right]\left\{\mathbb{E}_{t}\left[\frac{1}{T} \sum_{s=1}^{T} \hat{\phi}_{t+s}\right]+\mathbb{E}_{t}\left[\frac{1}{T} \sum_{s=1}^{T} \widetilde{\phi}_{t+s}^{j}\right]+\mathbb{E}_{t}\left[\frac{1}{T} \sum_{s=1}^{T} \widehat{\Lambda}_{t+s}\right]\right\}
\end{aligned}
$$

where we define $\widetilde{\phi}_{t+s}^{j}=\hat{\phi}_{t+s}^{j}-\hat{\phi}_{t+s}$ as the idiosyncratic shock to the resaleability of bond $j$ and use (A-64) for the last step. Similarly we get

$$
0=\widehat{\operatorname{nytm}}_{t}^{(T, l)}+\mathbb{E}_{t}\left[\frac{1}{T} \sum_{s=1}^{T} \hat{m}_{t+s}\right]-\mathbb{E}_{t}\left[\frac{1}{T} \sum_{s=1}^{T} \hat{\pi}_{t+s}\right]+\left[1-\beta \mathrm{ytm}^{(T, l)}\right] \mathbb{E}_{t}\left[\frac{1}{T} \sum_{s=1}^{T} \Lambda_{t+s}\right] .
$$

Taking the difference between the two, we obtain

$$
\begin{aligned}
\widehat{\operatorname{nytm}}_{t}^{(T, j)}-\widehat{\operatorname{nytm}}_{t}^{(T, l)}= & \beta\left[\mathrm{ytm}^{(T, j)}-\mathrm{ytm}^{(T, l)}\right] \mathbb{E}_{t}\left[\frac{1}{T} \sum_{s=0}^{T-1} \widehat{C Y}_{t+s}\right] \\
& -\left[1-\beta \mathrm{ytm}^{(T, j)}\right] \mathbb{E}_{t}\left[\frac{1}{T} \sum_{s=1}^{T} \hat{\phi}_{t+s}\right]-\left[1-\beta \mathrm{ytm}^{(T, j)}\right] \mathbb{E}_{t}\left[\frac{1}{T} \sum_{s=1}^{T} \widetilde{\phi}_{t+s}\right],
\end{aligned}
$$

using $\widehat{C Y}_{t}=\mathbb{E}_{t}\left(\widehat{\Lambda}_{t+1}\right)$.

If we assume that $\widehat{C Y}_{t}$ is approximately proportional to $\hat{\phi}_{t}$ as argued in footnote (31) and we assume both $\hat{\phi}_{t}$ and $\widehat{C Y}_{t}$ follow an $\operatorname{AR}(1)$ process with autoregressive coefficient $\rho_{\phi}$ we 
obtain

$$
\begin{aligned}
\widehat{\operatorname{nytm}}_{t}^{(T, j)}-\widehat{\operatorname{nytm}}_{t}^{(T, l)}= & \left\{\beta\left[\operatorname{ytm}^{(T, j)}-\mathrm{ytm}^{(T, l)}\right]-\left[1-\beta \mathrm{ytm}^{(T, j)}\right] \rho_{\phi}\left(\frac{\hat{\phi}_{t}}{\widehat{C Y}_{t}}\right)\right\} \frac{1-\rho_{\phi}^{T}}{\left(1-\rho_{\phi}\right) T} \widehat{C Y}_{t} \\
& -\left[1-\beta \mathrm{ytm}^{(T, j)}\right] \mathbb{E}_{t}\left[\frac{1}{T} \sum_{s=1}^{T} \widetilde{\phi}_{t+s}\right] .
\end{aligned}
$$

This equation shows the real yield spreads between many pairs of zero coupon bonds with the same payoff and different liquidity tend to comove with the convenience yield except for the term reflecting the idiosyncratic shocks to the resaleability of each bond. Using $\beta \operatorname{ytm}^{(T, j)}=$ $\frac{1}{1+\phi^{j} C Y}$ and $\beta_{y t m}(T, l)=\frac{1}{1+C Y}$ and ignoring the terms which are higher order than that is proportional to the convenience yield, obtain

$$
\begin{aligned}
\operatorname{nytm}_{t}^{(T, j)}-\operatorname{nytm}_{t}^{(T, l)}-\left[\operatorname{nytm}^{(T, j)}-\operatorname{nytm}^{(T, l)}\right] & \\
\simeq \frac{1-\phi^{j}-\phi^{j}(1+C Y) \rho_{\phi}\left(\frac{\hat{\phi}_{t}}{\overline{C Y}_{t}}\right)}{1+\phi^{j} C Y} \frac{1-\rho_{\phi}^{T}}{\left(1-\rho_{\phi}\right) T}\left[C Y_{t}-C Y\right] & -\frac{\phi^{j} C Y(1+C Y)}{1+\phi^{j} C Y} \mathbb{E}_{t}\left[\frac{1}{T} \sum_{s=1}^{T} \widetilde{\phi}_{t+s}\right] .
\end{aligned}
$$

(Here we also approximate $\pi /\left[\beta(1+C Y)^{2}\right] \simeq 1$ by assuming the length of period is short and that inflation rate is not too high). This is the base of our dynamic factor formula used in Section 3.2. Note that term $\left(\hat{\phi}_{t} / \widehat{C Y}_{t}\right)$ is negative in our model when shocks to resaleability are important.

For the special case of totally illiquid bond, we have

$$
\operatorname{nytm}_{t}^{(T, 0)}-\operatorname{nytm}_{t}^{(T, l)}-\left[\operatorname{nytm}^{(T, 0)}-\operatorname{nytm}^{(T, l)}\right] \simeq \frac{1-\rho_{\phi}^{T}}{\left(1-\rho_{\phi}\right) T}\left[C Y_{t}-C Y\right] .
$$

Thus to the extent the shock is not permanent so that $\frac{1-\rho_{\phi}^{T}}{\left(1-\rho_{\phi}\right) T}<1$, the change of the yield spread between totally illiquid and perfectly liquid long-term bonds in the left hand side underestimates the change of the convenience yield $C Y_{t}-C Y$ of our model. Our approximations ignore potentially very important covariance terms, associated with risks. Examining asset price implications of liquidity constraints and liquidity shocks which takes into account risks is a topic of future research. 


\section{Impulse Responses to Other Shocks}

In this section, we document the response of macroeconomic variables to standard shocks studied in the literature: productivity, monetary policy, and government spending. All three shocks follow a stationary autoregressive process

$$
\begin{aligned}
A_{t} & =\left(1-\rho_{A}\right) A+\rho_{A} A_{t-1}+\varepsilon_{A t} \\
\iota_{t} & =\rho_{\iota} \iota_{t-1}+\varepsilon_{\iota t} \\
G_{t} & =\left(1-\rho_{G}\right) G+\rho_{G} G_{t-1}+\varepsilon_{G t}
\end{aligned}
$$

The introduction of productivity and monetary policy shocks in the model is straightforward. The former affects the production function (A-4) while the latter enters the monetary policy rule (20). Both shocks, however, do not change the steady state. Conversely, the government spending shock requires some amendments to the steady state. The resource constraint now becomes

$$
Y_{t}=C_{t}+\left[1+S\left(\frac{I_{t}}{I}\right)\right]+G_{t}
$$

where $G_{t}$ is the level of government spending. The government budget constraint becomes

$$
q_{t} N_{t+1}^{g}+\frac{R_{t-1} L_{t}}{\Pi_{t}}=\tau_{t}-G_{t}+\left[R_{t}^{K}+(1-\delta) q_{t}\right] N_{t}^{g}+L_{t+1}
$$

We calibrate the ratio of government spending to GDP to $21 \%$, which corresponds to the postwar US data. In the KM model, the way government spending is financed is not neutral. If an increase in government spending is financed primarily via debt issuance, liquidity increases. To keep our results comparable with the literature, we study the response to a government spending shock assuming the fiscal authority keeps the real value of liquid assets constant $\left(B_{t} / P_{t}=b\right) .50$

For the productivity and government spending shock, we calibrate the size of the shocks (0.45 and $0.52 \%)$ and the persistence parameters $\left(\rho_{A}=0.95\right.$ and $\left.\rho_{G}=0.97\right)$ to the posterior mode in Smets and Wouters (2007). The size of the monetary policy shock is 25 basis points annualized, and we assume a high persistence parameter $\left(\rho_{\iota}=0.8\right)$ to compensate for the absence of interest rate smoothing in the monetary policy rule. ${ }^{51}$ 
Figure A-1: Response of macroeconomic variables to a productivity shock.
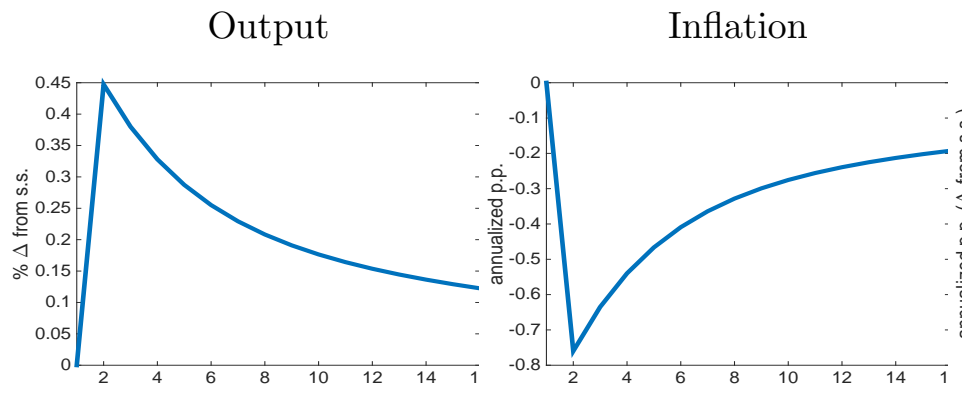

Nominal Interest Rate

Consumption

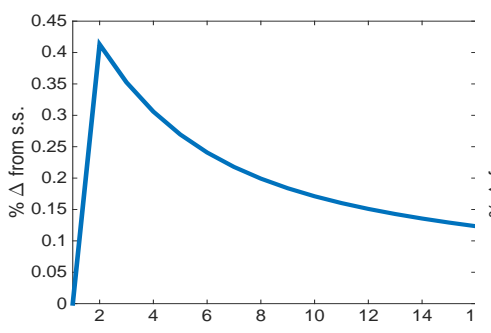

Investment
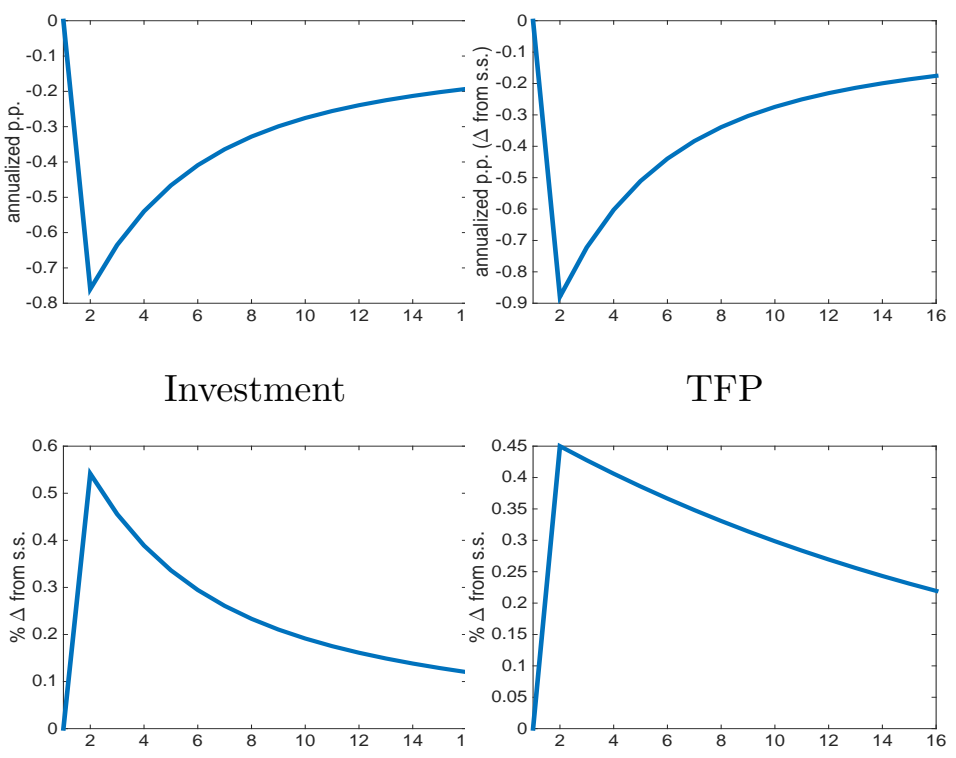

Notes: Impulse response function to an increase in productivity.

\section{C.1 Productivity Shocks}

In response to a persistent increase in productivity (see Figure A-1), all quantities (output, consumption and investment) increase as in a standard New Keynesian model. The higher level of productivity, however, reduces the firms' marginal cost, thus inducing disinflationary pressures. As a reaction, the central bank cuts the nominal interest rate.

\section{C.2 Monetary Policy Shocks}

In response to a persistent increase in nominal interest rates (see Figure A-2), aggregate demand falls, and so does inflation. The systematic component of the monetary policy rule accommodates the downturn, so in equilibrium the nominal interest rate actually increases less than the original shock.

\footnotetext{
${ }^{50}$ In a model similar to ours, Kara and Sin (Forthcoming) analyze how the government spending multiplier changes depending on the government financing decisions.

${ }^{51}$ This value is consistent with the posterior mode for the interest rate smoothing parameter in Smets and Wouters (2007).
} 
Figure A-2: Response of macroeconomic variables to a monetary policy shock.
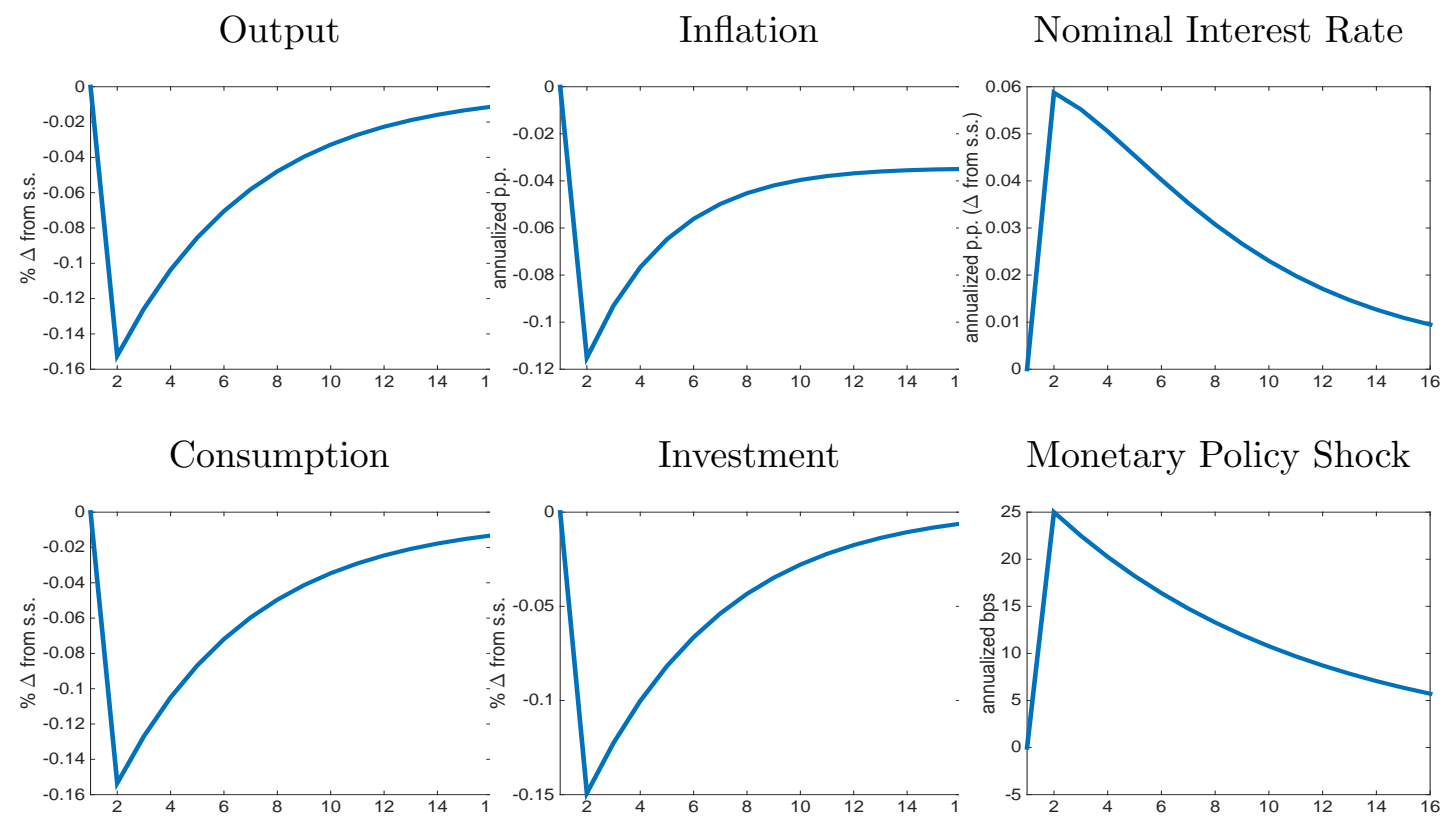

Notes: Impulse response function to an increase in the nominal interest rate.

\section{C.3 Government Spending Shocks}

The increase in government spending (see Figure A-3) raises output but crowds out private demand, so consumption and investment fall. The demand shock leads the central bank to increase the interest rate. In equilibrium, inflation falls, but the effect is small and the result depends on the high degree of persistence of the shock. With lower persistence, inflation would rise, at least on impact. 
Figure A-3: Response of macroeconomic variables to a government spending shock.

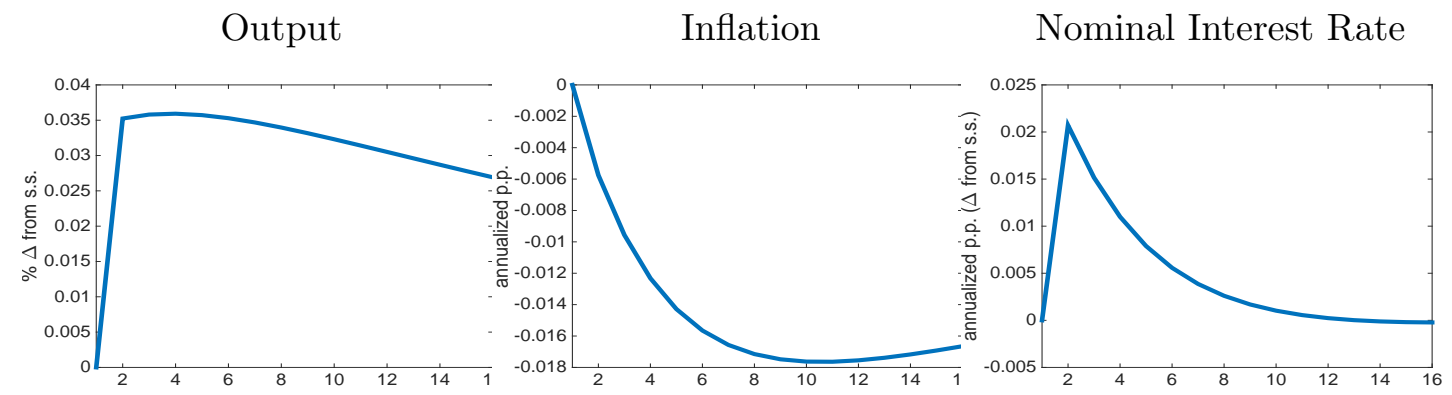

Consumption

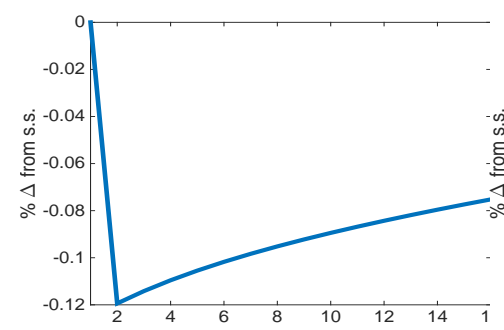

Investment

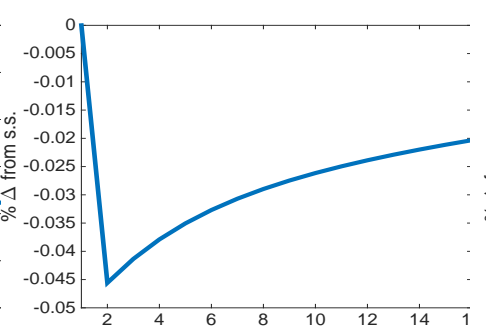

Government Spending Shock

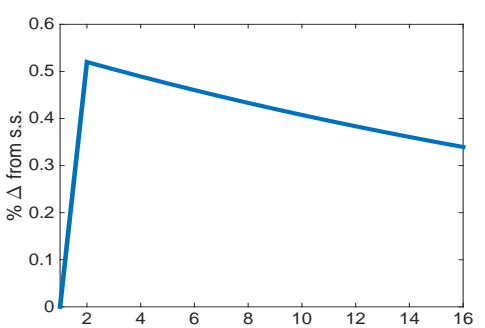

Notes: Impulse response function to an increase in government spending. 
Online appendix for The Great Escape

\section{Robustness}

In this section, we discuss the robustness of our quantitative results to changes of a selected number of key parameters: (i) the degree of price and wage rigidities $\zeta_{p}$ and $\zeta_{w}$; (ii) the coefficient of relative risk aversion $\sigma$; and (iii) the adjustment cost parameter $S^{\prime \prime}(1)$. We keep the shock fixed to the baseline case but adjust the feedback coefficient in the policy rule for private asset purchases $\psi_{k}$ so that the intervention remains $10 \%$ of GDP. Table A-1 summarizes the results.

The first column reports the impact response to the liquidity shock of output and its components, the inflation rate, the nominal value of the capital stock (all in percentage deviations from steady state), and the convenience yield (in annualized basis points) in the baseline case. In the next five columns, we vary one parameter at a time and report the same statistics.

Column (2) shows the implications of having a higher degree of price and wage rigidity relative to the baseline calibration, equal to 0.85 , implying that firms (unions) reset prices (wages) every six and a half quarters. A lower frequency of price changes induces a smaller drop in inflation relative to the baseline. Consequently, the real interest rate rises less, and the fall in output is less pronounced. Because the financial frictions affect investment largely independently of nominal rigidities, the effect on investment is still large, while the effect on consumption is proportionally smaller. Overall, the composition of output is still comparable to the data, with a much larger fall in investment than in consumption. The fall in the price of capital is smaller on account of the lower deflation. Column (3) considers the opposite experiment, that is, a lower degree of price and wage rigidity relative to the baseline calibration, equal to 0.66, implying that firms (unions) reset prices (wages) every three quarters. Not surprisingly, the direction of the change relative the baseline is the opposite of what just discussed for the case of higher price and wage rigidities. In this case, the fall in investment and consumption (and hence output) is closer to the data, but the model overestimates the effect on inflation, which now drops by almost five percent. More flexible prices make the intervention more powerful when the ZLB is binding, because the real interest rate increases by more when prices are more flexible.

Column (4) of Table A-1 reports the results of increasing the coefficient of relative risk aversion to 2. The fall in output is a bit smaller than in the baseline calibration. The intertemporal elasticity of substitution (the inverse of the coefficient of relative risk aversion) is now smaller, so consumption is less sensitive to the increase in the real rate that results from the combination of the zero lower bound and the deflationary pressures. Conversely, the fall in investment is roughly unchanged. Overall, this case is not very different from the baseline. 
The last two columns of Table A-1 show the results of decreasing (column 5) and increasing (column 6) adjustment costs. Here, the differences with the baseline calibration depend primarily on the relative response of investment and the value of equity. With lower adjustment costs, investment falls more, dragging down output, but the smaller decline in the value of equity falls partially tempers this effect. In this case, however, the increase in convenience yield is less than observed in the data. The opposite occurs with larger adjustment cost, as investment falls less than in the baseline, while the value of equity drops more and the convenience yield rises more significantly.

The last two rows report the response of output and inflation in the absence of intervention for the same parameters. The overall message is that the effect of the liquidity injection is roughly stable across parameterizations.

Table A-1: Robustness

\begin{tabular}{lcccccc}
\hline \hline & Baseline & \multicolumn{5}{c}{ Alternative Parameterizations } \\
& $(1)$ & $(2)$ & $(3)$ & $(4)$ & $(5)$ & $(6)$ \\
\hline Nominal Rigidities $\left(\zeta_{p}, \zeta_{w}\right)$ & 0.75 & 0.85 & 0.66 & & & \\
Risk Aversion $(\sigma)$ & 1 & & & 2 & & \\
Adjustment Costs $\left(S^{\prime \prime}(1)\right)$ & 0.75 & & & & 0.5 & 1 \\
\hline Period 1 response with intervention & & & & & \\
\hline Output & -4.41 & -3.89 & -5.28 & -4.22 & -5.14 & -3.99 \\
Consumption & -1.32 & -0.86 & -2.09 & -0.99 & -0.76 & -1.71 \\
Investment & -14.17 & -13.37 & -15.45 & -14.41 & -19.16 & -11.18 \\
Inflation & -2.51 & -0.79 & -4.90 & -2.66 & -2.48 & -2.52 \\
Value of Capital & -1.80 & -0.85 & -3.21 & -1.99 & -0.75 & -2.51 \\
Convenience Yield & 180 & 181 & 176 & 179 & 166 & 190 \\
\hline Period 1 response without intervention & & & & & \\
\hline Output & -5.78 & -4.62 & -7.46 & -5.23 & -6.36 & -5.40 \\
Inflation & -3.50 & -0.99 & -7.49 & -3.57 & -3.38 & -3.54 \\
\hline \hline
\end{tabular}

Note: The first three rows of the table show the alternative parameters that we consider. The next six rows report the firstperiod response of output, consumption, investment, inflation, the nominal value of capital, and the convenience yield for the baseline calibration with intervention and for alternative parameterizations of nominal rigidities, risk aversion, and adjustment costs. The last two rows report the first-period response of output and inflation without intervention for the same parameters. 


\section{E Additional Tables and Figures}

Table A-2: Average Returns and Implied $\phi_{j}$

\begin{tabular}{|c|c|c|c|c|c|}
\hline \multicolumn{3}{|c|}{$\begin{array}{c}2004 / 7 / 21-2007 / 6 / 29 \\
\text { CY: } 0.46\end{array}$} & \multicolumn{3}{|c|}{$\begin{array}{c}2008 / 10 / 1-2008 / 12 / 31 \\
\text { CY: } 3.42\end{array}$} \\
\hline & $\phi$ & spread & & $\phi$ & spread \\
\hline 1Y Refcorp & 1.150 & -0.07 & 20Y TIPS & 0.806 & 0.65 \\
\hline 6M Refcorp & 1.067 & -0.03 & On-Off & 0.795 & 0.69 \\
\hline 2Y Refcorp & 0.990 & 0.00 & 20Y Refcorp & 0.747 & 0.85 \\
\hline AA CDS-Bond Basis & 0.985 & 0.01 & 2Y Refcorp & 0.720 & 0.94 \\
\hline A CDS-Bond Basis & 0.945 & 0.02 & 5Y Refcorp & 0.702 & 1.01 \\
\hline 3Y Refcorp & 0.920 & 0.04 & 7Y Refcorp & 0.701 & 1.01 \\
\hline On-Off & 0.889 & 0.05 & 10Y Refcorp & 0.692 & 1.04 \\
\hline 5Y Refcorp & 0.854 & 0.07 & 1Y Refcorp & 0.690 & 1.05 \\
\hline BBB CDS-Bond Basis & 0.851 & 0.07 & 10Y TIPS & 0.682 & 1.07 \\
\hline 4Y Refcorp & 0.822 & 0.08 & 3Y Refcorp & 0.679 & 1.08 \\
\hline 7Y Refcorp & 0.779 & 0.10 & 4Y Refcorp & 0.665 & 1.13 \\
\hline 10Y Refcorp & 0.671 & 0.15 & $5 \mathrm{Y}$ TIPS & 0.654 & 1.17 \\
\hline 20Y Refcorp & 0.659 & 0.15 & 6M Refcorp & 0.612 & 1.31 \\
\hline 5Y TIPS & 0.371 & 0.28 & 7Y TIPS & 0.586 & 1.40 \\
\hline $7 \mathrm{Y}$ TIPS & 0.311 & 0.31 & AA CDS-Bond Basis & 0.548 & 1.53 \\
\hline $20 Y$ TIPS & 0.298 & 0.31 & $\mathrm{AAA}$ & 0.448 & 1.86 \\
\hline 10Y TIPS & 0.219 & 0.35 & A CDS-Bond Basis & 0.282 & 2.43 \\
\hline AAA & -0.294 & 0.58 & BBB CDS-Bond Basis & 0.000 & 3.39 \\
\hline
\end{tabular}

Notes: The two panels show the average spread for the securities listed above (see Appendix A.2 for a description) for the $2004 / 7 / 21-2007 / 6 / 29$ (left) and 2008/10/1-2008/12/31 (right) periods, as well as the implied $\phi^{j}$ computed according to formula (25). 
Figure A-4: The Liquidity Share in the Data

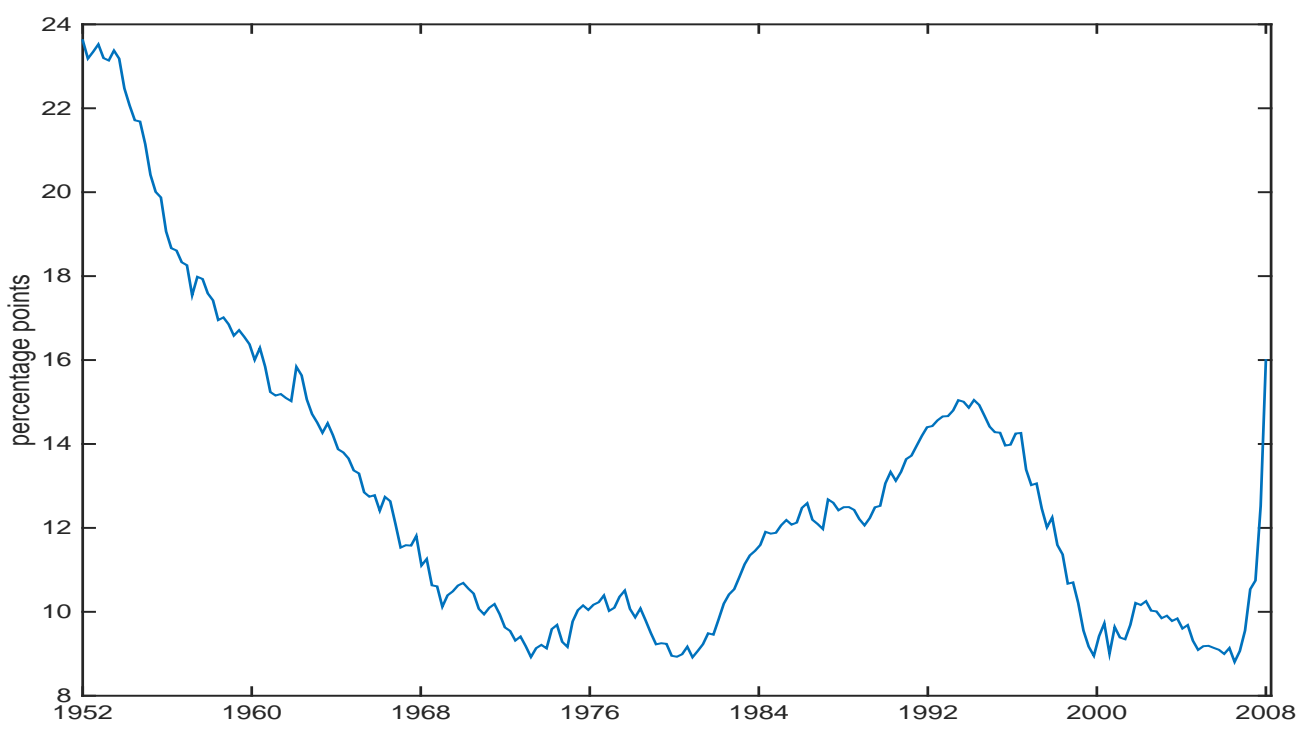

Notes: The figure plots the evolution of the liquidity share, defined as the ratio of government liabilities (liquid assets) to total assets in the U.S. economy, over the sample period 1953Q1:2008Q3.

Figure A-5: Steady State as a Function of $\phi$

Price of Equity $(q)$

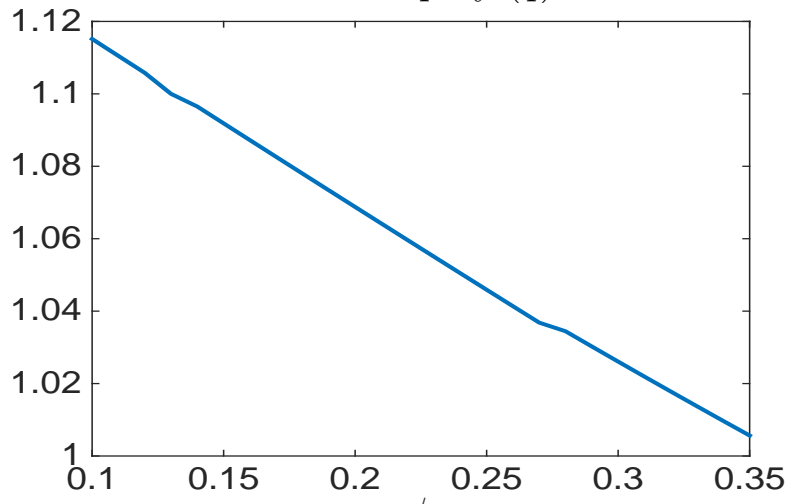

Liquidity Share

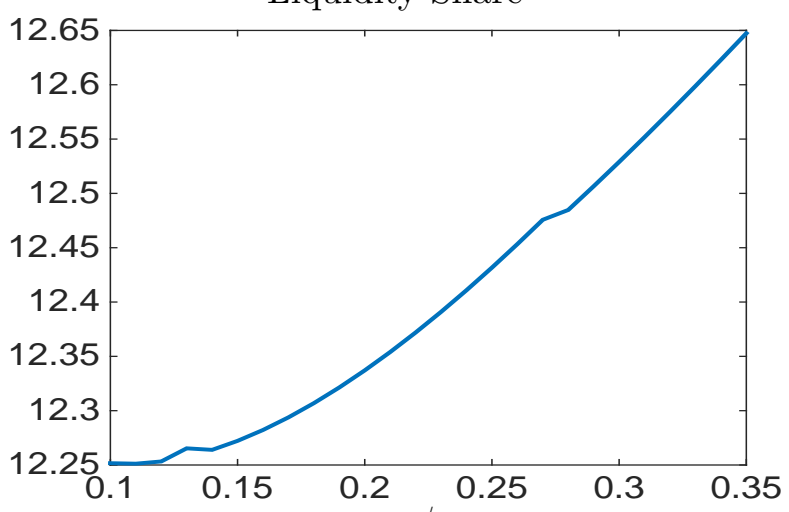

Notes: The figure plots the steady-state price of equity (left panel) and liquidity share (right panel) as a function of the steady-state value of the resaleability parameter $\phi$. 
Figure A-6: Liquidity Spreads and Common Factor
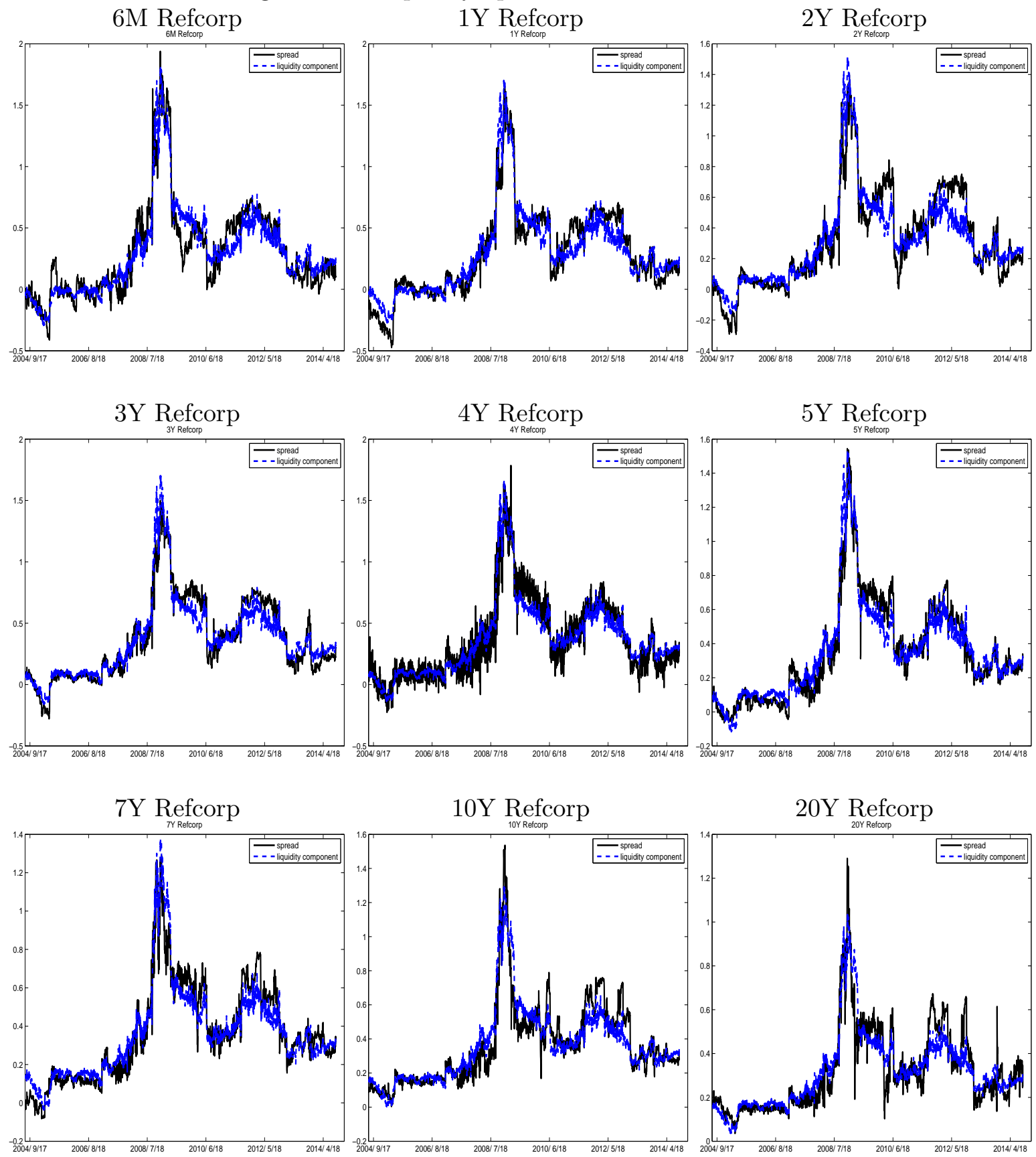

Notes: The figure shows the daily time series (black) of each spread as well as its projection on the first principal component and a constant (blue). 
Figure A-7: Liquidity Spreads and Common Factor - Continued
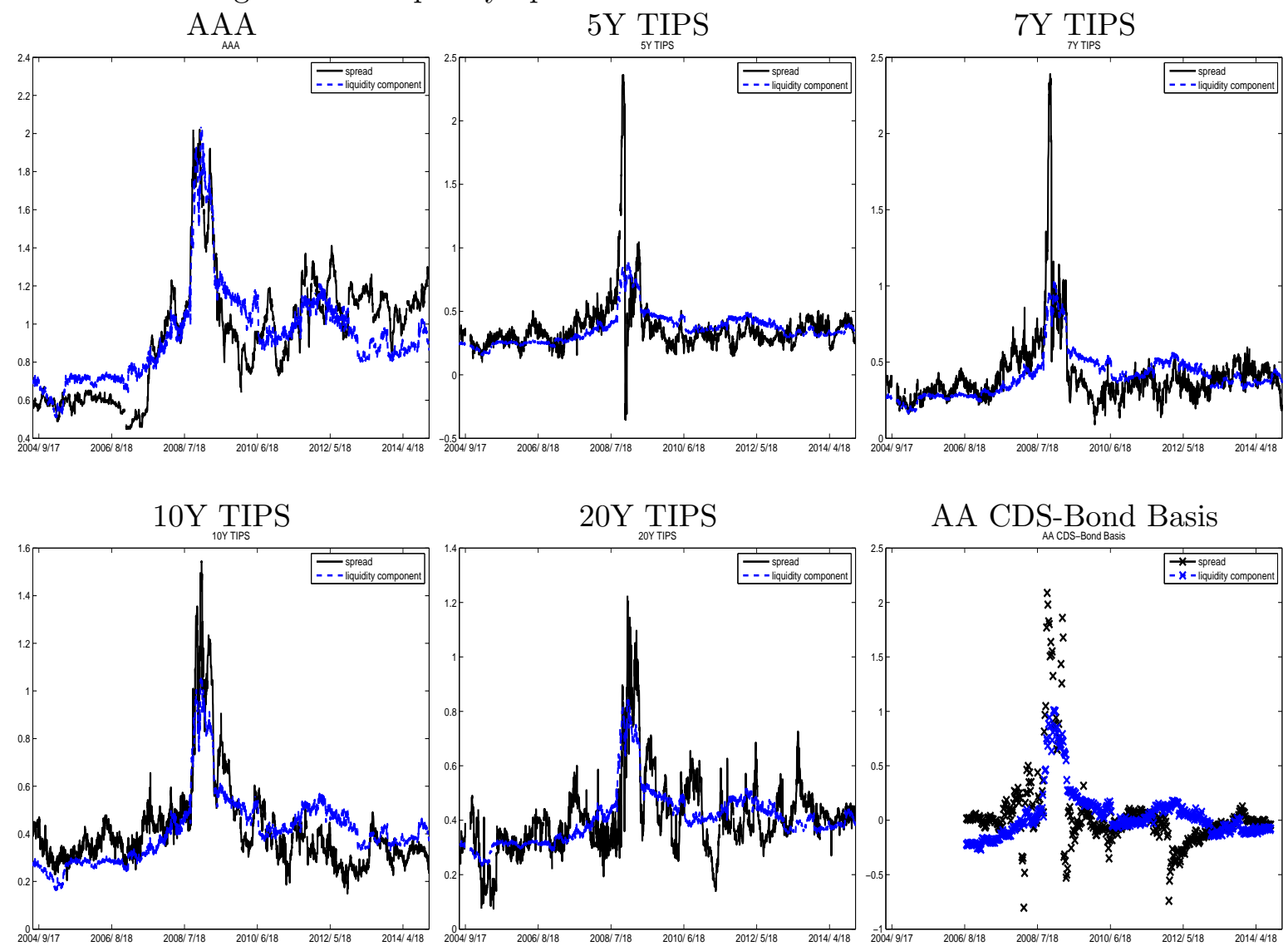

AA CDS-Bond Basis

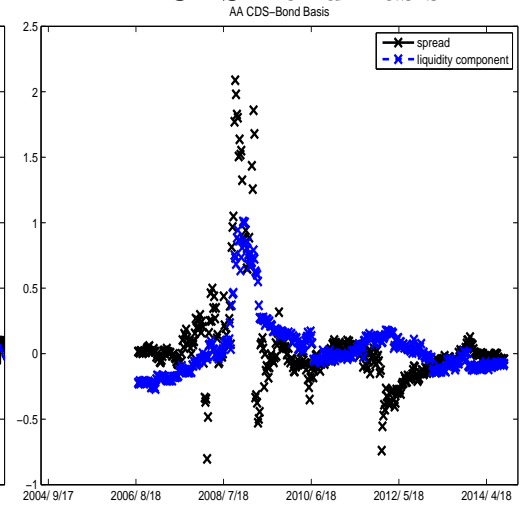

A CDS-Bond Basis
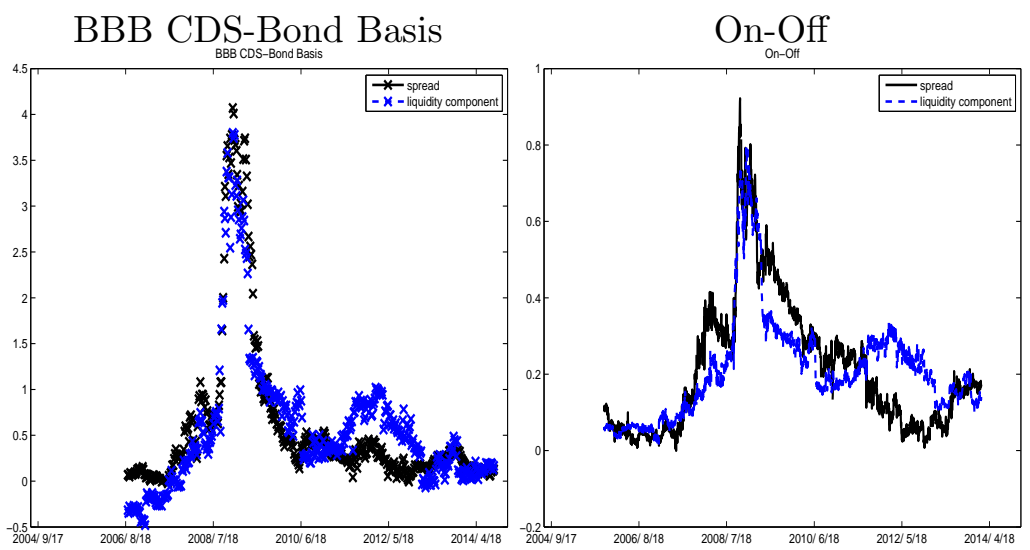

Notes: The figure shows the daily time series (black) of each spread as well as its projection on the first principal component and a constant (blue). 
Figure A-8: Liquidity Spreads and Common Factors - Two Factor Model
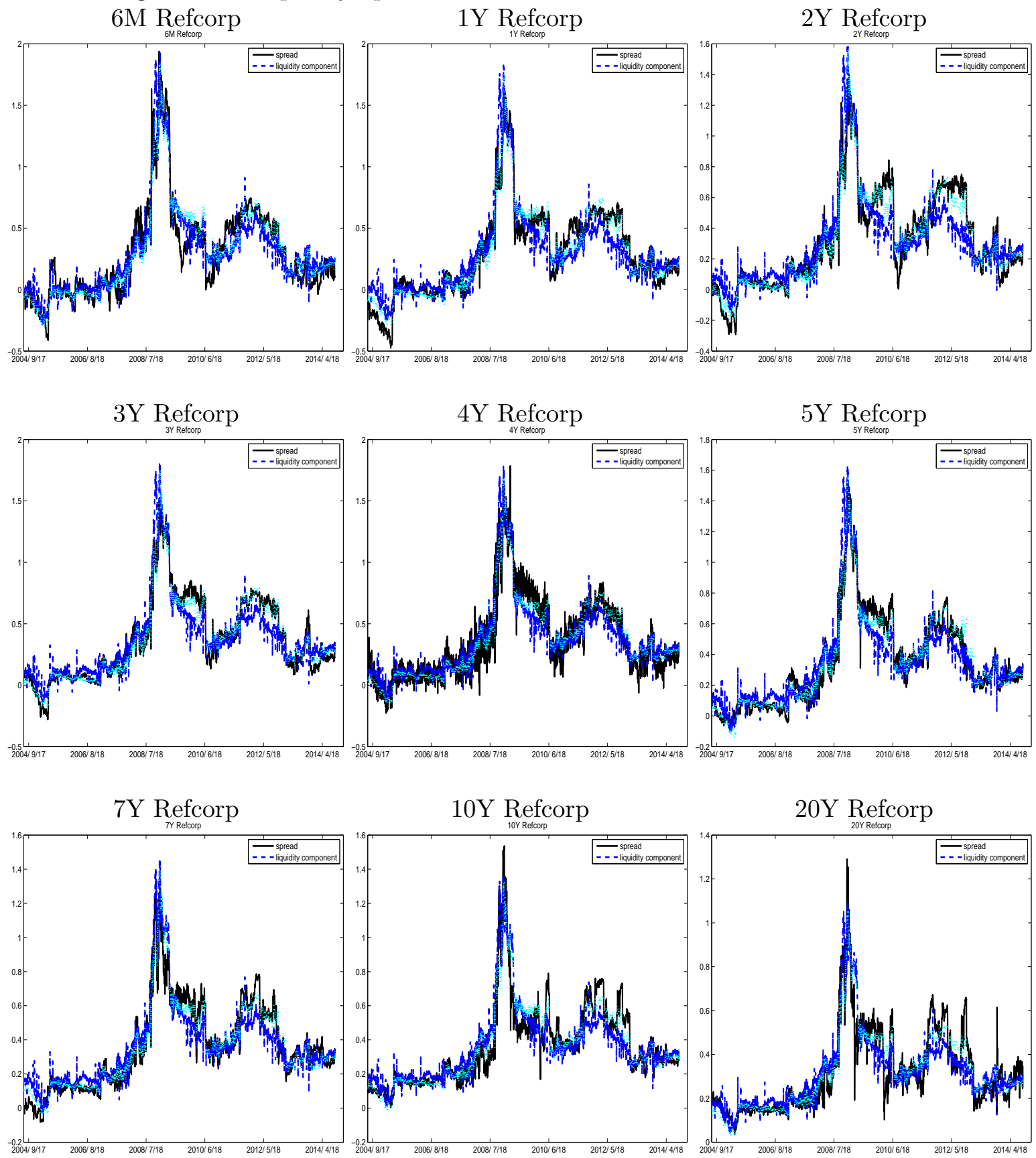

Notes: The figure shows the daily time series (black) of each spread as well as its projection on the first principal component and a constant (dark blue) and on the first two principal components and a constant (light blue). 
Figure A-9: Liquidity Spreads and Common Factors - Two Factor Model - Continued

AAA

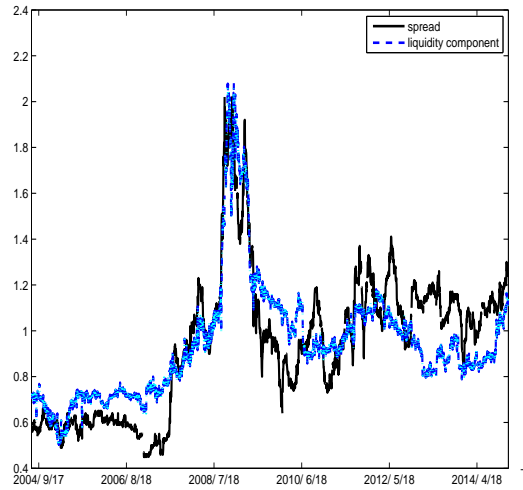

$10 Y$ TIPS

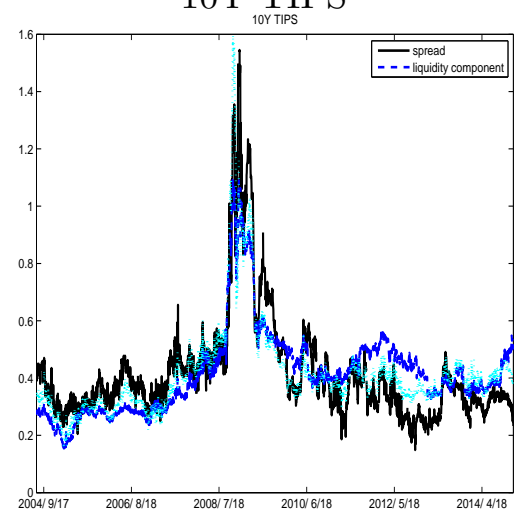

A CDS-Bond Basis

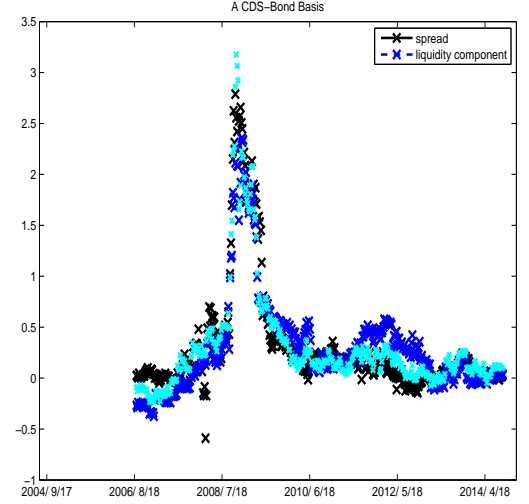

$5 Y \underset{5 Y \text { TIPS }}{\text { TIPS }}$

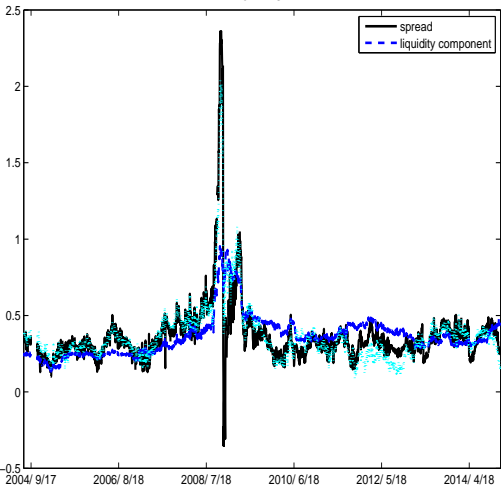

$20 Y$ TIPS

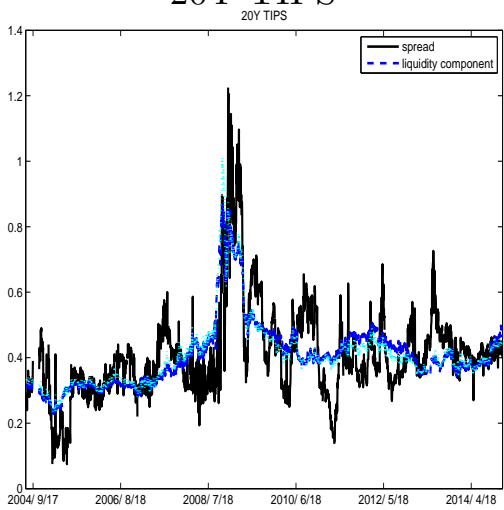

BBB CDS-Bond Basis

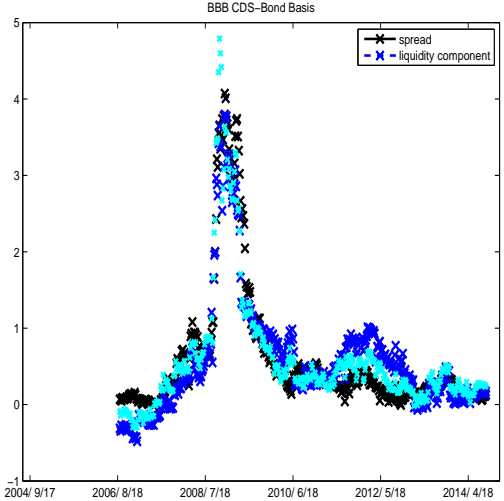

$7 \mathrm{Y} \underset{7 \gamma \text { TPPS }}{\text { TIPS }}$

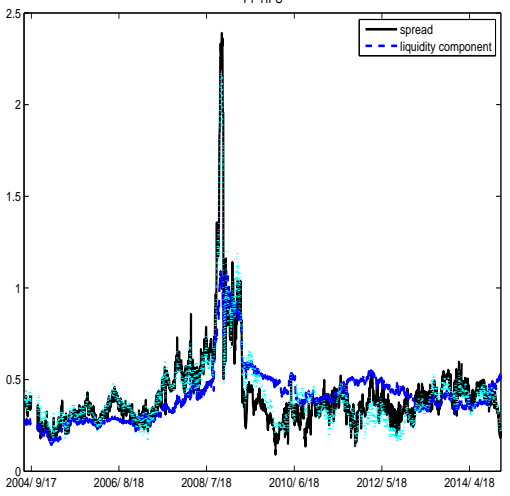

AA CDS-Bond Basis
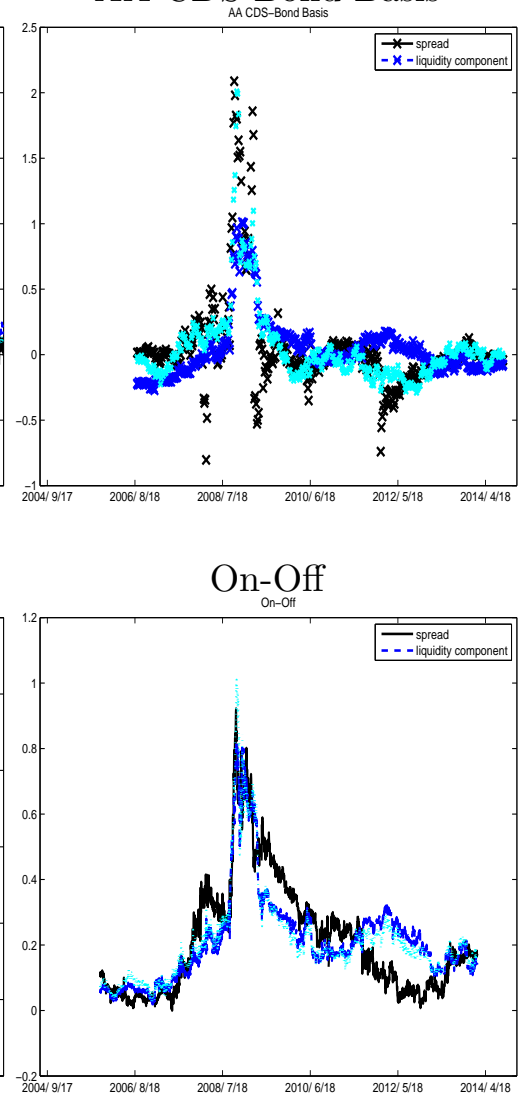

Notes: The figure shows the daily time series (black) of each spread as well as its projection on the first principal component and a constant (dark blue) and on the first two principal components and a constant (light blue). 
Figure A-10: Response of $q$ (the Relative Price of Capital in terms of Consumption) to the Baseline Liquidity Shock

Baseline

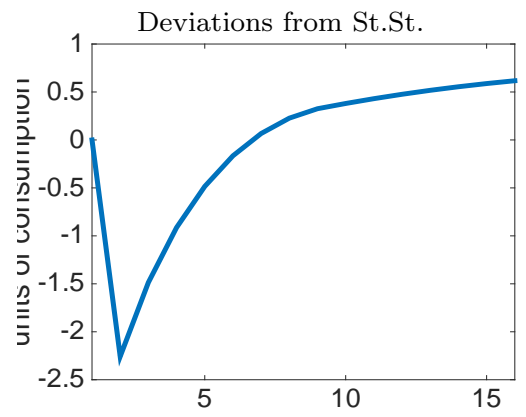

No ZLB

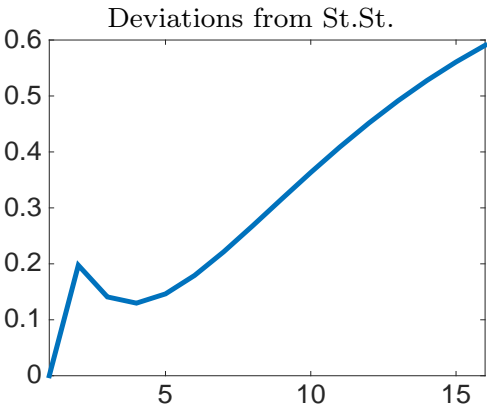

No Nominal Rigidities

Deviations from St.St.

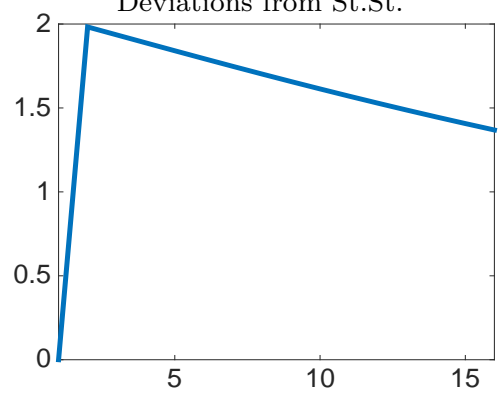

Notes: The figure plots the response of the value of capital to the calibrated liquidity shock in the baseline scenario (left panel), without zero lower bound (middle panel), and without nominal rigidities (right panel).

Figure A-11: Liquidity in the Model and Data
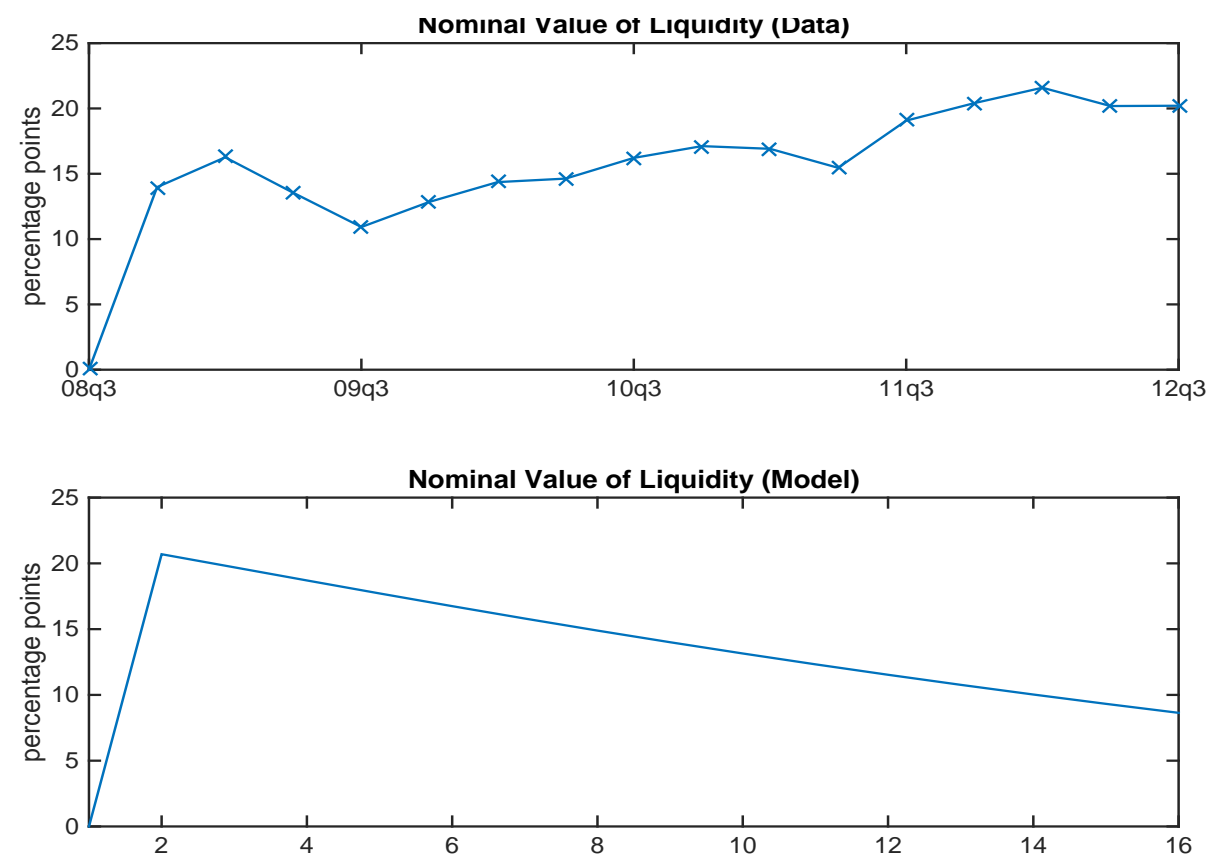

Notes: The top panel plots the evolution of nominal liquidity in the data, as defined in computing the liquidity share. The data are detrended and normalized to zero in 2008Q3. The bottom panel plots the response of nominal liquidity in the model. 
Figure A-12: Response of the Convenience Yield with and without Intervention.

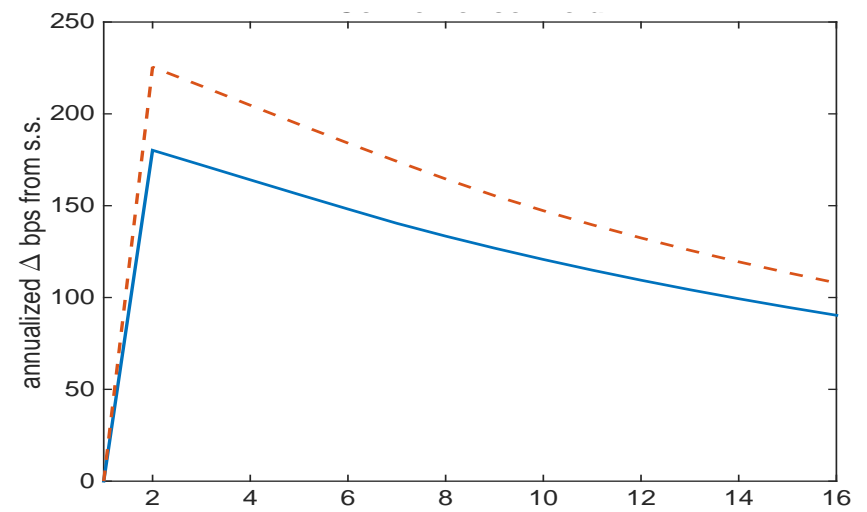

Notes: The continuous blue line reports the response of the convenience yield to the liquidity shock with intervention. The dashed red line reports the response of the convenience yield to the liquidity shock in the absence of intervention.

Figure A-13: Response of Output Under Baseline (10\% of GDP), Full Stabilization (75\% of GDP), Flex Prices/Wages Replication (45\% of GDP), and No ZLB Replication (30\% of GDP) Intervention.

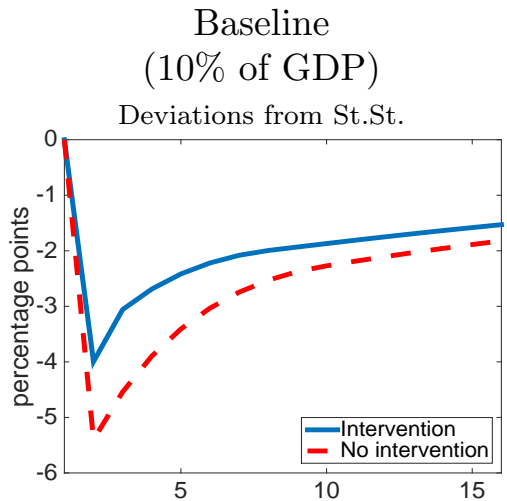

Flexible Prices/Wages

(45\% of GDP)

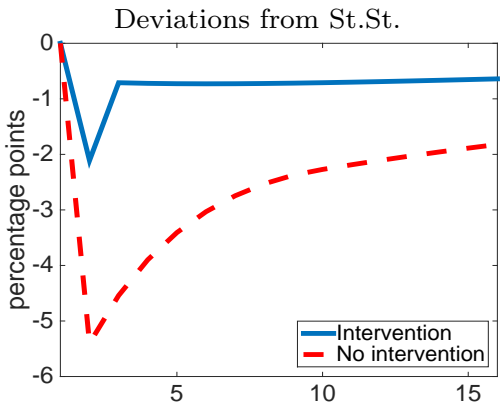

Full Stabilization

(75\% of GDP)

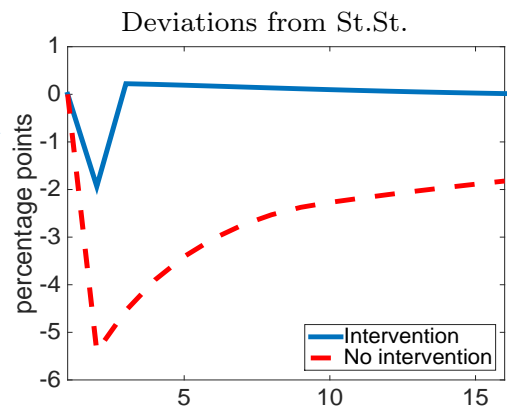

No ZLB

(30\% of GDP)

Deviations from St.St.

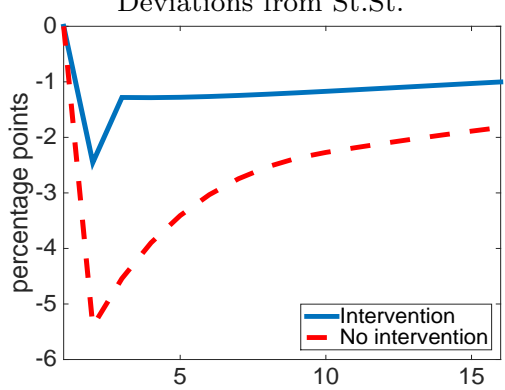

Notes: The figure plots the response of the output to the calibrated liquidity shock with (solid blue) and without (dashed red) intervention in four cases. The top-left panel is the baseline scenario. In the top-right panel, we calibrate the initial intervention to fully stabilize output from the second period of the crisis onward. In the bottom-left panel, we calibrate the initial intervention to approximate the path of output without nominal rigidities under the baseline intervention from the second period of the crisis onward. In the bottom-right panel, we calibrate the initial intervention to match the fall in output in the first period in the absence of the ZLB. 
Figure A-14: The Effect of the Liquidity Facilities on Output in the Baseline Case, Without the ZLB, and Without Nominal Rigidities

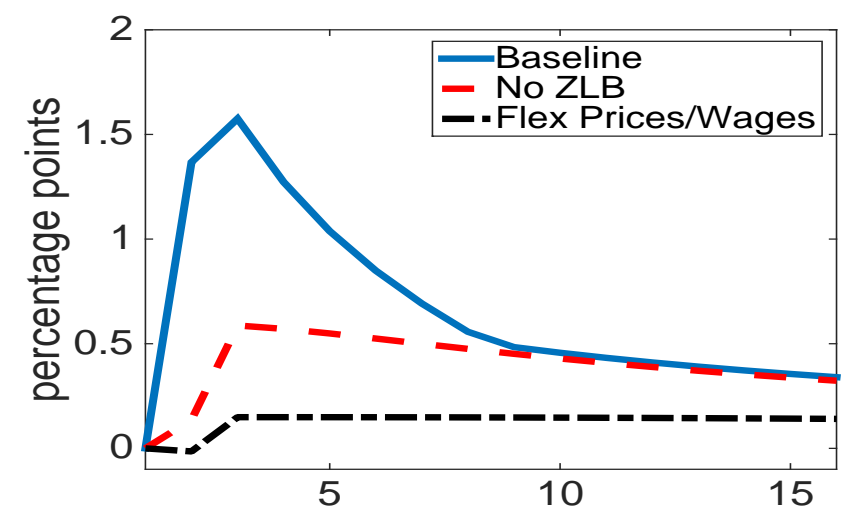

Notes: The figure shows the difference between counterfactual and actual response of output in the baseline scenario (solid blue), without the zero lower bound (dashed red), and without nominal rigidities (dashed-dotted black). 